\title{
Community level individual-based plant-pollinator networks unveil pollen flow dynamics and plant reproductive success
}

\author{
Alfonso Allen-Perkins ${ }^{1,2, 凶}$, María Hurtado ${ }^{3}$, David García-Callejas ${ }^{1,3}$, Oscar Godoy ${ }^{3}$, and Ig- \\ nasi Bartomeus ${ }^{1}$ \\ ${ }^{1}$ Departamento de Ecología Integrativa, Estación Biológica de Doñana, EBD-CSIC, Avda. Amrico Vespucio 26, Seville E- \\ 41092, Spain. \\ ${ }^{2}$ Departamento de Ingeniería Eléctrica, Electrónica, Automática y Física Aplicada, ETSIDI, Universidad Politécnica de \\ Madrid, 28040 Madrid, Spain. \\ ${ }^{3}$ Departamento de Biología, Instituto Universitario de Investigación Marina (INMAR), Universidad de Cádiz, Puerto Real, \\ E-11510, Spain.
}

Plant-pollinator networks are a widely used tool to understand the dynamics of such ecological communities. However, while most mutualistic networks have been defined at the species level, ecological processes, such as pollination, take place at the individual level. This recognition has led to the development of individual plant-level networks, yet current approaches only account for individuals of a single plant species due to conceptual and mathematical limitations. Here, we introduce a mechanistic multilayer framework based on the frequency of insect visits to plant individuals belonging to different species. It is designed to depict from the network structure the potential conspecific and heterospecific pollen flows among plant individuals. Pollen transfer is modeled as a transport-like system, where pollen grains are represented as random-walkers that diffuse on an ensemble of bipartite layers of conspecific plants and their floral visitors that are coupled through shared visitors. With this physical conceptualization, we investigate how the number of developed seeds of plant individuals is affected by the multilayer structure (network-level), as well as by their local network properties (motif- and nodelevel). We apply this multiscale analysis to a dataset of nine plant-pollinator networks from a Mediterranean grassland. At the network-level we show a highly modular structure, with insect visitors effectively connecting individuals of the same and different plant species. Interestingly, the network structure is critical for modulating individual plant reproduction for the three most attractive species. In particular, the motif-level, represented by the number of homospecific and heterospecific motifs, is the best descriptor of plant reproductive success, as it integrates local heterospecific and conspecific interactions. We provide a simple, but robust set of metrics to scale down network ecology to functioning properties at the individual level, where most ecological processes take place, hence moving forward the description and interpretation of multitrophic communities across scales.

Multilayer networks | Plant-pollinator networks | Pollination | Ecosystem function | Centrality | Map equation

Correspondence: alfonso.allen.perkins@gmail.com

\section{Introduction}

Network approaches have been increasingly used in ecology to interpret the complex structure of interactions among species (Bascompte et al., 2003, Martinez, 1991. Thebault \& Fontaine, 2010). By understanding ecological communities as networks in which species are linked through pairwise interactions, ecologists have shown, both theoretically and in the field, that network architecture strongly influences species dynamics (Bartomeus et al., 2021; Bascompte \& Jordano, 2013, Brose et al. 2006), with quantifiable effects on community properties such as local stability (Allesina \& Tang, 2012), robustness to extinctions (Memmott et al., 2004), or the impact of invasive species or climate change on local assemblages (Memmott et al. 2007). However, despite the fast-paced information gain on ecological network architecture, we are still lacking a solid foundation linking network architecture with higher-level properties, such as different functional effects of ecological communities (Bergamo et al. , 2020, Magrach et al. 2019; Poisot et al. 2013 Thompson et al. 2012).

To quantify ecological network structure and its links to ecological functioning, most approaches are based on a species-level perspective, yet this view ignores the fact that several ecological processes take place at the individual level and depend on individual variation (Bolnick et al., 2011, Dall et al. , 2012, Herrera, 2017, Sih et al., 2012; Wolf \& Weissing, 2012). For example, pollination is a key function mediated by insects that transport pollen from one plant individual to another. Collapsing all plant individuals from a given species into a single aggregate (i.e. node) assumes there is no intraspecific variation in traits such as floral display, plant height, or flower morphology, and ultimately on pollinator visitation rates. This simplification clashes with several empirical examples showing that withinspecies floral dissimilarities can result in different assem- 
blages of pollinators (Arroyo-Correa et al. 2021; Gómez et al. 2020). Pollinators can discern and respond to intraspecific flower variation (Herrera, 2017), influencing the vegetative (e.g., growth rate, carbon assimilation) and reproductive (e.g., fecundity) performance of individuals (Herrera, 2017). Not surprisingly, in the last decade the number of studies that analyze individualbased networks has grown from 6 studies in 2010 to 82 in 2020 (reviewed by Guimarães (2020)). Nevertheless, the study of individual-based networks is in its infancy (Guimarães, 2020). For instance, in the case of individual-based plant-insect pollination networks, which are the focus of this work, the number of studies drops to 11. This is due to both theoretical and methodological reasons. Empirically, the sampling effort required to resolve all species interactions into individual ones is labor-intensive, which partly explains the scarcity of empirical studies of individual-based networks, either for one species (Dáttilo et al. 2015; Gómez \& Perfectti, 2012, Gómez et al., 2011, Kuppler et al. 2017, 2016, Soares et al. |2020|| Tur et al. | 2013: Valverde et al., 2015) or more species (Dupont et al. ||2014, 2010|| Pornon et al. 2017). But a more concerning issue is that we lack robust methods able to depict the complexity of integrating individual nodes belonging to multiple species. As a consequence, most studies on individual-based networks focus on the individuals of one species (usually a plant species) linked by its floral visitors (Gómez \& Perfectti. 2012 Gómez et al. 2011; Soares et al. 2020 Valverde et al. 2015), ignoring other individuals of the plant community that belong to other species.

Here, we present a set of tools derived from multilayer networks to understand (i) the general patterns of interactions between conspecific and heterospecific plant individuals belonging to multiple species, and (ii) how that structure relates to individual plant fecundity measured as seed production. Multilayer networks are networks with nodes and links distributed across layers. Each layer represents aspects or features of the nodes or the links that belong to the layer, and the links that connect nodes in different layers (i.e. inter-layer edges) provide information on the processes or interdependencies operating between such layers (see the reviews of Boccaletti et al. (2014) and c for further details about the multilayer paradigm and its formal definitions). In ecology, multilayer networks typically depict species interactions through time and space, or across types of interactions (García-Callejas et al. 2017 , Hutchinson et al. 2018; Pilosof et al. |2017). Furthermore, they have also been used to build individual-based networks, as in the study by Crestani et al. (2019), where layers represent the different behaviors of frugivorous bird species that visit individual trees. Here we take advantage of the flexibility of multilayer formalism to conceptualize individual-based pollination networks as transport-like systems (Aleta et al., 2017, Domenico et al., 2014), and model pollen transfer mediated by floral visitors as an ensemble of bipartite layers of conspecific plants coupled through insect species. Specifically, conspecific plant individuals and their floral visitor' species are the nodes of each layer, whereas interlayer links account for interspecific floral visits of insects among plant species that bloom simultaneously (Fig. 1). TBy using a random walker approach, we model pollen grains that diffuse in the multilayers and, thus, the potential pollen flows induced by the floral visitors. This mechanistic and stochastic analogy allows us to study in detail the structure and effects of interactions at increasing scales: 1) node-level, by analyzing node roles through properties such as their strength centrality (Gómez \& Perfectti, 2012; Gómez, 2019) and PageRank indices (Gómez, 2019); 2) motif-level, through the study of local interaction patterns, or motifs (Delmas et al. 2018 ; Milo et al. 2002, Simmons et al. 2018); and 3) network-level, i.e. the identification of the modular partition of the whole network that better describes the flows of random walkers that we use to model potential pollen diffusion (Farage et al., 2021: Rosvall et al. 2009). Integrating different scales in a common formalism allows us to explore the relative importance of scale for individual plant reproduction. In particular, it has been recently suggested that motif-level processes may be particularly important for analyzing the functional consequences of community structure because, at that scale, the local patterns of realised direct interactions can reveal the different mechanisms through which individual- and speciesbased nodes can indirectly influence each other (Simmons et al. 2018). In order to explore in detail the motif-level of pollen transport networks, here we use network three-node motifs or triplets (i.e., subgraphs representing patterns of interactions between three nodes) that contain two plant individual nodes. To take into account indirect interactions with conspecific and heterospecific partners, respectively, we introduce the concept of homospecific and heterospecific motifs, that is, motifs in which both plant individuals belong to the same species and motifs with two heterospecific individuals, respectively (see Figs. 1(a), (b) and (e)). We use both types of motifs to estimate the number of conspecific and heterospecific partners of each plant individual.

We illustrate our approach by analyzing the reproductive success of plant individuals from nine field plots in a Mediterranean grassland ecosystem. In each plot we use the frequency of insect visits to plant species at fine scale resolution to build a proxy of an individualbased plant-pollinator network. Hereafter, we will refer to those proxies just as individual-based networks. Our general aim is to assess which level of analysis (i.e., network-, motif- or node-level) better explains the reproductive success of plant individuals. We hypothesize that being a central plant node in an individualbased plant-pollinator network increases seed production if this position maximizes the (potential) conspecific pollen flow. Conversely, it can also entail a de- 
crease in reproductive success if potential pollen-flows mediated by insects increase conspecific pollen loss and heterospecific pollen deposition on stigmas as it has been previously showed experimentally (Morales \& Traveset, 2009, Moreira-Hernández \& Muchhala 2019). Specifically, we aim to: (i) Describe the structure of the system at three community levels, taking into account the whole set of plant species that receive insect visits: node-level, through the use of node-level network properties, such as the strength centrality and Pagerank indices; motiflevel, through the use of homospecific and heterospecific network motifs; and network-level, through the use of multilayer structure and modularity; and (ii) evaluate the relative importance of ecological structure at these different levels for the reproductive success of plant individuals for the three most attractive species for insects.

\section{Material and methods}

Data collection. We conducted our observational study in Caracoles Ranch, a 2680 ha grassland located within Doñana NP, SW Spain (3704'01.0" N, 6¹9'16.2” W). The climate is Mediterranean with mild winters and average 50-year annual rainfall of $550-570 \mathrm{~mm}$ with high interannual oscillations. Soils are sodic saline (electric conductivity $>4 \mathrm{dS} / \mathrm{m}$ and $\mathrm{pH}<8.5$ ) and annual vegetation dominates the grassland with no perennial species present (Lanuza et al. 2018). Along a $1 \mathrm{~km}$ long $\times 800$ $\mathrm{m}$ wide area we established in 2015 nine square plots of side $8.5 \mathrm{~m}$ distributed in three subareas: three plots were in the upper part, three in the middle, and three in the lower part. The plots in the upper part are rarely flooded, whereas those in the middle and lower parts are annually flooded by vernal pools. The average distance between these three locations was $300 \mathrm{~m}$ and the average distance between plots within each location was 40 $\mathrm{m}$. This spatial configuration of plots allows capturing the small scale variation (due to the different soil conditions created by salinity, among other variables) as well as large scale variation (induced by vernal pools) in the dynamics of annual plant communities in our system. Each plot was divided into 36 square subplots of side $1 \mathrm{~m}$ with aisles of $0.5 \mathrm{~m}$ in between to allow access to subplots where measurements were taken (324 subplots in total).

During spring 2020, we sampled plant individuals and their floral visitors across the nine established plots. Specifically, we observed 23 co-occurring annual plant species (Supplementary material Appendix 1 table A1. We surveyed weekly (weather permitting) the identities of floral visitors and their number of visits to each plant species within each subplot from February to June, that is, covering the phenology of all plant species (see Supplementary material Appendix 2). Visits were only considered when the floral visitor touched the reproductive organs of the plant. All subplots within a plot were simultaneously sampled for $30 \mathrm{~min}$ each week by walking slowly between the subplots. Plot survey was ran- domised between weeks to avoid sampling effects. All floral visitors were either identified during the survey or they were net-collected for their posterior identification at the lab. Overall, this procedure rendered approximately 54 hours of floral visitors sampled over 19 weeks, and an estimated sampling coverage of (individual) plant-pollinator interactions in each plot network of $90 \%$ (see Appendix 3 for further details in Supplementary material). Thus, our sampling procedure is appropriate to quantitatively characterize plant-pollinator interactions in our system. Floral visitors were sorted by morphospecies and identified to the species $(42.34 \%)$ or morphospecies $(57.56 \%)$ level (Supplementary material Appendix 5 table A5. In addition, to analyse the composition of the visitor spectrum of each plant species, we also assigned each insect to one of the following eleven taxonomic groups: small beetles, big beetles, butterflies, flies, flower beetles, house flies, hoverflies, humbleflies, small flies, solitary bees, and wasps (Supplementary material Appendix 5 table A5. While some of these floral visitor types (like solitary bees) act as true mutualists, others (such as flower beetles) may rob plant nectar or pollen, and can even damage flowers (Morris et al. 2003). Insects only visited the flowers of 10 of the 23 species present (Supplementary material Appendix 2 Fig. A2.1, and most of these visits were concentrated on three Asteraceae species, namely: Chamaemelum fuscatum, Leontodon maroccanus and Pulicaria paludosa.

To assess plant reproductive success, we sampled at least one individual plant species present per subplot and plot (Supplementary material Appendix 1 table A1), and we counted in the field the number of fruits per individual plant species. We also collected one fruit per individual per subplot and plot from the three most attractive species for insects ( $C$. fuscatum, L. maroccanus and P. paludosa) which represent $95.65 \%$ of all insect visits and, thus, are the focus of the reproductive success analysis (see below). We cleaned the collected fruits and counted the number of developed seeds. Then, the seed production of a given focal individual was estimated as the number of fruits collected for that species multiplied by its number of seeds per fruit. For 49 speciessubplot combinations (out of 1,402 combinations, 3.50\%) for which we could not obtain seed production information, we used the mean number of seeds per species of their plot.

Multilayer assembly. As mentioned above, we have individual-based data for reproductive-success, but not for the frequency of visitation of the sampled plant individuals. To tackle that issue and test our multilayer framework, we aggregate the information on the number of visits for each species in each subplot in a single node for which we can associate their visitation patterns and reproductive success. From visitation frequency data, we built nine multilayer networks (one per plot) to describe (i) the potential pollen flow between individual plant nodes mediated by insect visitors (i.e. we as- 
sume that floral visitors connecting two plant individuals are transferring pollen), and (ii) the effect of flowering phenology on such potential flow. In our multilayer networks, layers contain conspecific plants (individualbased nodes) and their interactions (intralinks) with their floral visitors (species-based nodes), and those visitors connect layers, through interlinks (see below the definition of intra- and inter-links, respectively). If an insect species visits several plant species, we include one copy of that insect node in the layer of those plant species. For that reason, our multilayers can be seen as ensembles of bipartite layers of conspecific plants that are coupled through insect species (see Figs. 11(a) and (e), and 2 for an example). Thus, our networks fit in the "diagonally coupled" category described in (Pilosof et al. 2017)), where networks with different interaction types (defined here by the plant species involved) are connected through shared species. In addition, they can also be described as node-colored multilayers, where each layer or plant species represents a color (see (Kivela et al. 2014) ).

As mentioned above, here the intralayer links (or intralinks) are the connections within a given layer and they represent interactions between conspecific plant individuals with its insect visitors. We estimated intralinks as follows. Firstly, for each plant-species $\mathcal{P}$, we built a weighted, undirected bipartite graph, denoted here as visitation network (VN-P), from the individual plant-insect interaction matrix of each plot (see lefthand side of Fig. 1 (c) for an example). Here the weight of links represents the total number of visits during the sampling period that the focal individual $i$ of species $\mathcal{P}$ recieved from an insect species $j$, and such number is given by all the recorded visits of $j$ to $\mathcal{P}$ in $i$ 's subplot. Secondly, assuming that, in a given visitation network $\mathrm{VN}-\mathcal{P}$, the larger the weight of a connection $w_{i j}^{\mathcal{P}}$ between nodes $i$ and $j$, the more likely that the interaction will transfer pollen between such individuals, we derived a directed flow network from the undirected visitation graph by assigning the following value to the weight of the link from node $i$ to $j$ :

$$
f_{i j}^{\mathcal{P}}=\frac{\varepsilon_{i j} w_{i j}^{\mathcal{P}}}{\sum_{s \in V(V N-\mathcal{P})} w_{i s}^{\mathcal{P}}}
$$

where $f_{i j}^{\mathcal{P}}$ represents the fraction of pollen grains allocated in $i$ that flows to $j$ in the layer $\mathcal{P}, \varepsilon_{i j}$ is the efficiency of the exchanges from node $i$ to $j, \mathrm{~V}(\mathrm{VN}-\mathcal{P})$ denotes the nodes in the visitation network of $\mathcal{P}$, and $w_{i j}^{\mathcal{P}}=0$ if $i$ and $j$ are disconnected in VN-P (see Fig. 1. (c) for an example). Notice that (i) both $f_{i j}^{\mathcal{P}}$ and $\varepsilon_{i j}$ take values between 0 and 1 , and (ii) $f_{i j}^{\mathcal{P}}$ and $\varepsilon_{i j}$ can be different from $f_{j i}^{\mathcal{P}}$ and $\varepsilon_{j i}$, respectively (i.e., flow networks are directed). For the sake of simplicity, hereafter we assume $\varepsilon_{i j}=1$ for every pair $i$ and $j$, meaning that all exchanges are equally efficient regardless of the species and individuals involved. We also assume that pollen flow between two plant individuals does not decay with distance, that is, visitor species effectively link plant individuals at the plot level. These two assumptions are justified in our study system because we do not know pollinator efficiency for different species, and we consider that all the insects can move within the plot easily. Nevertheless, this approach can be easily extended to impose efficiencies per guild, if known, and/or pollen flow decay with distance. Here, since $\varepsilon_{i j}=1$, the interactions $f_{i j}^{\mathcal{P}}$ of a given plot network are the intralayer connections of its layer $\mathcal{P}$.

Finally, to couple the different layers and, thus, assemble the multilayer network, we introduced the interlayer links (or interlinks), i.e., interconnections between insects of the same species that are present in several plant species (layers). We used these interlinks to model how easily the pollen flows from one plant species to another due to the phenological overlap between them and the interspecific floral visits of insects. To do so, we proceeded as follows: if a given insect visitor $x$ was present in layers $\mathcal{P}$ and $\mathcal{L}$, we created one interlink from node $x$ in layer $\mathcal{P}\left(\right.$ i.e., $x^{\mathcal{P}}$ ) to $x$ in layer $\mathcal{L}$ (i.e., $x^{\mathcal{L}}$ ) with

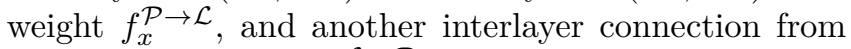
$\mathcal{L}$ to $\mathcal{P}$ with weight $f_{x}^{\mathcal{L} \rightarrow \mathcal{P}}$, where $\mathcal{P}$ and $\mathcal{L}$ denote respectively two plant species, and $f_{x}^{\mathcal{P} \rightarrow \mathcal{L}}$ is equal to the phenological overlap of $\mathcal{P}$ and $\mathcal{L}$ divided by the total duration of $\mathcal{P}$ 's phenology (see Fig. 11(d) for an example of these calculations). In each plot, we estimated phenologies for each plant species from its weekly record of insect visits (see further details in Supplementary Materials Appendix 21. We analyze an alternative definition of interlinks weighted by the number of shared visits in Supplementary material Appendix 4 To conclude, note that, according to previous definitions, interlayer edges are directed (i.e., $f_{x}^{\mathcal{P} \rightarrow \mathcal{L}}$ and $f_{x}^{\mathcal{L} \rightarrow \mathcal{P}}$ can be different), and their weights take values between 0 and 1 (see Fig. 1(d) for an example).

Network metrics. Once we created the multilayer arrangements, we assessed how their structures shape the pollen flow that reaches each individual plant. To do so, we estimated a series of network metrics related to multilayer network- and node-level structural patterns, and we complemented it with motif-level descriptors. For the network-level structure, we calculated (i) the modular partitions that better describe network pollen flows (see subsection "Modularity"). For the node-level structure, we obtained (ii) the within-layer and among-layer centralities, which are related with the individual's probability of receiving pollen and the effect of interlinks in such probability, respectively. Below we explain in detail each of these metrics (see subsection "Centrality metrics"). Finally, for each plot we characterized motiflevel structure through (iii) the 3-node motif characterizations, denoted as homospecific motifs and heterospecific motifs (see subsection "Motif analysis"). 
bioRxiv preprint doi: https://doi.org/10.1101/2021.04.23.441120; this version posted August 6, 2021. The copyright holder for this preprint (which was not certified by peer review) is the author/funder, who has granted bioRxiv a license to display the preprint in perpetuity. It is made available under aCC-BY-NC-ND 4.0 International license.

(a) Network

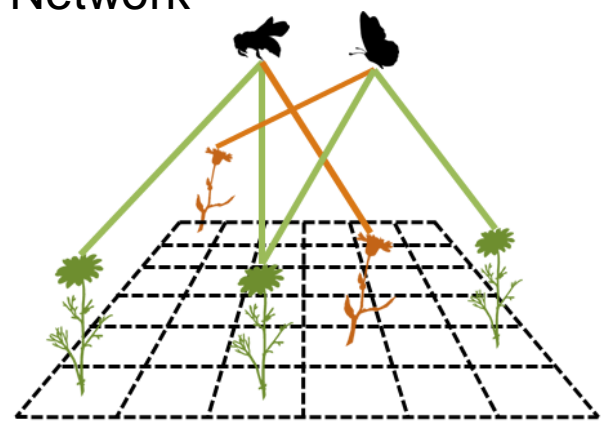

(b) Motifs

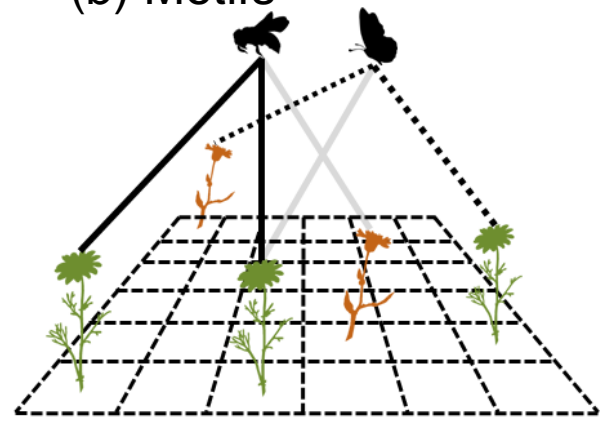

(c) Intralinks

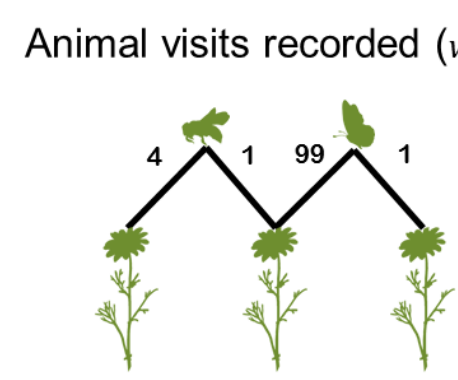

(d) Interlinks

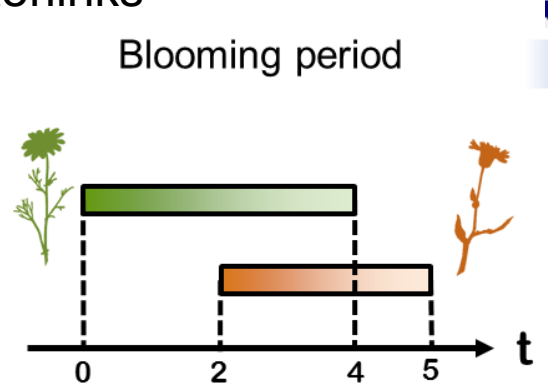

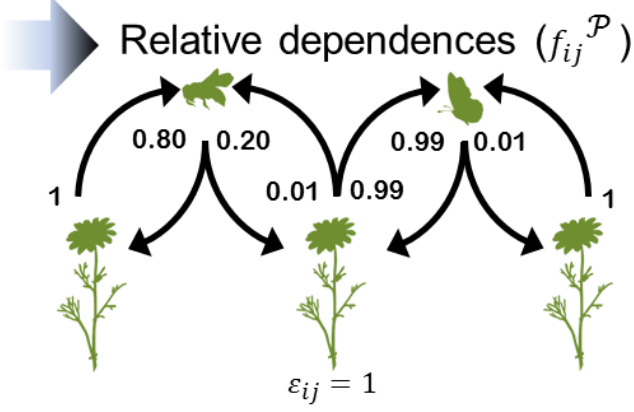

U.R

\section{Phenological overlap}

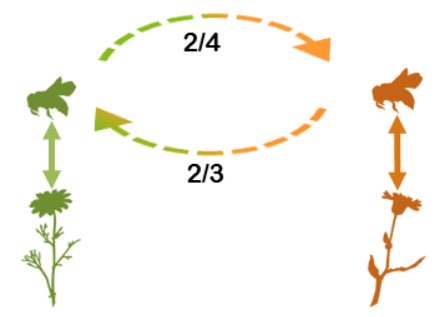

(e) Multilayer

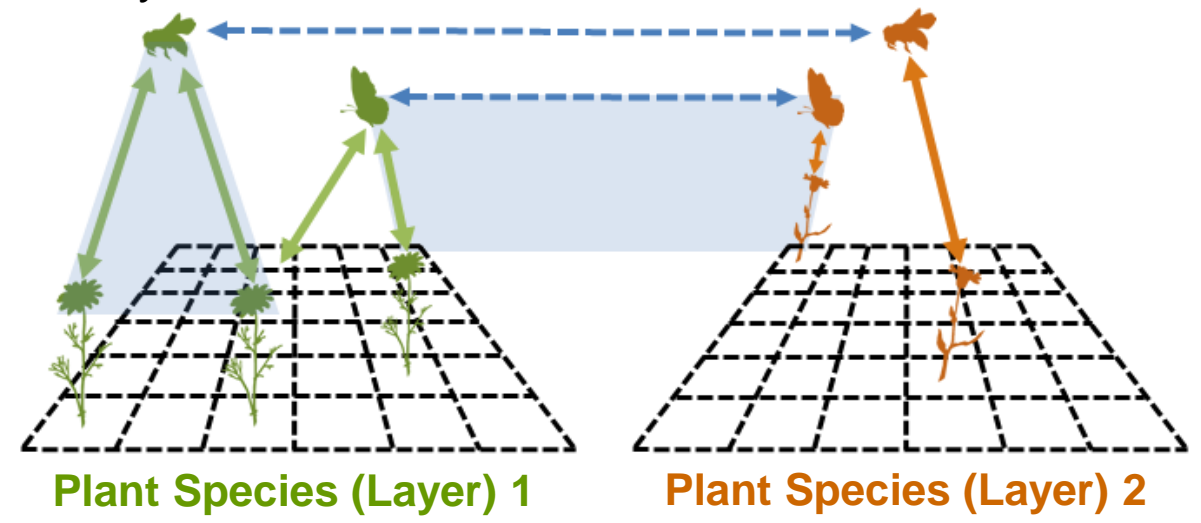

Fig. 1. (a) An example of a visitation network for a $6 \times 6$ plot with two plant species and two insect visitors, respectively. For the sake of readability, weights $w_{i j}^{\mathcal{P}}$ have been omitted. (b) In this panel we highlight examples of homospecific (black solid lines) and heterospecific (black dotted lines) motifs, respectively, in Fig. 1(a). (c) An example of a visitation network and the resulting flow arrangement for plant species 1 (green) in Fig. 1. a). (d) An example of the estimation of interlinks for plant species 1 and 2 (green and orange, respectively) in Fig. 1.a). (e) Resulting multilayer network for the arrangement in Fig. 1. (a). Continuous double-arrows represent directed intralayer links, whereas dashed ones show directed interlinks. Shaded areas highlight the multilayer analogs of the motifs in Fig. 1 (b). As can be seen, layers are made up of conspecific focal individual plants and their interactions with their insect visitors, and shared insects connect layers, depending on their interspecific floral visits and on the phenological overlap among plant species. Thus, if a given layer is isolated (i.e., it has no interlinks with weight greater than zero), its plant individuals only receive conspecific pollen mediated by insects; otherwise floral visitors will transport conspecific and heterospecific pollen among layers of plant species. 
Modularity. Network modularity measures how closely connected nodes are divided into modules or compartments (Delmas et al. 2018). Since our multilayers encode potential pollen flows, we defined modules as nonoverlapping groups of nodes that capture flows within and across layers for a relatively long time, rather than clusters with a high internal density of links (i.e. (Domenico et al. . 2015)). For that reason, we used Infomap and its random walk approach ( $\mathrm{R}$ package "infomapecology", (Farage et al. , 2021)) to unveil the module organization of our multilayers. Specifically, Infomap uses the map equation to measure the minimum number of bits (or code length, $L$ ) that are needed to describe the movement of a random walker in and between the modules of a given network partition $M$ (Farage et al. 2021 Rosvall et al. 2009). Then, the algorithm finds the partition that requires the least amount of information to describe modular flows. Infomap's approach contrasts with the usual strategy to detect modules in studies of ecological networks, namely: to identify modular partitions that maximize the internal density of links within the modules, by maximizing the objective function $Q$, called modularity, or its generalizations (reviewed in Thébault (2012)). Although network flows depend on the density of links, the optimization of the map equation and the one of $Q$ usually produce different compartments. Since there is no single "true" network partition (Peel et al. . 2017), here we applied Infomap because that is the method that best matches our interest in flows' characterization. Furthermore, Infomap has been thoroughly described mathematically and computationally, is widely used in non-ecological disciplines, and its use in ecological applications is increasing (reviewed in Farage et al. (2021)).

For each (observed) multilayer network, we estimated the optimal module partition and tested if the total number of modules $m$ and of the code length $L$ can be explained at random. To do so, in each plot, we compared the observed values for the map equation $\left(L_{\text {Observed }}\right)$ and the number of modules ( $\left.m_{\text {Observed }}\right)$ with the distributions of $L$ and $m$ obtained from two null models that randomize the intralinks of the plot multilayers and preserve the observed phenologies (see Appendix 9 in Supplementary materials).

In a supplementary analysis, to characterize how multilayer's nodes are connecting the modules of the optimal partition, we calculated the specialization roles (sensu (Olesen et al. 2007) of each node and classified them in the following categories: (i) peripherals, i.e., vertices linked to very few nodes that usually are within their module; (ii) module hubs, i.e., highly connected vertices linked to many nodes within their own module; (iii) connectors, i.e., nodes that link several modules; and (iv) network hubs, i.e., nodes acting as both connectors and module hubs (Olesen et al. 2007) (see further details in Supplementary material Appendix 8).
Centrality metrics. Centrality is a measure of how "important" (or central) a node is in a network. Since such "importance" depends on the structural features or dynamic behaviour we are interested in, there are several ways of being central and, thus, different means of scoring centrality (Delmas et al., 2018 , Gómez, 2019). The in- and out-strength of a node are the sum of the weights of its in-links and out-links, respectively, where the inlinks are the links that arrive at a node (or in-links) and the out-links those that depart from it (Gómez, 2019). PageRank centrality is a ranking method that can be intuitively described as follows: a node has a high rank if the sum of the ranks of the links pointing to it is high (see (Gómez, 2019) for a formal definition of the ranking algorithm). Due to their definitions, in- and outstrength of a node only depends on its neighbors (that is, on those nodes connected to it). For that reason, it is considered a local centrality measure. Instead, given that Pagerank values depend on the structure of the entire network (that is, any change in the number of nodes and/or in the patterns of connections among the nodes will modify the value of this index for a given node), this metric is considered as a global centrality measure. In addition, we developed a new metric to assess the influence of interlinks on the rankings obtained with the PageRank algorithm, the among-layer centrality ratio, denoted as $R$. For each node, that ratio is given by $R=M C / L C$, where $M C$ and $L C$ denote the PageRank value of the node when all the layers are coupled (i.e., when all the interlinks are present) and isolated (i.e., when we remove all the interlinks of the multilayer or we set their weights to zero), respectively.

All the previous centrality metrics are key from the pollen diffusion perspective (modeled with randomwalks) adopted in this work. If pollen grains diffuse as random walkers, the larger the in-strength of a node (hereafter within-layer centrality), the larger its probability is of receiving pollen grains from its direct neighbors. Instead, the probability that one node transfers its load of pollen to its neighbors is proportional to its out-strength. Regarding the PageRank index, its value represents the asymptotic probability of finding a grain of pollen (that diffuses on the system) in a given node, when time tends to infinity. Consequently, plant nodes with larger PageRank are likely to receive larger amounts of pollen flows than those with smaller values. Hereafter we will refer to the PageRank index as the pollen arrival probability. Finally, according to the latter interpretation of PageRank, we can reinterpret the values of the among-layer centrality ratio of a node $(R=M C / L C)$ as follows: if $R$ is smaller than 1 , the probability of receiving pollen is reduced when plant species coupling is considered, and vice versa. That means that plants with $R<1$ are more connected with its conspecifics than with heterospecific plant individuals. Notice that, if there are interlinks, pollen flows are loaded with heterospecific pollen, depending on the phe- 
nologies of co-occurring plants, whether $R>1$ or $R<1$. To calculate the centrality metrics of our multilayer networks we used the igraph package in $\mathrm{R}$ (Csardi \& Nepusz, 2006).

Motif analysis. To complement the network- and nodelevel descriptions of the multilayer structures, we incorporate additional details on the local architecture of direct and indirect interactions among nodes (i.e., individual or species) by decomposing the networks into motifs, the basic building blocks of communities (Milo et al. 2002). Motifs are well developed for food webs (Cirtwill et al. 2018), mutualistic (Simmons et al. 2020. 2018), and competitive networks (Godoy et al. 2017$)$, but have been seldom applied to multilayer networks. In our case, we analyzed the number of undirected triplets present in our visitation networks, that is, the pattern of connections of undirected path graphs with length 2 (see examples in Fig. 1.(b)). However, even such simple three-node motifs can be differentiated according to the layers involved (see examples in Fig. 1(e)). Considering motifs containing one or two layers is interesting because it perfectly maps onto the effects of indirect conspecific and heterospecific pollen flows on focal individual's per capita seed production. In addition, it moves forward the bipartite motif descriptions from species-based networks, in which all the subgraph nodes are heterospecific (see Simmons et al. (2020, 2018)), to individual-based arrangements with conspecific and heterospecific individuals.

To conduct our motif analyses, we introduced a novel motif categorization according to the plant species involved: If all the plant individuals belong to the same species, the motif was referred to as homospecific motif; otherwise, the motif was classified as heterospecific (see Fig. 1. b)). According to previous studies on species-based mutualistic bipartite networks, such motifs can represent indirect competitive (Mitchell et al. 2009: Ye et al., 2013) or facilitative interactions (Carvalheiro et al. 2014 Ghazoul, 2006). For example, in Fig. 11(a) plant individuals may be involved in exploitative competition for finite pollinator resources, or interference competition through interspecific pollen deposition (Flanagan et al. 2010, Mitchell et al., 2009, Ye et al. 2013). Conversely, facilitative effects may occur when the presence of one focal individual increases pollinator visits to a coflowering individual.

To conduct our analysis, in each plot we focused on the number of homospecific and heterospecific motifs of a given plant node (denoted as target plant node), which inform about how many other conspecific and heterospecific plant nodes (acting plant nodes) contribute to the diet of its insect visitors, respectively. Since the acting plant nodes of a given target plant may not belong to the module of the latter, homospecific and heterospecific motifs complement and enhance the description of the indirect interactions of plant nodes. Furthermore, to incorporate species' phenological overlap in our motif analysis, we calculated both types of motifs from the interspecific individual plant level bipartite networks that arose weekly in a given plot (see Fig. 11(a) for an example of such networks). Thus, heterospecific motifs only appear when different coflowering species that share insect visitors are present in a given week and plot. Then, the total number of homospecific and of heterospecific motifs for a given focal individual and plot were estimated by summing up the weekly number of motifs in which that individual plant was present. Notice that, according to the previous methodology, we assumed that all floral visitors can easily reach all the subplots in a given plot, as we did when assembling the multilayer networks. It is worth mentioning that other metrics can be downscaled to the individual level to explore the effects of the intra- and interspecific competition on plants at individual-based level, such as the Müller's indices in (Carvalheiro et al. 2014), which quantify how much one acting plant contributes to the diet of each insect species of another target plant (i.e., Müller's indices are proportions, and for a given plant individual there are as many indices as conspecific and heterospecific plant individuals). The main advantage of using the number of homospecific and heterospecific motifs is that, unlike Müller's indices, it is possible to characterize a given plant with only two integer numbers and, since they are not proportions, when adding the results for each metric in different weeks, their respective interpretations hold. Consequently, they are easy to integrate into a multiscale analysis.

Finally, we tested whether the number of homo and heterospecific motifs per focal individual and plot differed from a random expectation by using a null model that preserves the experimental phenology, that is, the total number of observed visits per plant species and per insect visitor in each plot and week (see Supplementary material Appendix 11). A guide to calculating all the presented multilayer metrics is included in the associated code (see section "Code availability").

Reproductive success analysis. One key aspect of this multilayer approach is that we can study the impact of direct and indirect interactions between plants and floral visitors at different structural scales on individual plant reproduction success (i.e. seed production). We explore that relationship by fitting generalized mixed models (GMMs) to the individuals of the three species that attracted more insect visitors (C. fuscatum, L. maroccanus, and P. paludosa, an early, middle, and late phenology species, respectively). Since our response variable (individual seed production) represents count data and we detected overdispersion issues and excess of zeroes in our exploratory analysis, we used negative binomial models in our inferences with a log link function and a constant zero-inflated term (see Eq. A13.1) in Supplementary material Appendix 13). As explanatory variables, all models included (i) node-level structure descriptors, that is, the plant individuals' within-layer cen- 
trality (i.e. in-strength) and among-layer centrality ratio (i.e. the pollen arrival probabilities when the layers are coupled over the pollen arrival probabilities when layers are isolated); and (ii) motif-level structure descriptors, i.e. the number of homospecific and heterospecific motifs. We also used plot as a random intercept to account for multiple individuals of the same plant species measured at each plot. In addition, we tested how the results of our models vary if we add the total number of visits that an individual plant received to the previous list of explanatory variables (see Supplementary material Appendix 14.

To keep the regression variables on similar scales and use the fitted parameters of the models as (withinstudy) effect-sizes, that is, measures of variable importance (Schielzeth, 2010), all numeric explanatory variables were centered and scaled during the analysis. Finally, note that our models contain both individuals that received insect visits and individuals that did not. Network metrics for the latter group were estimated by assuming that their corresponding nodes were isolated from each other, as well as from the corresponding multilayers. For that reason, and taking into account our high sampling completeness, their within-layer centralities and their number of homospecific and heterospecific motifs were set to zero, respectively, and the amonglayer centrality ratio was set to one. Notice that, by definition, the value of PageRank for isolated nodes does not depend on the presence or absence of interlinks (see Eq. (8.32) in (Gómez, 2019)). Hence, $M C=L C$, and, consequently, $R=M C / L C=1$.

Our analyses were conducted in $\mathrm{R}$, with the "glmmTMB" package (Brooks et al., 2017). We found no collinearity among explanatory variables when we checked their variance inflation factors with the Rpackage "performance" (Lüdecke et al. 2020$)$. We also checked model assumptions with the R-package "DHARMa" (Hartig, 2020).

\section{Results}

We recorded 1,794 insect visits in our system from February to June 2020. The distributions of visits among the taxonomic groups of floral visitors, plant species, and plots, respectively, showed a high variation (Supplementary materials Appendix 7Fig. A7.1). Small beetles (756), flower beetles (395 observations), solitary bees (280), and small flies (135) were the most common functional groups of floral visitors observed, and most interactions involved $L$. maroccanus (1,337 observations) and, to a lesser extent, C. fuscatum (268) or P. paludosa (111). Small flies and flower beetles were the most abundant insects visiting $C$. fuscatum, while small beetles and flower beetles were the most abundant for $L$. maroccanus, and solitary bees for $P$. paludosa. the number of visits per plot ranges between 360 and 44, with a mean value of $199.33 \pm 113.18$ insect visits.
Community structure. Plot multilayers obtained from the above field observations contain on average $4.4 \pm 2.13$ plant species (layers), $71.89 \pm 37.34$ nodes (of which $49.00 \pm 25.29$ are plant individuals and $22.89 \pm 12.09$ insect nodes), $176.89 \pm 89.23$ intralinks, and $16.00 \pm 14.21$ interlinks. (see Fig. 2 for an example of the multilayer networks analyzed and Supplementary material Appendix 6 for the graphs of the remaining multilayers).

By using Informap, we found on average 10.78 modules per plot, being $(3,16)$ the corresponding $95 \%$ confidence interval (CI), obtained from a non-parametric bootstrap resampling of the number of modules, by using the functions boot and ci.boot in the R-package "boot" (Canty \& Ripley, 2020). One third of the modules contains at least two plant species (Fig. 3), Supplementary materials Appendix 7 Fig. A7.3, which shows that insect visitors are effectively linking plant layers. Overall, the modules contain few plant individuals and most of them belong to the same species when the cluster contains several plant species. The average size of modules is 6.67 nodes with CI $(2,36)$ and the average number of plant individuals per module is 4.55 with CI $(1,26)$. As expected, the larger the plot richness, the larger the number of modules (the coefficient of determination between both variables is 0.85 , with $\mathrm{p}$-value $=0.0002$ ). Our results also suggest that modules reflect phenological constraints. For instance, C. fuscatum plant individuals in plot 2 do not share modules with those of $P$. paludosa (Fig. 3) because their respective phenologies do not overlap (Supplementary material Appendix 2 Fig. A2.1).

RResults for insect species, which represent on average one third of the nodes per module (2.12 insect nodes per module with CI $(1,6)$ ), are very similar to those of plant individuals (Supplementary materials Appendix 7 Fig. A7.3. Additional details on module features can be found in Supplementary materials (see Appendix 7). Finally, we tested if the observed module partitions are different from a random expectation. According to our results, the optimal partitions of our multilayers provide a significantly better description of the pollen flows within the whole system (or exhibit more modular regularities, i.e., the observed values for the map equation, $L_{\text {Observed }}$, are smaller) than those estimated for random graphs, although the number of modules is not significantly different from that of null models in most plots (see Supplementary material Appendix 9). In other words, while the number of modules obtained is consistent with a random expectation, their composition is significantly different from it.

Centralities. Overall, within-layer centrality (i.e., instrength) of plant individuals correlates with the total number of visits that a focal individual received (Spearman's $\rho=0.34, \mathrm{n}=433$, $\mathrm{p}$-value $<0.05)$. Furthermore, we also found a generally strong, positive, and significant correlation between the within-layer centrality values and pollen arrival probabilities (Supplementary ma- 
bioRxiv preprint doi: https://doi.org/10.1101/2021.04.23.441120; this version posted August 6, 2021. The copyright holder for this preprint (which was not certified by peer review) is the author/funder, who has granted bioRxiv a license to display the preprint in perpetuity. It is made available under aCC-BY-NC-ND 4.0 International license.

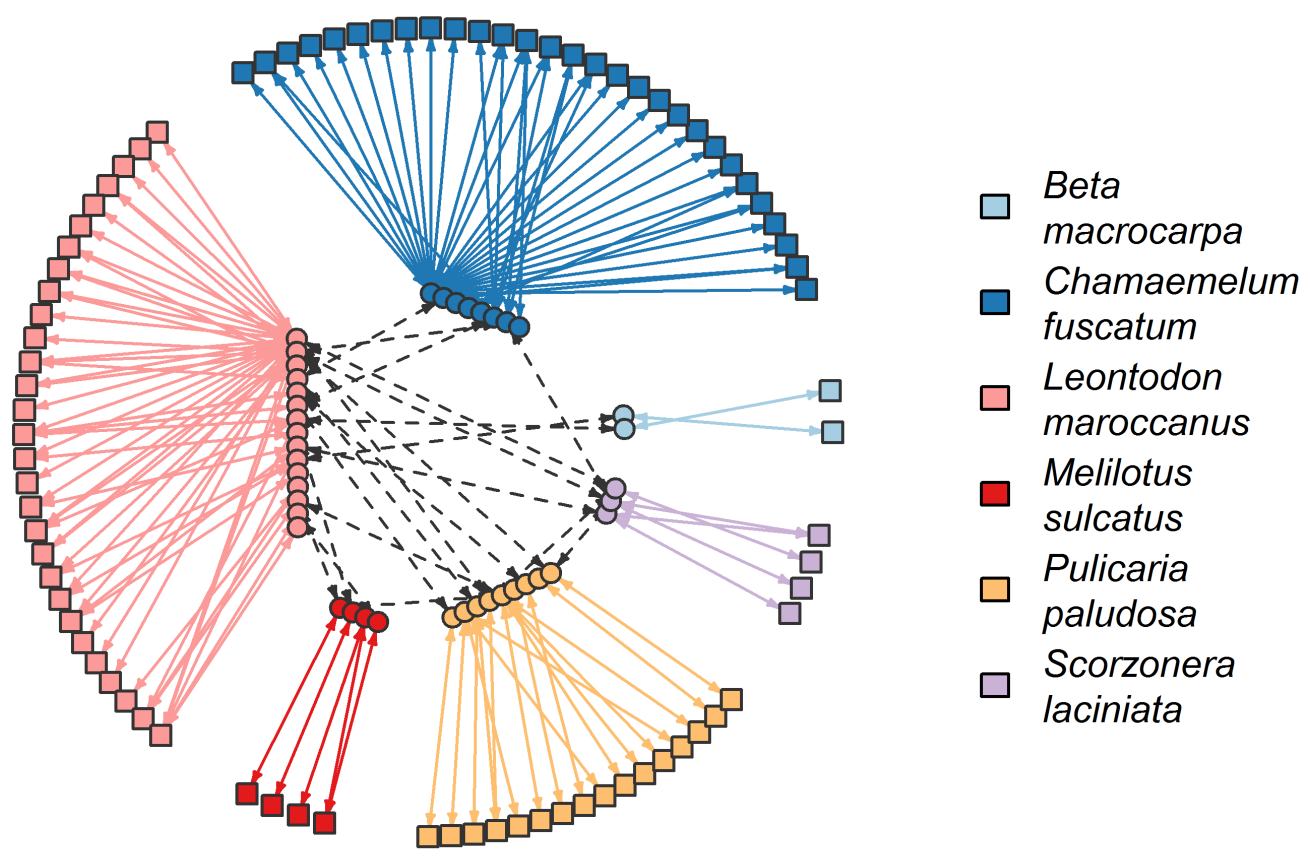

Fig. 2. Resulting multilayer for plot 8. Each color refers to a layer: B. macrocarpa (light blue), C. fuscatum (blue), L. maroccanus (pink), M. sulcatus (red), P. paludosa (yellow), and S. laciniata (malve). We represent plant individuals and insect species with square and circular nodes, respectively. For clarity, we use double-headed arrows to depict the directed interactions that are present in the plot. Continuous and dashed edges refer to intra-links and inter-links, respectively.
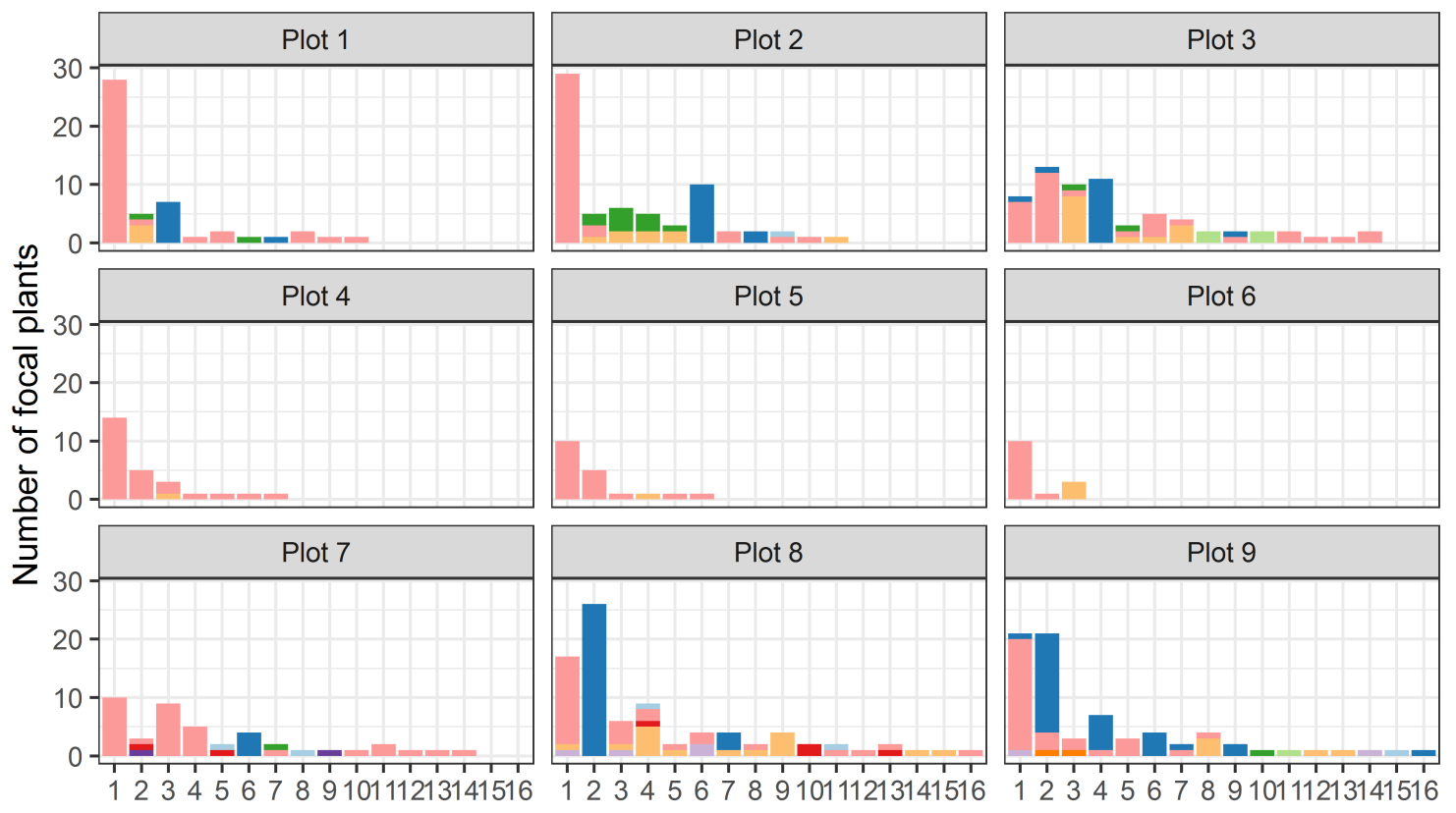

Module

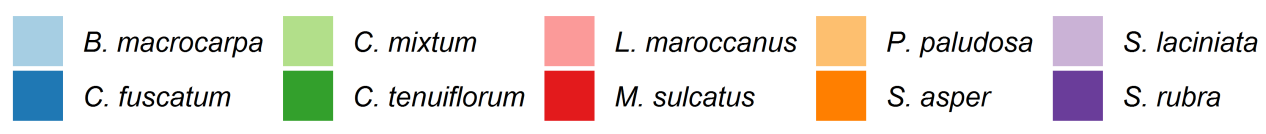

Fig. 3. Number of plant individuals per module, plant species and plot.

terials Appendix 10 Fig. A10.1). This is expected because the asymptotic probability of finding a grain of pollen in a given node depends on the probability of receiving such grain from the direct neighbors (which is mediated by the within-layer centrality of the node).

Pollen arrival probability is also positively correlated with the total number of visits that a focal individual received (Spearman's $\rho=0.47, \mathrm{n}=433$, $\mathrm{p}$-value $<0.05$ ). 


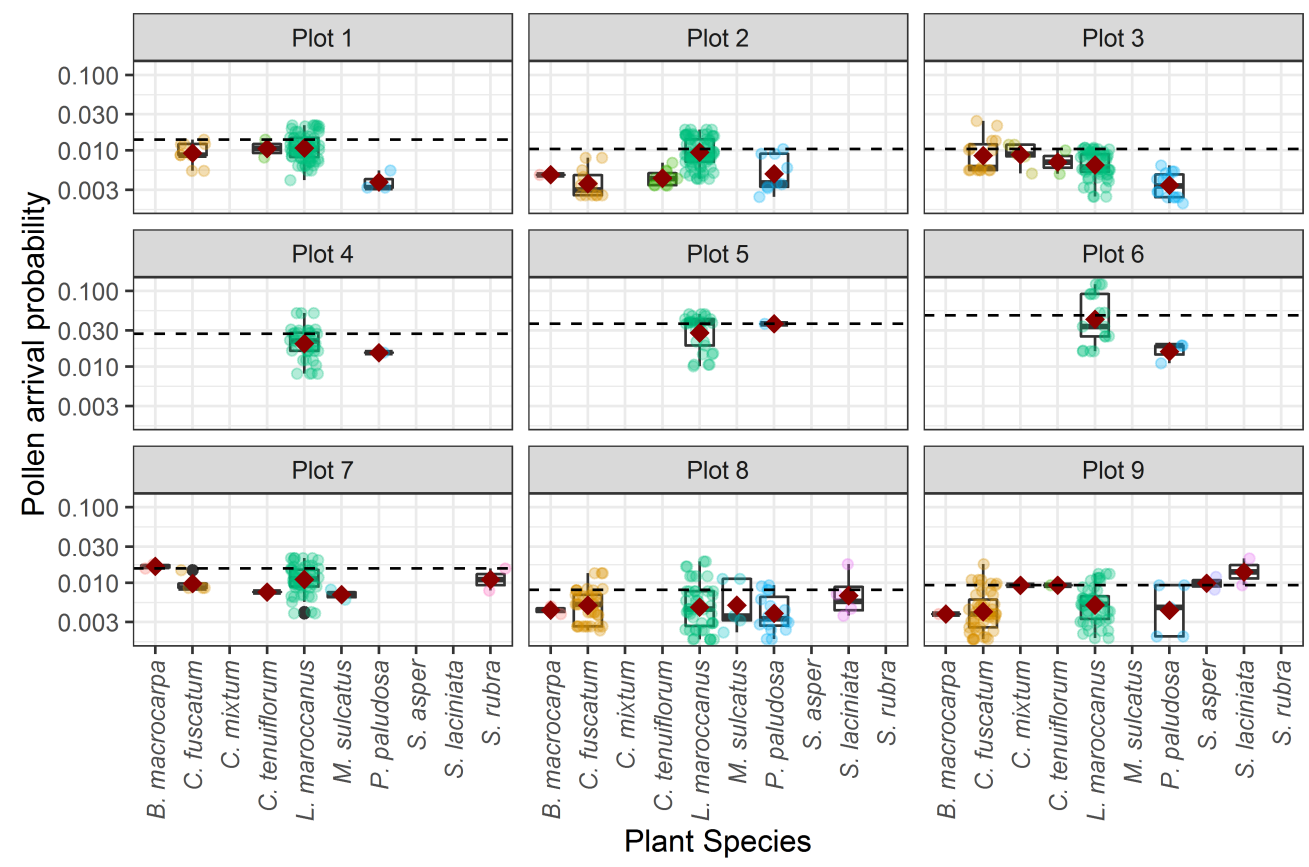

Fig. 4. Dependence of plant individuals' pollen arrival probability (or PageRank index) on plot and species. Mean values are shown with red diamonds. Points show results for individual plants. Dashed lines show the theoretical pollen arrival probability if all the nodes had the same probability.

In Fig. 4 we show pollen arrival probability results per plant species and plot. The variance within a given plant species is smaller than the one among species (see Supplementary material Appendix 12 . In addition, we can see that the larger the total number of plant individuals per plot, the smaller the average pollen arrival probability (Spearman's $\rho=-0.98, \mathrm{n}=9$, p-value $<0.05$ ) and the theoretical pollen arrival probability, which is calculated as if all the nodes would have the same arrival probability (dashed lines in Fig. 4).

Finally, we see a moderate positive correlation between the among-layer centrality ratio $(R)$ and the total number of visits (Spearman's $\rho=0.26, \mathrm{n}=433$, p-value $<$ $0.05)$. According to our results, considering interlinks in our communities induces, on average, a loss of centrality in most plant individuals (i.e., $R<1$ ). That is, on average most plant individuals receive much less conspecific pollen mediated by insect visitors, when the multilayer is coupled. Only L. maroccanus and S. laciniata plant individuals gain centrality (on average) when the plant layers are connected (Supplementary materials Appendix 10 Fig. A10.2). Indeed, differences among plant species are significant in each plot (Kruskal-Wallis rank test: $\mathrm{p}$-value $<0.05)$.

Homospecific and heterospecific motifs. In our communities, the number of homospecific motifs is highly correlated with the total number of visits (Spearman's $\rho=0.73, \mathrm{n}=433, \mathrm{p}$-value $<0.05)$, whereas the number of heterospecific motifs is not (Spearman's $\rho=0.11, \mathrm{n}$ $=433$, p-value $<0.05)$. Homospecific motifs are more abundant than heterospecific ones in $C$. fuscatum and $L$. maroccanus individuals (paired Wilcoxon-test: p-value
$<0.05$ for both plant species), whereas both metrics are comparable in most focal individuals of $P$. paludosa (paired Wilcoxon-test: $\mathrm{p}$-value $=0.14$ ), and, in the case of other plant species, heterospecific motifs predominate over homospecific motifs (paired Wilcoxon-test: p-value $<0.05$ only for C. tenuiflorum) (Fig. 5). Plant species with the largest number of visits and the smallest diversity of floral visitors (such as C. fuscatum and $L$. maroccanus) accumulate the largest number of homospecific motifs in each plot (Supplementary materials Appendix 7 Fig. A7.1). That is, C. fuscatum and L. maroccanus individuals tend to share more weekly visits of the same insects within their conspecific individuals than with heterospecific individuals. Indeed, we found generally significant differences in the average number of homospecific motifs among plant species in each plot (Kruskal-Wallis rank test: $\mathrm{p}$-value $<0.05$ ).

Regarding heterospecific motifs, both extremely common (i.e. L. maroccanus) or rare plant species show the largest number of such motifs. This is due to the fact that the latter species share all insect visitors with the former, along the sampling weeks (Supplementary material Appendix 2 Fig. A2.2.

Reproductive success analysis. Results for the GLMMs of the three plant species that attracted most insect visitors (C. fuscatum, L. maroccanus and P. paludosa) show that, overall, our motif-level descriptors (i.e., the total number of homospecific and heterospecific motifs) exert a stronger influence on the seed production of the plant individuals considered than the node-level metrics (i.e., the within-layer centrality and among-layer centrality ratio) (see table 1 and Fig. 6). 
bioRxiv preprint doi: https://doi.org/10.1101/2021.04.23.441120; this version posted August 6, 2021. The copyright holder for this preprint (which was not certified by peer review) is the author/funder, who has granted bioRxiv a license to display the preprint in perpetuity. It is made available under aCC-BY-NC-ND 4.0 International license.

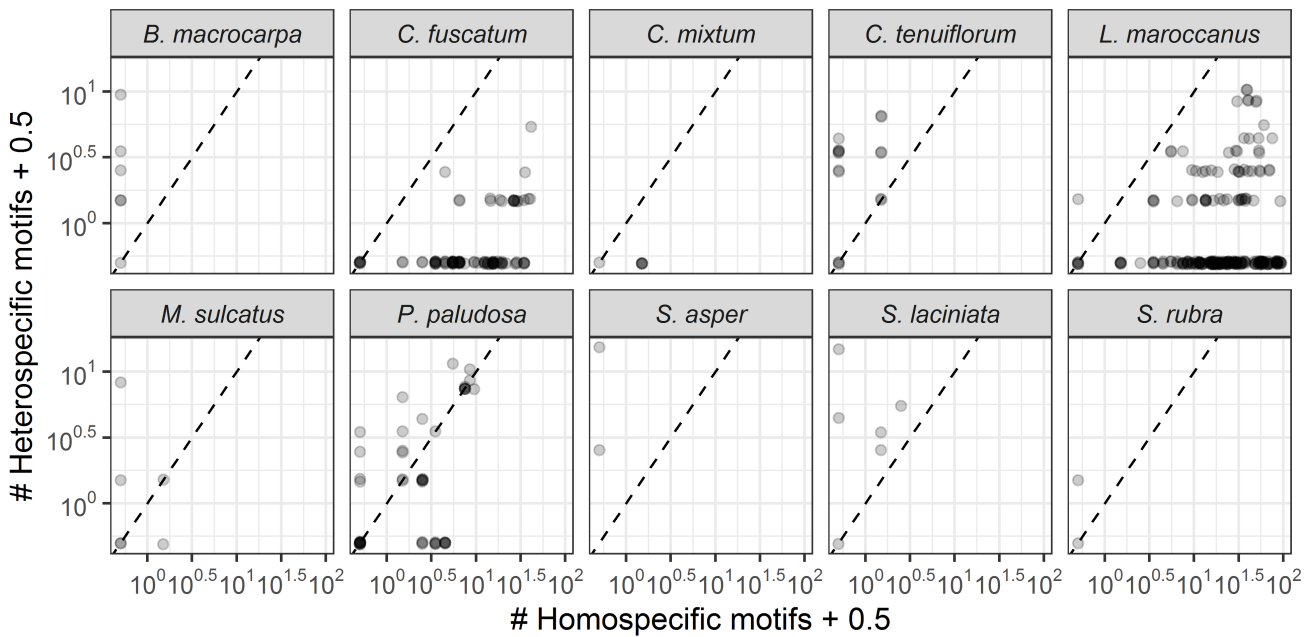

Fig. 5. Number of different homospecific and heterospecific motifs per focal individual and plant species, pooling the data for all nine plot networks. Points show results for individual plants. Dashed lines locate those plant individuals whose numbers of homospecific and heterospecific motifs are equal.

Table 1. Results for the GLMMs of C. fuscatum (a), L. maroccanus (b), $P$. paludosa (c) showing the effect on plant reproductive success (seeds per individual plant). The term $Z I_{0}$ describes the zero inflation probability $\varphi_{i j}$, given by $\operatorname{logit}\left(\varphi_{i j}\right)=Z I_{0}$ (see Eq. A13.1 in Supplementary material Appendix 13. We highlighted in bold the most important estimates based on effect sizes and its variability. P-values have been obtained from the Wald test reported in the summary on the models fitted with R-library glmmTMB (Brooks et al. 2017).

(a) C. fuscatum: the model contains 163 plant individuals. Conditional $R^{2}=$ 0.319 , marginal $R^{2}=0.052$, with $\sigma_{u}^{2}=0.4821$ and $\theta=1.09$.

\begin{tabular}{lclll}
$\begin{array}{l}\text { Seeds per } \\
\text { indiv. plant }\end{array}$ & Est. & $\begin{array}{l}\text { Std. } \\
\text { Error }\end{array}$ & $\begin{array}{l}\mathrm{Z} \\
\text { value }\end{array}$ & $\begin{array}{l}\mathrm{p} \\
\text { value }\end{array}$ \\
\hline $\begin{array}{l}\text { (Intercept) } \\
\text { Homospec. } \\
\text { motifs }\end{array}$ & $\mathbf{5 . 0 4 9}$ & $\mathbf{0 . 2 6 5}$ & $\mathbf{1 9 . 0 3}$ & $<\mathbf{2 e - 1 6}$ \\
$\begin{array}{l}\text { Heterospec. } \\
\text { motifs }\end{array}$ & $\mathbf{0 . 2 8 5}$ & $\mathbf{0 . 1 4 0}$ & $\mathbf{2 . 0 4}$ & $\mathbf{0 . 0 4 1 7}$ \\
$\begin{array}{l}\text { Within-layer } \\
\text { centrality }\end{array}$ & 0.138 & 0.095 & 1.46 & 0.1448 \\
$\begin{array}{l}\text { Among-layer } \\
\text { centr. ratio }\end{array}$ & $\mathbf{0 . 0 2 7}$ & $\mathbf{0 . 1 0 5}$ & $\mathbf{0 . 2 6}$ & $\mathbf{0 . 7 9 8 6}$ \\
$\mathbf{Z I}_{\mathbf{0}}$ & $\mathbf{- 3 . 7 8 4}$ & $\mathbf{0 . 6 3 9}$ & $\mathbf{- 5 . 9 2}$ & $\mathbf{3 . 1 5 e - 0 9}$
\end{tabular}

(b) L. maroccanus: the model contains 293 plant individuals. Conditional $R^{2}=0.304$, marginal $R^{2}=0.065$, with $\sigma_{u}^{2}=0.2503$ and $\theta=2.37$.

\begin{tabular}{lclll}
$\begin{array}{l}\text { Seeds per } \\
\text { indiv. plant }\end{array}$ & Est. & $\begin{array}{l}\text { Std. } \\
\text { Error }\end{array}$ & $\begin{array}{l}\mathrm{z} \\
\text { value }\end{array}$ & $\begin{array}{l}\mathrm{p} \\
\text { value }\end{array}$ \\
\hline $\begin{array}{l}\text { (Intercept) } \\
\text { Homospec. } \\
\text { motifs }\end{array}$ & $\mathbf{5 . 7 1 1}$ & $\mathbf{0 . 1 7 2}$ & $\mathbf{3 3 . 2 6}$ & $<\mathbf{2 e - 1 6}$ \\
$\begin{array}{l}\text { Heterospec. } \\
\text { motifs }\end{array}$ & -0.046 & 0.043 & -1.05 & 0.2940 \\
$\begin{array}{l}\text { Within-layer } \\
\text { centrality }\end{array}$ & -0.012 & 0.042 & -0.27 & 0.7860 \\
$\begin{array}{l}\text { Among-layer } \\
\text { centr. ratio }\end{array}$ & $\mathbf{0 . 0 9 1}$ & $\mathbf{0 . 0 5 5}$ & $\mathbf{1 . 6 6}$ & $\mathbf{0 . 0 9 6 7}$ \\
$\begin{array}{l}Z I_{0} \\
\end{array}$ & $\mathbf{- 2 0 . 9 9}$ & 2111.82 & -0.01 & 0.992
\end{tabular}

(c) P. paludosa: the model contains 150 plant individuals. Conditional $R^{2}=$ 0.190 , marginal $R^{2}=0.068$, with $\sigma_{u}^{2}=0.1373$ and $\theta=0.834$.

\begin{tabular}{lclll}
$\begin{array}{l}\text { Seeds per } \\
\text { indiv. plant }\end{array}$ & Est. & $\begin{array}{l}\text { Std. } \\
\text { Error }\end{array}$ & $\begin{array}{l}\mathrm{z} \\
\text { value }\end{array}$ & $\begin{array}{l}\mathrm{p} \\
\text { value }\end{array}$ \\
\hline $\begin{array}{l}\text { (Intercept) } \\
\text { Homospec. } \\
\text { motifs }\end{array}$ & $\mathbf{5 . 6 4 6}$ & $\mathbf{0 . 1 6 7}$ & $\mathbf{3 3 . 8 9}$ & $<\mathbf{2 e - 1 6}$ \\
$\begin{array}{l}\text { Heterospec. } \\
\text { motifs }\end{array}$ & $\mathbf{0 . 3 1 2}$ & $\mathbf{0 . 1 8 0}$ & $\mathbf{1 . 7 3}$ & $\mathbf{0 . 0 8 3}$ \\
$\begin{array}{l}\text { Within-layer } \\
\text { centrality }\end{array}$ & -0.031 & 0.110 & -0.28 & 0.779 \\
$\begin{array}{l}\text { Among-layer } \\
\text { centr. ratio }\end{array}$ & -0.166 & 0.125 & -1.33 & 0.185 \\
$\mathbf{Z I}_{\mathbf{0}}$ & $\mathbf{- 2 . 4 6 7}$ & $\mathbf{0 . 3 2 6}$ & $\mathbf{- 7 . 5 6}$ & $\mathbf{3 . 9 7 e - 1 4}$
\end{tabular}

Results for $C$. fuscatum and L. maroccanus indicate that the larger the number of homospecific (heterospecific) motifs, the larger the increase (decrease) in seed production. Nevertheless, the effect-sizes of homospecific motifs for C. fuscatum (0.28) and L. maroccanus (0.23) are approximately two and six times larger than those for heterospecific motifs $(|-0.14|$ and $|-0.04|)$, respectively. Besides, for both plant species gaining centrality leads to an increase in seed production, although the effect-sizes of their centrality variables are smaller than or equal to those of centrality metrics and their corresponding p-values are larger than 0.05. However $C$. fuscatum individuals with higher seed production are those showing larger values of within-layer centrality (effectsize: 0.14), regardless of the coupling between the layers (effect-size: 0.03). In contrast, since the within-layer centrality barely exerts any influence (effect-size: |-0.01|) in L. maroccanus, its individuals mainly benefit from being central when their among-layer centrality ratio grows (effect-size: 0.09), that is, there is an increase in seed production when plants have more connections to other species through shared insects. These different ways of benefiting from centrality may reflect their different phenological overlaps: L. maroccanus' phenology overlaps 
completely with those of the remaining plant species, except $C$. fuscatum, whose overlap is only partial (Supplementary material Appendix 2 Fig. A2.1). Indeed, C. fuscatum individuals barely share one of their main visitors (small flies) with other plant species (Supplementary material Appendix 2 Fig. A2.2.

Unlike C. fuscatum and L. maroccanus, P. paludosa individuals show a decrease in seed production when the number of homospecific motifs increases and an increase in seed production with heterospecific motifs. Besides, in this species the effect sizes of heterospecific motifs (0.31) is larger than that of homospecific motifs $(|-0.20|)$, although both variables have $p$-value $>0.05$. Regarding centrality metrics, being more connected to other species through shared insect visitors has a negative impact on $P$. paludosa's seed production, which is similar to that of the number of homospecific motifs (effect-size: $|-0.17|$, with p-value $>0.05$ ). Instead, the effect-size of within-layer centrality is negligible $(|-0.03|)$ compared to those of the other variables. These opposed results compared to the other two Asteraceae species can reflect that, unlike $C$. fuscatum individuals, $P$. paludosa individuals share all their main visitors (i.e., solitary bees and house flies) with $L$. maroccanus (Supplementary material Appendix 2 Fig. A2.2). Finally, since the number of developed seeds are correlated with visitation rates (Spearman's $\rho$ s are $0.23,0.43$ and 0.24 for C. fuscatum, L. maroccanus and P. paludosa, respectively, with $\mathrm{n}$ equal to 163,293 and 150 , respectively, and $\mathrm{p}<0.05)$, we tested the results of our models when the covariate "visits" is added to each of them (see Supplementary material Appendix 14). Overall, in those supplementary models for $C$. fuscatum and P. paludosa, the size-effects of the variables in table 1 decrease, and that of "visits" exhibits the largest value. Nevertheless, in those models the value of at least one motif-level metric is comparable to that of visits. In contrast, the new model for $L$. maroccanus shows that the effect-sizes described in table 1 barely vary, and the effect-size for visits is negligible.

\section{Discussion}

Our approach shows that multilayer representations of individual-based insect-plant visitation networks allow a deep description of the pollen flow processes and their connections with plant reproductive success. To achieve this, we modeled the connections between plant individuals mediated by floral visitors in each community as a transport-like system, in which there is an ensemble of bipartite layers of conspecific plants that are coupled through insect species that transfer pollen. Here layers contain conspecific focal individual plants and their interactions (intralinks) with their insect visitors, and those visitors connect layers (through the interlinks), depending on their interspecific floral visits and on the phenological overlap among plant species. Below, we first discuss how our framework translates into a description of community structure, second, we highlight how to link these metrics to ecological processes such as pollination, and finally, we describe potential caveats and improvements.

Describing community-level individual-based networks. In species-rich plant communities, depicting individuals of each species in their own layer and layers linked via shared insect visitors can rapidly help to visualize the within-species and among-species dynamics. For example, our nine individual plant-pollinator networks contain few layers that are coupled by a small number of directed interlinks, suggesting that plant species have dissimilar phenologies and share few species of floral visitors. Of course, these patterns may depend on the type of community studied and the attractiveness of their plant species. For example, more clustered structures, where interlinks are abundant, may describe potential insect competition among plant species (Pauw, 2013). However, even the small number of interlinks observed in our study system are key determinants of the network structure from a flow perspective. Firstly, this is because, at the network-level, interlinks shape the modular organization of the different individuals in clusters. The identity of the individuals of these modules is likely determined by the pollen flow dynamics. In our case, despite modules being dominated by single species, we observe modules that contain up to four different plant species. Indeed, those insect species that channel interlinks turn out to be network and module hubs of our arrangements (Supplementary material Appendix 8). Second, at the node-level, interlinks alter the plant individuals' probability of receiving pollen flow, and the heterospecific pollen movement between plant individuals (Lanuza et al. 2021). In general, pollen arrival probability of most plant individuals in our study drops when multilayers are coupled with the exception of several L. maroccanus individuals. Finally, the motiflevel descriptors also reflect the number of interlinks observed, such that in our case, and as expected, a paucity of interlinks translates into the overabundance of homospecific motifs for those plant species with the largest number of visits and smallest diversity of floral visitors (such as C. fuscatum and L. maroccanus).

Linking network structure to network functioning. Beyond the description of network patterns, our individualbased approach directly maps into ecological processes and functions such as pollination, providing a mechanistic interpretation that other simpler proxies (like those based on the overall visitation rates) lack. In fact, we found that the best descriptors of plant reproductive success are found at the motif-level, since those descriptors integrate all the conspecific and heterospecific interactions of a given individual. This result agrees with recent suggestions that the motif-level captures important information from the local topology of the network, without adding too much complexity Simmons 
bioRxiv preprint doi: https://doi.org/10.1101/2021.04.23.441120; this version posted August 6, 2021. The copyright holder for this preprint (which was not certified by peer review) is the author/funder, who has granted bioRxiv a license to display the preprint in perpetuity. It is made available under aCC-BY-NC-ND 4.0 International license.

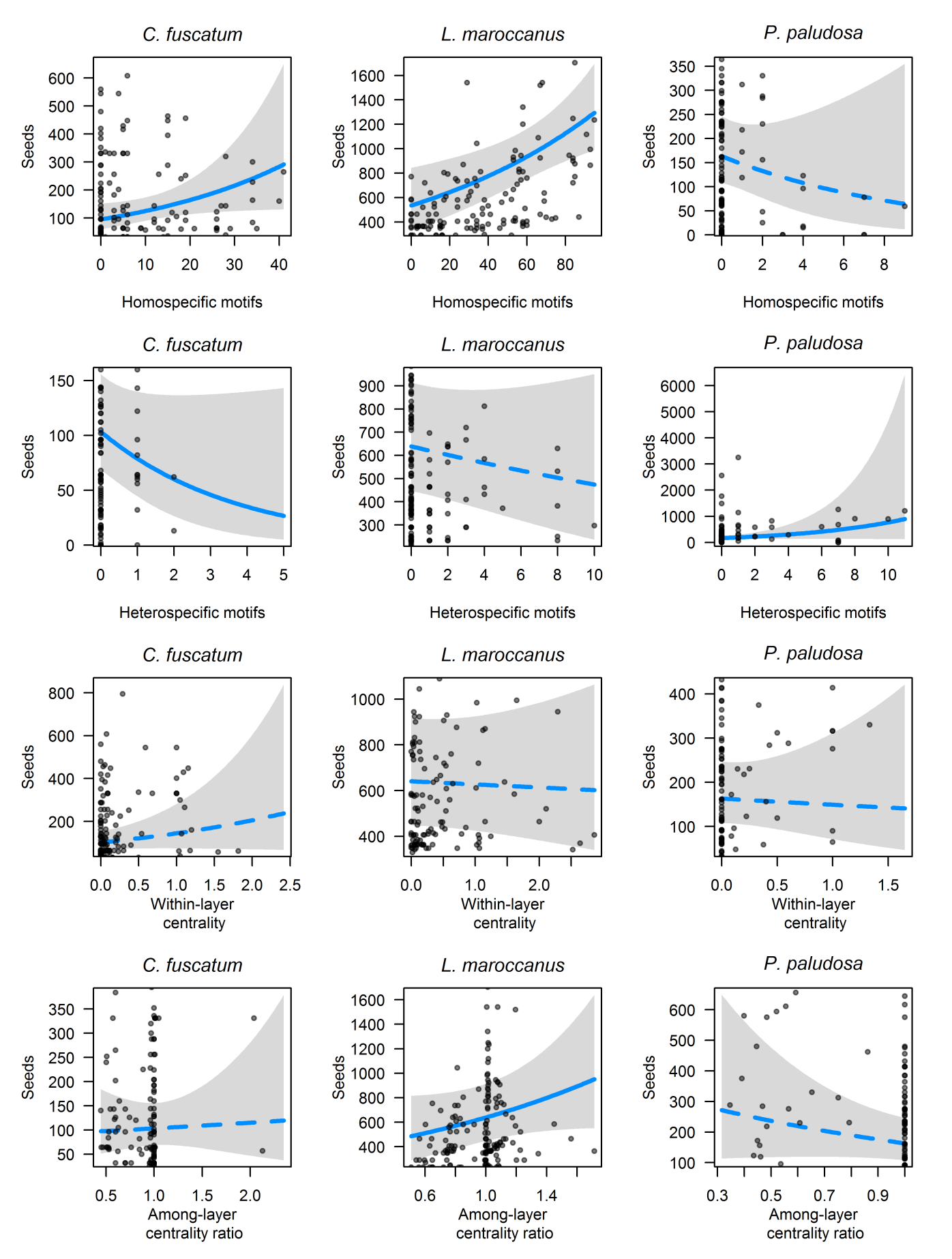

Fig. 6. Conditional plots for plant explanatory variables (R-package "visreg" (Breheny \& Burchett 2017)): Homospecific motifs (first row), heterospecific motifs (second row), within-layer centrality (third row), and among-layer centrality ratio (fourth row). Notice that, for the conditioning, the other variables are set to their median. In each panel, we represent (i) the expected values of explanatory variables (continuous lines for variables with p-value $<0.1$ and dashed lines otherwise), (ii) the confidence interval for the expected values (gray band), and (iii) dependence of seed production on the explanatory variable (dark gray dots). 
et al. 2018). In our models for C. fuscatum, L. maroccanus and $P$. paludosa, the total number of homospecific motifs, depicting the number of conspecific plant partners, showed strong relationships with the seed production of all those species (|effect size $\mid>0.20$ in all three cases, and p-values $<0.05$ except for $P$. paludosa). We observed that homospecific motifs exerted a positive effect on the reproductive success of $C$. fuscatum and $L$. maroccanus individuals, which is expected if homospecific motifs quantify the number of conspecific visits. In addition, the number of heterospecific motifs, whose relations with seed production are weaker than those of homospecific motifs, showed the opposite trend, indicating that visits coming from heterospecifics do not contribute, and can even harm reproductive success (Ashman \& Schoen, 1996; Lopezaraiza-Mikel et al. 2007 Morales \& Traveset, 2008). Surprisingly, we found the opposite trend for $P$. paludosa. This species is the less abundant of the three Asteraceae species studied in detail and while the main visitor of the other two species are small flies and beetles, its main visitors are highly mobile solitary bees (Andrena and Lassioglossum species) which act as network hubs, and which are also strongly coupled with $L$. maroccanus. Indeed, our field observations show that $P$. paludosa may act as a magnet species (Johnson et al. 2003 , Thomson et al., 2018) because bees visited $L$. maroccanus mainly in plots with the presence of $P$. paludosa. Bees are efficient pollinators that can carry different pollen species on different body parts due to differences in flower morphology and stigma position (Armbruster et al. 1994). This speciesspecific pollen placement may contribute to preventing high levels of heterospecific pollen deposition. Hence, the relationship between heterospecific motifs and reproductive success may depend on pollinator foraging behaviour, such as their floral constancy (Jakobsson et al. 2008). Harder to explain is the negative relationship of homospecific motifs with reproductive success. Bearing in mind that this relationship is comparatively weaker than that of heterospecific motifs (effect sizes: $|-0.20|$ and 0.31 , respectively; see also Fig. 6) and thus we cannot rule out the possibility of a spurious trend, a possibility is that the few insects that visit P. paludosa and create its scarce homospecific motifs are also connected to other plant species (see the multilayers with P. paludosa in Supplementary material Appendix 66). That increases the probability that those insects in $P$. paludosa's homospecific motifs will transfer conspecific pollen to heterospecific individuals, and vice versa, as suggested by the following fact: most modules with $P$. paludosa individuals also contain individuals of $L$. maroccanus, and only $20 \%$ of those modules are dominated by $P$. paludosa (i.e., the percentage of plant individuals of $P$. paludosa is larger than $50 \%$ ), whereas more than $83 \%$ of the modules with $C$. fuscatum or L. maroccanus are dominated by the focal individuals of those species.

Despite the weaker effects of individual plants within- layer centrality, we also observed a general positive effect similar to the results found by Gómez \& Perfectti (2012). In addition, among-layer centrality also seems to be important for $L$. maroccanus. This finding suggests that those L. maroccanus individuals that gain centrality when the multilayer is coupled (i.e., those that attract more insects) increase their chance of intercrossing with a higher number of conspecifics via longer loops or pollen carryover, which occurs when pollen collected from a plant is dispersed not only to the next plant but also to subsequent plants visited by a pollinator (Karron et al. . 1995). However, following the reasoning in Gómez \& Perfectti (2012), since the main visitors of L. maroccanus are small beetles and flower beetles that usually feed on pollen and spend long periods of time on each flower they visit, the positive trend we found is apparently counter-intuitive. Despite Brassicogethes sp. and Psilothrix viridicoerulea, the most abundant floral visitor species, are described as poor pollinators (Bartomeus et al. 2008), adults in flowers have pollen on their bodies and can disperse pollen at both within-field and landscape scales (Ramsay et al., 2003 ). Further, their high abundance may be contributing to the relative importance we observed, as predicted by the mass ratio hypothesis, which proposes that pollination success would be best predicted by the traits of the numerically dominant species (Grime, 1998). Besides, our model did not account for the effect that selfing induced by insect visits may be exerting in L. maroccanus. Indeed, pollinator exclosures for L. maroccanus show that selfing in this species assures high production of developed seeds (Unpublished data). Measuring pollinator efficiency (King et al. 2013) may be a further step needed to understand the full picture.

Caveats and future directions. Collecting data to model individual-based networks at the community level is a daunting task, but as more examples emerge, we will be able to document generalities and validate untested assumptions of our framework. The most critical assumption is that individuals linked by the same pollinator species have larger probabilities of mating (ArroyoCorrea et al., 2021; Gómez et al., 2020). While reasonable at the scales investigated, pollinator behaviour (Devaux et al. 2014) and morphology are expected to further modulate this relationship. Following individual pollinators to test for floral constancy (e.g. Jakobsson et al. (2008)), diet breadth overlap between individuals (Brosi 2016), or analyzing pollen loads on pollinators bodies (Bosch et al. 2009) deserves future attention to test this assumption. Once collected this information, it can be readily included in our framework as it allows including assessments about different pollinator efficiencies or a distance decay function between nodes. In addition, since the connections among layers and plant individuals rely on the taxonomic identification of insect nodes and resolving those nodes to species level may not always be possible (due to taxonomic or logistical 
constraints), future research assessing an adequate taxonomic level (or mixture of levels) for modeling the mating events encoded in our multilayers can be relevant. Here we used morphology-based keys that exploit the morphological differences between the sampled organisms, along with species and family designations. Thus, we expect that resolving those higher taxonomic identifications to species level may reduce the weight and number of the interlinks in our networks. Further, our framework is exemplified with a plant-pollinator system, but it is widely applicable to other types of interaction networks.

In our framework, we have used only undirected motifs with three nodes to test our pollen flow approach. However, as pointed out by Simmons et al. (2018), it may be important to consider larger motifs in order to adequately capture motif-level structure. Nevertheless, although more complex structures can be computed, the challenge remains in linking specific motifs to a clear ecological process. Thus, future work extending the downscaling of motifs to individual-level by considering quadruplets and other motifs of conspecific and heterospecific individuals with more than three nodes can be relevant to gain further insight into the functional consequences of community structure. Besides, since we have focused on binary interactions to perform our motif calculations (that is, to define a motif we were only interested in the presence or absence of interactions and not in the interaction strengths), another future research direction is to include quantitative information on interaction weights. Incorporating that extra layer of information may be relevant to identify how indirect interactions affect final ecosystem functions. However, despite being a promising direction for future investigation, quantitative bipartite motif analysis is not yet fully developed (see examples in Simmons et al. (2018) and further work is needed to conceptualize it and interpret their results (Simmons et al., 2020).

Overall, we provide a solid set of flexible tools to further explore individual-based networks. Downscaling interaction network ecology to the individual level may be important to map functions and process occurring at such scale, and to better capture intraspecific variability. Further research on individual-based communitywide networks would enable us to link network theory to processes determining the emergent properties of ecological communities at multiple scales.

\section{Speculations}

In our work, individuals of an abundant plant species like $L$. Maroccanus enhance their reproductive success by having a large number of homospecific triplets and being central, whereas other rarer species like P. Paludosa benefit from their indirect interactions with coflowering heterospecific partners. How general this pattern is remains to be seen, but the outcome of these metrics may depend on the context, including species abundance, pollinator behaviour or spatial distribution. For example, the spatial clustering and the degree of spatial intermixing among plant species will influence the effects of homospecific and heterospecific motifs over seed production (Thomson et al. 2018 ). For instance, it is very unlikely that the facilitative effect of heterospecific motifs on P. Paludosa appears when species occur in larger, spatially segregated patches. This is particularly relevant when upscaling our mechanistic framework with individual-based networks to other interaction types such as individual plant-frugivore interaction networks, where the birds linking different layers cover wider distances and exert more complex behaviours (Crestani et al. 2019).

\section{Data availability}

The empirical data and the R-scripts that we used are archived at: https://github.com/RadicalCommEcol/ Multi_motifs

\section{ACKNOWLEDGEMENTS}

The authors thank Doñana National Park for granting access to their facilities (permit 2019/14). We also acknowledge Francisco P. Molina (Seville, Spain) and Álvaro PérezGómez (Cádiz, Spain) for helping with insect classification, and Pedro Jordano Lab for fruitful discussion. A.A.-P. and I.B. were funded through the 2017-2018 Belmont Forum and BiodivERsA joint call for research proposals, under the BiodivScen ERA-Net COFUND programme, and with the funding organisations AEI, NWO, ECCyT and NSF. O.G. acknowledges financial support provided by the Spanish Ministry of Economy and Competitiveness (MINECO) and by the European Social Fund through the Ramón y Cajal Program (RYC-2017- 23666). This study was partly funded by the Spanish Ministry of Science and Innovation (MICINN) and the European Social fund through the MeDiNaS project (Mechanisms of maintenance of species diversity in variable environments, RTI2018-098888-A-I00). M.H. acknowledges financial support provided by Spanish Ministry of Science, Innovation and Universities (Grant No. PRE2019-088280).

\section{References}

Aleta, A., Meloni, S. \& Moreno, Y. (2017). A multilayer perspective for the analysis of urban transportation systems. Scientific Reports, 7.

Allesina, S. \& Tang, S. (2012). Stability criteria for complex ecosystems. Nature, 483, 205-208.

Armbruster, W. S., Edwards, M. E. \& Debevec, E. M. (1994). Floral character displacement generates assemblage structure of western australian triggerplants (stylidium). Ecology, 75, 315-329.

Arroyo-Correa, B., Bartomeus, I. \& Jordano, P. (2021). Individual-based plant-pollinator networks are structured by phenotypic and microsite plant traits. Journal of Ecology.

Ashman, T.-L. \& Schoen, D. J. (1996). Floral longevity: Fitness consequences and resource costs. In: Floral 
Biology. Springer US, pp. 112-139. URL https:// doi.org/10.1007/978-1-4613-1165-2_5

Bartomeus, I., Bosch, J. \& Vilà, M. (2008). High invasive pollen transfer, yet low deposition on native stigmas in a carpobrotus-invaded community. Annals of Botany, $102,417-424$.

Bartomeus, I., Saavedra, S., Rohr, R. P. \& Godoy, O. (2021). Experimental evidence of the importance of multitrophic structure for species persistence. Proceedings of the National Academy of Sciences, 118, e2023872118.

Bascompte, J. \& Jordano, P. (2013). Mutualistic Networks. Princeton University Press. URL https: //doi.org/10.1515/9781400848720.

Bascompte, J., Jordano, P., Melian, C. J. \& Olesen, J. M. (2003). The nested assembly of plant-animal mutualistic networks. Proceedings of the National Academy of Sciences, 100, 9383-9387.

Bergamo, P. J., Streher, N. S., Wolowski, M. \& Sazima, M. (2020). Pollinator-mediated facilitation is associated with floral abundance, trait similarity and enhanced community-level fitness. Journal of Ecology, 108, 1334-1346.

Blüthgen, N. (2010). Why network analysis is often disconnected from community ecology: A critique and an ecologist's guide. Basic and Applied Ecology, 11, $185-195$.

Blüthgen, N., Fründ, J., Vázquez, D. P. \& Menzel, F. (2008). WHAT DO INTERACTION NETWORK METRICS TELL US ABOUT SPECIALIZATION AND BIOLOGICAL TRAITS. Ecology, 89, 33873399 .

Boccaletti, S., Bianconi, G., Criado, R., del Genio, C., Gómez-Gardeñes, J., Romance, M., Sendiña-Nadal, I., Wang, Z. \& Zanin, M. (2014). The structure and dynamics of multilayer networks. Physics Reports, $544,1-122$.

Bolnick, D. I., Amarasekare, P., Araújo, M. S., Bürger, R., Levine, J. M., Novak, M., Rudolf, V. H., Schreiber, S. J., Urban, M. C. \& Vasseur, D. A. (2011). Why intraspecific trait variation matters in community ecology. Trends in Ecology \&s Evolution, 26, 183-192.

Bosch, J., González, A. M. M., Rodrigo, A. \& Navarro, D. (2009). Plant-pollinator networks: adding the pollinator's perspective. Ecology Letters, 12, 409-419.

Breheny, P. \& Burchett, W. (2017). Visualization of regression models using visreg. The $R$ Journal, 9, 5671.

Brooks, M. E., Kristensen, K., van Benthem, K. J., Magnusson, A., Berg, C. W., Nielsen, A., Skaug, H. J., Maechler, M. \& Bolker, B. M. (2017). glmmTMB balances speed and flexibility among packages for zeroinflated generalized linear mixed modeling. The $R$ Journal, 9, 378-400.

Brose, U., Williams, R. J. \& Martinez, N. D. (2006). Allometric scaling enhances stability in complex food webs. Ecology Letters, 9, 1228-1236.
Brosi, B. J. (2016). Pollinator specialization: from the individual to the community. New Phytologist, 210, 1190-1194.

Canty, A. \& Ripley, B. D. (2020). boot: Bootstrap R (S-Plus) Functions. R package version 1.3-25.

Carvalheiro, L. G., Biesmeijer, J. C., Benadi, G., Fründ, J., Stang, M., Bartomeus, I., Kaiser-Bunbury, C. N., Baude, M., Gomes, S. I. F., Merckx, V., Baldock, K. C. R., Bennett, A. T. D., Boada, R., Bommarco, R., Cartar, R., Chacoff, N., Dänhardt, J., Dicks, L. V., Dormann, C. F., Ekroos, J., Henson, K. S., Holzschuh, A., Junker, R. R., Lopezaraiza-Mikel, M., Memmott, J., Montero-Castaño, A., Nelson, I. L., Petanidou, T., Power, E. F., Rundlöf, M., Smith, H. G., Stout, J. C., Temitope, K., Tscharntke, T., Tscheulin, T., Vilà, M. \& Kunin, W. E. (2014). The potential for indirect effects between co-flowering plants via shared pollinators depends on resource abundance, accessibility and relatedness. Ecology Letters, 17, 1389-1399.

Chao, A., Gotelli, N. J., Hsieh, T. C., Sander, E. L., Ma, K. H., Colwell, R. K. \& Ellison, A. M. (2014). Rarefaction and extrapolation with hill numbers: a framework for sampling and estimation in species diversity studies. Ecological Monographs, 84, 45-67.

Cirtwill, A. R., Riva, G. V. D., Gaiarsa, M. P., Bimler, M. D., Cagua, E. F., Coux, C. \& Dehling, D. M. (2018). A review of species role concepts in food webs. Food Webs, 16, e00093.

Crestani, A., Mello, M. \& Cazetta, E. (2019). Interindividual variations in plant and fruit traits affect the structure of a plant-frugivore network. Acta Oecologica, 95, 120-127.

Csardi, G. \& Nepusz, T. (2006). The igraph software package for complex network research. InterJournal, Complex Systems, 1695.

Dall, S. R. X., Bell, A. M., Bolnick, D. I. \& Ratnieks, F. L. W. (2012). An evolutionary ecology of individual differences. Ecology Letters, 15, 1189-1198.

Dáttilo, W., Aguirre, A., Quesada, M. \& Dirzo, R. (2015). Tropical forest fragmentation affects floral visitors but not the structure of individual-based palmpollinator networks. PLOS ONE, 10, e0121275.

Delmas, E., Besson, M., Brice, M.-H., Burkle, L. A., Riva, G. V. D., Fortin, M.-J., Gravel, D., Guimarães, P. R., Hembry, D. H., Newman, E. A., Olesen, J. M., Pires, M. M., Yeakel, J. D. \& Poisot, T. (2018). Analysing ecological networks of species interactions. Biological Reviews, 94, 16-36.

Devaux, C., Lepers, C. \& Porcher, E. (2014). Constraints imposed by pollinator behaviour on the ecology and evolution of plant mating systems. Journal of Evolutionary Biology, 27, 1413-1430.

Domenico, M. D., Lancichinetti, A., Arenas, A. \& Rosvall, M. (2015). Identifying modular flows on multilayer networks reveals highly overlapping organization in interconnected systems. Physical Review X, 5 .

Domenico, M. D., Sole-Ribalta, A., Gomez, S. \& Arenas, 
A. (2014). Navigability of interconnected networks under random failures. Proceedings of the National Academy of Sciences, 111, 8351-8356.

Dormann, C. F. \& Strauss, R. (2013). A method for detecting modules in quantitative bipartite networks. Methods in Ecology and Evolution, 5, 90-98.

Dupont, Y. L., Trøjelsgaard, K., Hagen, M., Henriksen, M. V., Olesen, J. M., Pedersen, N. M. E. \& Kissling, W. D. (2014). Spatial structure of an individual-based plant-pollinator network. Oikos, 123, 1301-1310.

Dupont, Y. L., Trøjelsgaard, K. \& Olesen, J. M. (2010). Scaling down from species to individuals: a flowervisitation network between individual honeybees and thistle plants. Oikos, 120, 170-177.

Farage, C., Edler, D., Eklöf, A., Rosvall, M. \& Pilosof, S. (2021). Identifying flow modules in ecological networks using infomap. Methods in Ecology and Evolution, 12, 778-786.

Flanagan, R. J., Mitchell, R. J. \& Karron, J. D. (2010). Increased relative abundance of an invasive competitor for pollination, lythrum salicaria, reduces seed number in mimulus ringens. Oecologia, 164, 445-454.

García-Callejas, D., Molowny-Horas, R. \& Araújo, M. B. (2017). Multiple interactions networks: towards more realistic descriptions of the web of life. Oikos, 127, $5-22$.

Ghazoul, J. (2006). Floral diversity and the facilitation of pollination. Journal of Ecology, 94, 295-304.

Godoy, O., Stouffer, D. B., Kraft, N. J. B. \& Levine, J. M. (2017). Intransitivity is infrequent and fails to promote annual plant coexistence without pairwise niche differences. Ecology, 98, 1193-1200.

Gómez, J. M. \& Perfectti, F. (2012). Fitness consequences of centrality in mutualistic individual-based networks. Proceedings of the Royal Society B: Biological Sciences, 279, 1754-1760.

Gómez, J. M., Perfectti, F., Armas, C., Narbona, E., González-Megías, A., Navarro, L., DeSoto, L. \& Torices, R. (2020). Within-individual phenotypic plasticity in flowers fosters pollination niche shift. Nature Communications, 11.

Gómez, J. M., Perfectti, F. \& Jordano, P. (2011). The functional consequences of mutualistic network architecture. PLoS ONE, 6, e16143.

Gómez, S. (2019). Centrality in networks: Finding the most important nodes. In: Business and Consumer Analytics: New Ideas. Springer International Publishing, pp. 401-433. URL https://doi.org/10.1007/ 978-3-030-06222-4_8

Grime, J. P. (1998). Benefits of plant diversity to ecosystems: immediate, filter and founder effects. Journal of Ecology, 86, 902-910.

Guimarães, P. R. (2020). The structure of ecological networks across levels of organization. Annual Review of Ecology, Evolution, and Systematics, 51, 433-460.

Guimerà, R. \& Amaral, L. A. N. (2005). Functional cartography of complex metabolic networks. Nature,
433, 895-900.

Hartig, F. (2020). DHARMa: Residual Diagnostics for Hierarchical (Multi-Level / Mixed) Regression Models. URL https://CRAN.R-project.org/package= DHARMa $R$ package version 0.3.0.

Herrera, C. M. (2017). The ecology of subindividual variability in plants: patterns, processes, and prospects. Web Ecology, 17, 51-64.

Hsieh, T. C., Ma, K. H. \& Chao, A. (2016). iNEXT: an $\mathrm{r}$ package for rarefaction and extrapolation of species diversity (hill numbers). Methods in Ecology and Evolution, 7, 1451-1456.

Hutchinson, M. C., Mora, B. B., Pilosof, S., Barner, A. K., Kéfi, S., Thébault, E., Jordano, P. \& Stouffer, D. B. (2018). Seeing the forest for the trees: Putting multilayer networks to work for community ecology. Functional Ecology, 33, 206-217.

Jakobsson, A., Padrón, B. \& Traveset, A. (2008). Pollen transfer from invasive carpobrotus spp. to natives - a study of pollinator behaviour and reproduction success. Biological Conservation, 141, 136-145.

Johnson, S. D., Peter, C. I., Nilsson, L. A. \& Ågren, J. (2003). POLLINATION SUCCESS IN a DECEPTIVE ORCHID IS ENHANCED BY COOCCURRING REWARDING MAGNET PLANTS. Ecology, 84, 2919-2927.

Jordano, P. (2016). Sampling networks of ecological interactions. Functional Ecology, 30, 1883-1893.

Karron, J. D., Tucker, R., Thumser, N. N. \& Reinartz, J. A. (1995). Comparison of pollinator flight movements and gene dispersal patterns in mimulus ringens. Heredity, 75, 612-617.

King, C., Ballantyne, G. \& Willmer, P. G. (2013). Why flower visitation is a poor proxy for pollination: measuring single-visit pollen deposition, with implications for pollination networks and conservation. Methods in Ecology and Evolution, 4, 811-818.

Kivela, M., Arenas, A., Barthelemy, M., Gleeson, J. P., Moreno, Y. \& Porter, M. A. (2014). Multilayer networks. Journal of Complex Networks, 2, 203-271.

Kuppler, J., Grasegger, T., Peters, B., Popp, S., Schlager, M. \& Junker, R. R. (2017). Volatility of network indices due to undersampling of intraspecific variation in plant-insect interactions. Arthropod-Plant Interactions, 11, 561-566.

Kuppler, J., Höfers, M. K., Wiesmann, L. \& Junker, R. R. (2016). Time-invariant differences between plant individuals in interactions with arthropods correlate with intraspecific variation in plant phenology, morphology and floral scent. New Phytologist, 210, 13571368.

Lanuza, J. B., Bartomeus, I., Ashman, T.-L., Bible, G. \& Rader, R. (2021). Recipient and donor characteristics govern the hierarchical structure of heterospecific pollen competition networks. Journal of Ecology.

Lanuza, J. B., Bartomeus, I. \& Godoy, O. (2018). Opposing effects of floral visitors and soil conditions on 
the determinants of competitive outcomes maintain species diversity in heterogeneous landscapes. Ecology Letters, 21, 865-874.

Lopezaraiza-Mikel, M. E., Hayes, R. B., Whalley, M. R. \& Memmott, J. (2007). The impact of an alien plant on a native plant-pollinator network: an experimental approach. Ecology Letters, 10, 539-550.

Lüdecke, D., Makowski, D., Waggoner, P. \& Patil, I. (2020). performance: Assessment of regression models performance. CRAN.

Magrach, A., Molina, F. P. \& Bartomeus, I. (2019). Niche complementarity among pollinators increases community-level plant reproductive success.

Martinez, N. D. (1991). Artifacts or attributes? effects of resolution on the little rock lake food web. Ecological Monographs, 61, 367-392.

Memmott, J., Craze, P. G., Waser, N. M. \& Price, M. V. (2007). Global warming and the disruption of plant?pollinator interactions. Ecology Letters, 10, 710-717.

Memmott, J., Waser, N. M. \& Price, M. V. (2004). Tolerance of pollination networks to species extinctions. Proceedings of the Royal Society of London. Series B: Biological Sciences, 271, 2605-2611.

Milo, R., Shen-Orr, S., Itzkovitz, S., Kashtan, N., Chklovskii, D. \& Alon, U. (2002). Network motifs: Simple building blocks of complex networks. Science, 298, 824-827.

Mitchell, R. J., Flanagan, R. J., Brown, B. J., Waser, N. M. \& Karron, J. D. (2009). New frontiers in competition for pollination. Annals of Botany, 103, 14031413.

Moghimbeigi, A., Eshraghian, M. R., Mohammad, K. \& Mcardle, B. (2008). Multilevel zero-inflated negative binomial regression modeling for over-dispersed count data with extra zeros. Journal of Applied Statistics, 35, 1193-1202.

Morales, C. L. \& Traveset, A. (2008). Interspecific pollen transfer: Magnitude, prevalence and consequences for plant fitness. Critical Reviews in Plant Sciences, 27, 221-238.

Morales, C. L. \& Traveset, A. (2009). A meta-analysis of impacts of alien vs. native plants on pollinator visitation and reproductive success of co-flowering native plants. Ecology Letters, 12, 716-728.

Moreira-Hernández, J. I. \& Muchhala, N. (2019). Importance of pollinator-mediated interspecific pollen transfer for angiosperm evolution. Annual Review of Ecology, Evolution, and Systematics, 50, 191-217.

Morris, W. F., Bronstein, J. L. \& Wilson, W. G. (2003). Three-way coexistence in obligate mutualist-exploiter interactions: The potential role of competition. The American Naturalist, 161, 860-875.

Olesen, J. M., Bascompte, J., Dupont, Y. L. \& Jordano, P. (2007). The modularity of pollination networks. Proceedings of the National Academy of Sciences, 104, 19891-19896.
Pauw, A. (2013). Can pollination niches facilitate plant coexistence? Trends in Ecology $\&$ Evolution, 28, 3037.

Peel, L., Larremore, D. B. \& Clauset, A. (2017). The ground truth about metadata and community detection in networks. Science Advances, 3, e1602548.

Pilosof, S., Porter, M. A., Pascual, M. \& Kéfi, S. (2017). The multilayer nature of ecological networks. Nature Ecology \& Evolution, 1.

Poisot, T., Mouquet, N. \& Gravel, D. (2013). Trophic complementarity drives the biodiversity-ecosystem functioning relationship in food webs. Ecology Letters, 16, 853-861.

Pornon, A., Andalo, C., Burrus, M. \& Escaravage, N. (2017). DNA metabarcoding data unveils invisible pollination networks. Scientific Reports, 7.

Ramsay, G., Thompson, C. \& Squire, G. (2003). Quantifying landscape-scale gene flow in oilseed rape. department for environment, food and rural affairs.

Rosvall, M., Axelsson, D. \& Bergstrom, C. T. (2009). The map equation. The European Physical Journal Special Topics, 178, 13-23.

Schielzeth, H. (2010). Simple means to improve the interpretability of regression coefficients. Methods in Ecology and Evolution, 1, 103-113.

Sih, A., Cote, J., Evans, M., Fogarty, S. \& Pruitt, J. (2012). Ecological implications of behavioural syndromes. Ecology Letters, 15, 278-289.

Simmons, B. I., Beckerman, A. P., Hansen, K., Maruyama, P. K., Televantos, C., Vizentin-Bugoni, J. \& Dalsgaard, B. (2020). Niche and neutral processes leave distinct structural imprints on indirect interactions in mutualistic networks. Functional Ecology, 35, 753-763.

Simmons, B. I., Cirtwill, A. R., Baker, N. J., Wauchope, H. S., Dicks, L. V., Stouffer, D. B. \& Sutherland, W. J. (2018). Motifs in bipartite ecological networks: uncovering indirect interactions. Oikos, 128, 154-170.

Smiljanić, J., Edler, D. \& Rosvall, M. (2020). Mapping flows on sparse networks with missing links. Physical Review E, 102.

Soares, N. C., Maruyama, P. K., Staggemeier, V. G., Morellato, L. P. C. \& Araújo, M. S. (2020). The role of individual variation in flowering and pollination in the reproductive success of a crepuscular buzz-pollinated plant. Annals of Botany, 127, 213-222.

Thébault, E. (2012). Identifying compartments in presence-absence matrices and bipartite networks: insights into modularity measures. Journal of Biogeography, 40, 759-768.

Thebault, E. \& Fontaine, C. (2010). Stability of ecological communities and the architecture of mutualistic and trophic networks. Science, 329, 853-856.

Thompson, R. M., Brose, U., Dunne, J. A., Hall, R. O., Hladyz, S., Kitching, R. L., Martinez, N. D., Rantala, H., Romanuk, T. N., Stouffer, D. B. \& Tylianakis, J. M. (2012). Food webs: reconciling the structure 
and function of biodiversity. Trends in Ecology \& Evolution, 27, 689-697.

Thomson, J. D., Fung, H. F. \& Ogilvie, J. E. (2018). Effects of spatial patterning of co-flowering plant species on pollination quantity and purity. Annals of Botany, 123, 303-310.

Tur, C., Vigalondo, B., Trøjelsgaard, K., Olesen, J. M. \& Traveset, A. (2013). Downscaling pollen-transport networks to the level of individuals. Journal of Animal Ecology, 83, 306-317.

Valverde, J., Gómez, J. M. \& Perfectti, F. (2015). The temporal dimension in individual-based plant pollination networks. Oikos, 125, 468-479.

Watts, S., Dormann, C. F., González, A. M. M. \& Ollerton, J. (2016). The influence of floral traits on specialization and modularity of plant-pollinator networks in a biodiversity hotspot in the peruvian andes. Annals of Botany, 118, 415-429.

Wolf, M. \& Weissing, F. J. (2012). Animal personalities: consequences for ecology and evolution. Trends in Ecology 83 Evolution, 27, 452-461.

Ye, Z.-M., Dai, W.-K., Jin, X.-F., Gituru, R. W., Wang, Q.-F. \& Yang, C.-F. (2013). Competition and facilitation among plants for pollination: can pollinator abundance shift the plant-plant interactions? Plant Ecology, 215, 3-13.

Young, J.-G., Cantwell, G. T. \& Newman, M. E. J. (2020). Bayesian inference of network structure from unreliable data. Journal of Complex Networks, 8.

Young, J.-G., Valdovinos, F. S. \& Newman, M. E. J. (2021). Reconstruction of plant-pollinator networks from observational data. Nature Communications, 12. 
bioRxiv preprint doi: https://doi.org/10.1101/2021.04.23.441120; this version posted August 6, 2021. The copyright holder for this preprint (which was not certified by peer review) is the author/funder, who has granted bioRxiv a license to display the preprint in perpetuity. It is made available under aCC-BY-NC-ND 4.0 International license.

\section{Appendix 1: List plant species observed in Caracoles (2020)}

Table A1. List of plant species observed in Caracoles Ranch with floral visitors from a total of 23 species surveyed in the community. Taxonomic family of each species is provided. Sample size represents the total number of individuals sampled for reproductive success for each focal species, and it is correlated with their natural abundance observed at the study site.

\begin{tabular}{cccc}
\hline Species & Family & Abundance & Sample size \\
\hline Beta macrocarpa & Amaranthaceae & 1,992 & 250 \\
Centaurium tenuiflorum & Gentianaceae & 1,946 & 190 \\
Chamaemelum fuscatum & Asteraceae & 1,347 & 151 \\
Chamaemelum mixtum & Asteraceae & 143 & 14 \\
Leontodon maroccanus & Asteraceae & 9,090 & 269 \\
Melilotus sulcatus & Fabaceae & 1,100 & 53 \\
Pulicaria paludosa & Asteraceae & 1,418 & 137 \\
Scorzonera laciniata & Asteraceae & 791 & 117 \\
Sonchus asper & Asteraceae & 1,012 & 106 \\
Spergularia rubra & Caryophyllaceae & 2,318 & 58 \\
\hline
\end{tabular}

\section{Appendix 2: Plant phenologies}

Plant phenologies were extracted from our records of insect visits. Detailed weekly surveys of floral visitors during the flowering season showed that insects only visited the flowers of 10 of the species, and most of those visits were concentrated on only three of them (Chamaemelum fuscatum, Leontodon maroccanus and Pulicaria paludosa). As can be seen in Fig. A2.1, the phenologies of the plant species that received insect visits are varied, being able to differentiate early, medium and late phenologies. The earlier species is C. fuscatum; the medium species are $L$. maroccanus, Spergularia rubra, Scorzonera laciniata, Sonchus asper, Chamaemelum mixtum, Melilotus sulcatus and Beta macrocarpa; and the late species are P. paludosa, Centaurium tenuiflorum, and in 2020 a second flowering peak of L. maroccanus.

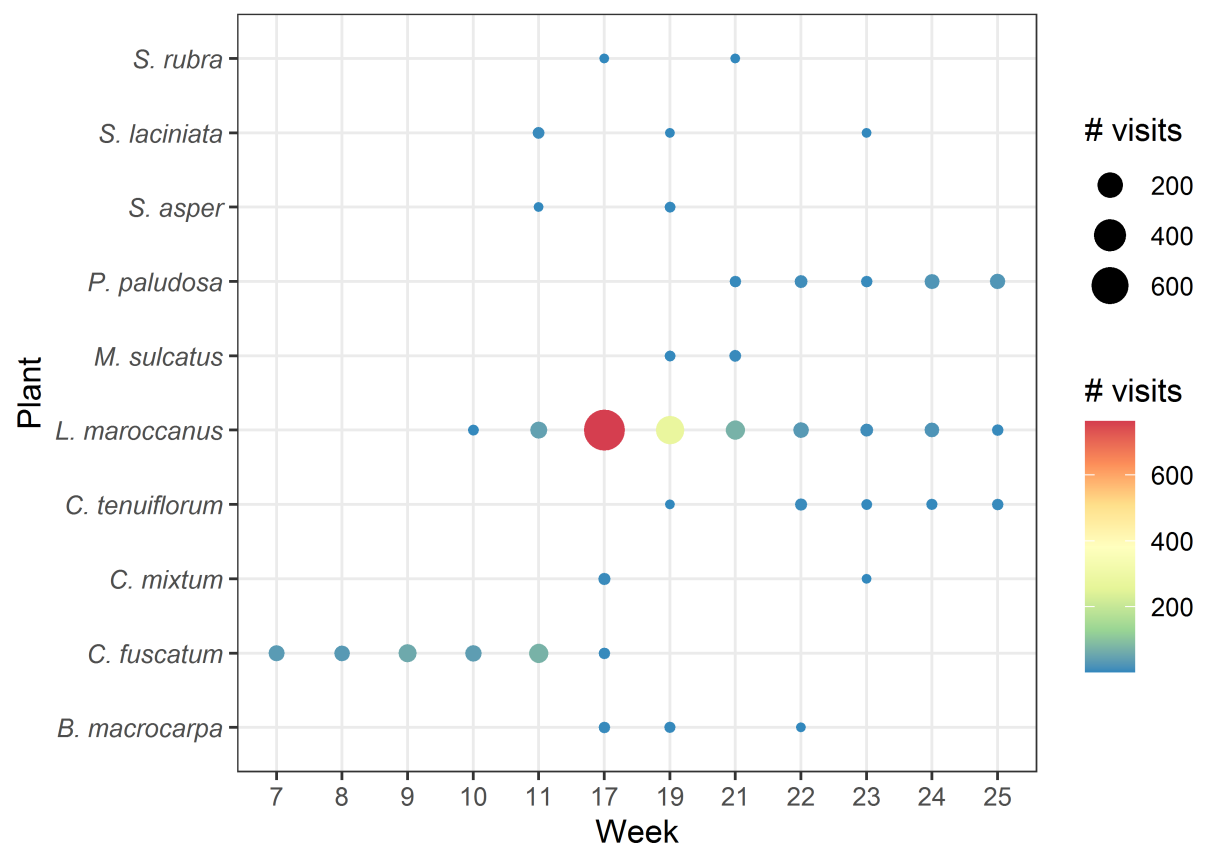

Fig. A2.1. Total number of insect visits received by plant species per week in 2020

To estimate the duration of plant phenologies (in weeks), we assumed that, if a plant species received insect visits in weeks $i$ and $j$ (for $i \neq j$ ), then such plant species were also visited during the period between $i$ and $j$. For instance, B. macrocarpa's phenology lasts 6 weeks (from the 17 th week to the 22nd one).

Finally, in Fig. A2.2 we disaggregate the phenological overlap among plant species by using the taxonomic groups of flower visitors. 
bioRxiv preprint doi: https://doi.org/10.1101/2021.04.23.441120; this version posted August 6, 2021. The copyright holder for this preprint (which was not certified by peer review) is the author/funder, who has granted bioRxiv a license to display the preprint in perpetuity. It is made available under aCC-BY-NC-ND 4.0 International license.

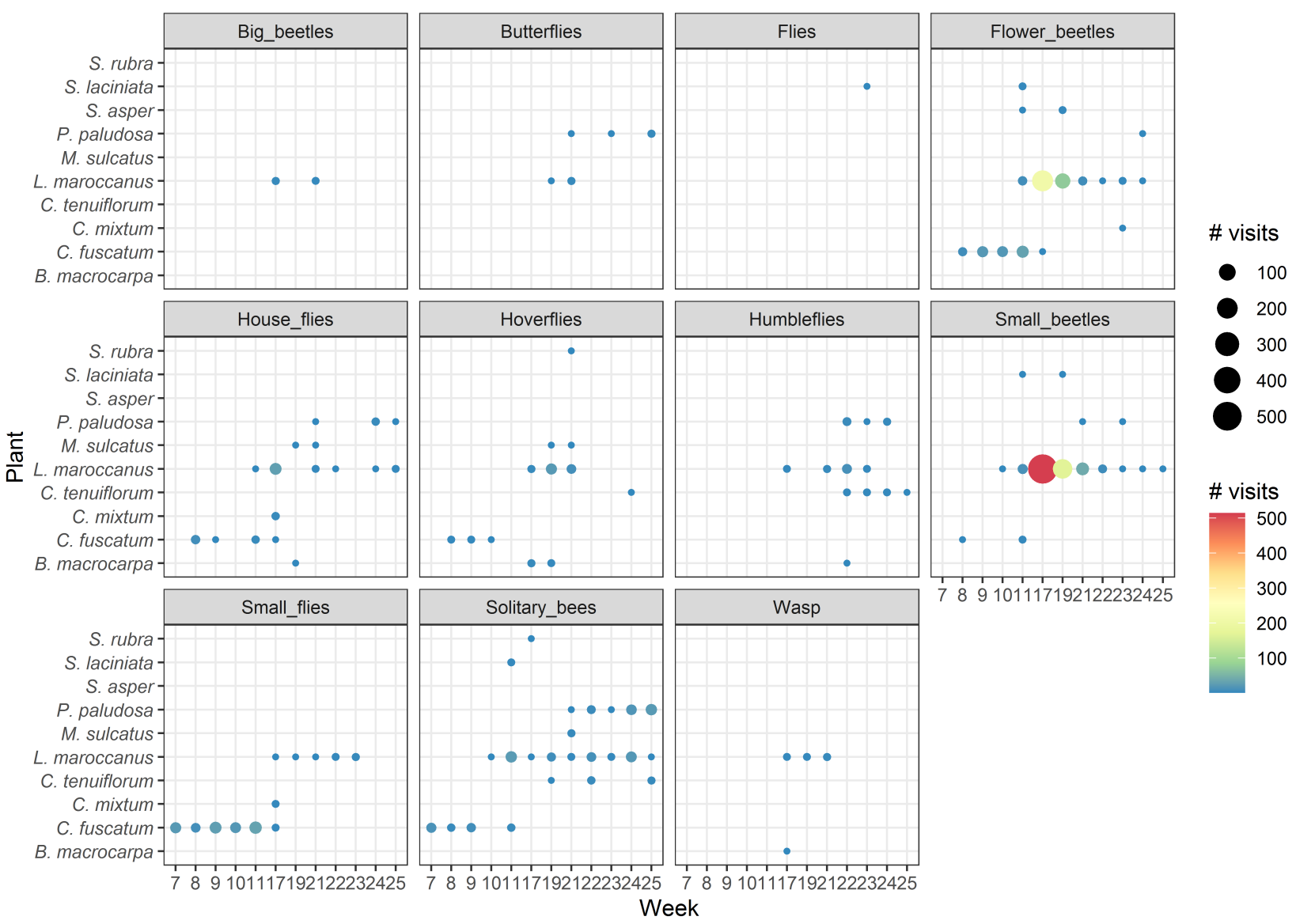

Fig. A2.2. Total number of insect visits received by plant species and taxonomic group of visitors per week in 2020 .

\section{Appendix 3: Sampling coverage of Caracoles (2020)}

We have estimated the sampling coverage of (individual) plant-pollinator interactions in each plot network, pooling the data for all plant species, and using the coverage framework introduced in (Chao et al. . 2014). The sampling coverage (or coverage) of the observed interactions is simply their total relative abundances, or equivalently, the proportion of the total number of interactions in an assemblage that belong to interactions represented in the sample. To calculate the coverage in each plot, we used the R-package "iNEXT" (Hsieh et al. 2016$)$. As can be seen in Fig A3.1 the sampling coverage in all the plots is approximately equal to 90\%. This means that less than $10 \%$ of the total interactions in the assemblage belong to undetected interactions. For this reason, extremely rare, undetected interactions do not make a significant contribution to that proportion, even if there are many such interactions. In addition, note that the above estimations do not account for the existence of forbidden interactions, that is, non-occurrences of pairwise interactions that can be accounted for by biological constraints, such as spatiotemporal uncoupling, size or reward mismatching, foraging constraints and physiological-biochemical constraints (Jordano, 2016). Hence, the real sampling coverage of our pollination networks could be higher than $90 \%$.

Finally, it is important to note that all empirical networks may be biased by incomplete sampling, for instance, failing to detect the interactions of rare species (Blüthgen, 2010. Blüthgen et al. 2008 ). This uncertainty affects the community detection presented in this work, as well as the network metrics we discussed so far. For instance, the map equation assumes complete data and, when networks are sparse and may contain missing links, the optimal solution is distorted (Smiljanić et al. 2020$)$. To overcome these obstacles, further investigation should consider the use of improved flow-based community detection algorithms in development (Smiljanić et al. 2020, Young et al. 2020, 2021). 


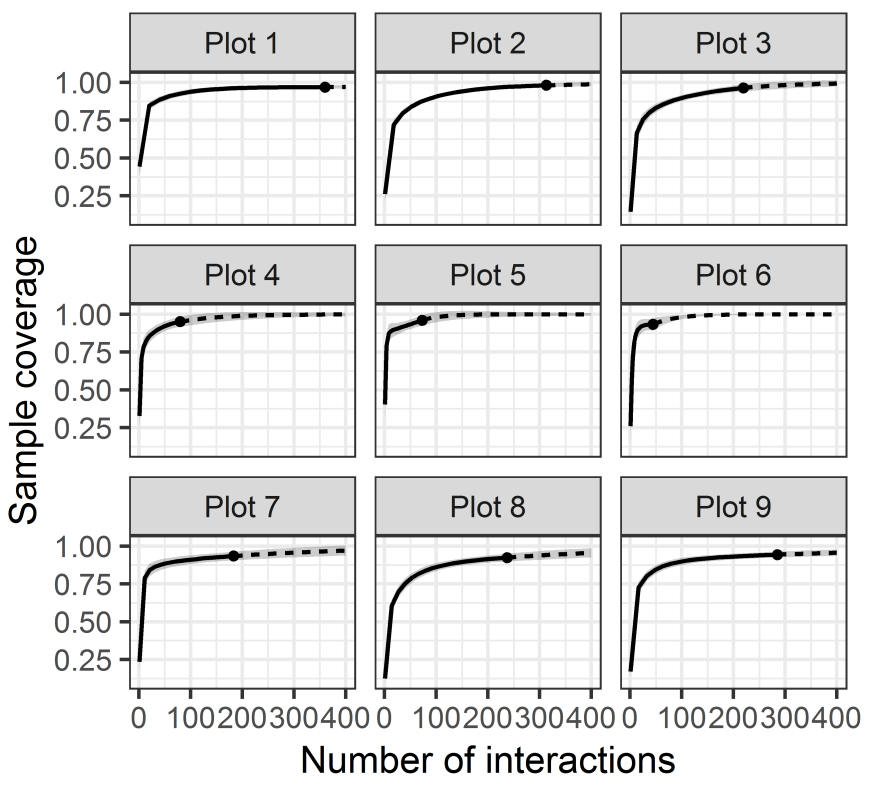

Fig. A3.1. Sample coverage for rarefied samples (solid line) and extrapolated samples (dashed line) as a function of sample size for interaction samples from the plot networks studied. The $95 \%$ confidence intervals were obtained by a bootstrap method based on 200 replications. Reference samples are denoted by solid dots.

\section{Appendix 4: Alternative interlink weights}

The estimation the weight of interlinks that is described on the main text can be refined, by considering that interlinks can be also proportional to the number of visits of a given pollinator shared by the two plant species $\mathcal{P}$ and $\mathcal{L}$ in proportion to the total of visits received by each plant species. If we do so, then, as expected, the average weight of interlinks decreases in all plant species (see Fig. A4.1). Thus, the coupling between layers is weaker.

However, after recalculating the PageRank indices and the among-layer centrality ratios, the results presented in the main text and those of the models for C. Fuscatum, L. Maroccanus and P. Paludosa barely changed (see table A4).

Table A4. Results for the GLMMs of C. fuscatum (a), L. maroccanus (b), P. paludosa (c) showing the effect on plant reproductive success (seeds per individual plant), after correcting the weights of interlinks. Here, the variable Plot is nested with the variable Subarea: the upper, middle and lower parts (see "Data collection"). The term $Z I_{0}$ describes the zero inflation probability $\varphi_{i j}$, given by logit $\left(\varphi_{i j}\right)=Z I_{0}$ (see Eq. A13.1 in Supplementary material Appendix 13 . p-values have been obtained from the Wald test reported in the summary on the models fitted with R-library glmmTMB (Brooks et al. 2017).

(a) C. fuscatum: the model contains 163 plant individuals. Conditional $R^{2}=0.318$, marginal $R^{2}=0.058$, with $\sigma_{\text {Plot-Line }}^{2}=0.2260$ and $\sigma_{\text {Line }}^{2}=0.2634$, and $\theta=1.09$.

\begin{tabular}{lclcl}
$\begin{array}{l}\text { Seeds per } \\
\text { indiv. plant }\end{array}$ & Est. & $\begin{array}{l}\text { Std. } \\
\text { Error }\end{array}$ & $\begin{array}{l}\mathrm{z} \\
\text { value }\end{array}$ & $\begin{array}{l}\mathrm{p} \\
\text { value }\end{array}$ \\
\hline $\begin{array}{l}\text { (Intercept) } \\
\text { Homospec. }\end{array}$ & 5.00876 & 0.36093 & 13.877 & $<2 \mathrm{e}-16$ \\
$\begin{array}{l}\text { motifs } \\
\begin{array}{l}\text { Heterospec. } \\
\text { motifs }\end{array}\end{array}$ & -0.31925 & 0.14030 & 2.275 & 0.0229 \\
$\begin{array}{l}\text { Within-layer } \\
\text { centrality }\end{array}$ & 0.12795 & 0.08213 & -1.769 & 0.0768 \\
$\begin{array}{l}\text { Among-layer } \\
\text { centr. ratio }\end{array}$ & 0.02791 & 0.10391 & 0.269 & 0.7882 \\
$Z I_{0}$ & -3.7778 & 0.6346 & -5.953 & $2.63 \mathrm{e}-09$
\end{tabular}


(b) L. maroccanus: the model contains 293 plant individuals. Conditional $R^{2}=0.302$, marginal $R^{2}=0.057$, with $\sigma_{\text {Plot }- \text { Line }}^{2}=0.17513$ and $\sigma_{\text {Line }}^{2}=0.08188$, and $\theta=2.37$.

\begin{tabular}{lclcl}
$\begin{array}{l}\text { Seeds per } \\
\text { indiv. plant }\end{array}$ & Est. & $\begin{array}{l}\text { Std. } \\
\text { Error }\end{array}$ & $\begin{array}{l}\mathrm{z} \\
\text { value }\end{array}$ & $\begin{array}{l}\mathrm{p} \\
\text { value }\end{array}$ \\
\hline $\begin{array}{l}\text { (Intercept) } \\
\text { Homospec. }\end{array}$ & 5.706286 & 0.220095 & 25.926 & $<2 \mathrm{e}-16$ \\
$\begin{array}{l}\text { motifs } \\
\begin{array}{l}\text { Heterospec. } \\
\text { motifs }\end{array}\end{array}$ & -0.217119 & 0.076847 & 2.825 & 0.00472 \\
$\begin{array}{l}\text { Within-layer } \\
\text { centrality }\end{array}$ & -0.007582 & 0.042631 & -0.178 & 0.85884 \\
$\begin{array}{l}\text { Among-layer } \\
\text { centr. ratio }\end{array}$ & 0.087297 & 0.054813 & 1.593 & 0.11124 \\
$Z I_{0}$ & -20.94 & 2055.74 & -0.01 & 0.992
\end{tabular}

(c) P. paludosa: the model contains 150 plant individuals. Conditional $R^{2}=\mathrm{NA}$ (Not available), marginal $R^{2}=0.078$, with $\sigma_{P l o t-L i n e}^{2}=1.373 e-01$ and $\sigma_{\text {Line }}^{2}=6.861 e-09$, and $\theta=0.834$.

\begin{tabular}{lclll}
$\begin{array}{l}\text { Seeds per } \\
\text { indiv. plant }\end{array}$ & Est. & $\begin{array}{l}\text { Std. } \\
\text { Error }\end{array}$ & $\begin{array}{l}\mathrm{z} \\
\text { value }\end{array}$ & $\begin{array}{l}\mathrm{p} \\
\text { value }\end{array}$ \\
\hline $\begin{array}{l}\text { (Intercept) } \\
\text { Homospec. } \\
\text { motifs }\end{array}$ & -0.64562 & 0.16658 & 33.89 & $<2 \mathrm{e}-16$ \\
$\begin{array}{l}\text { Heterospec. } \\
\text { motifs }\end{array}$ & 0.31179 & 0.17984 & 1.73 & 0.083 \\
$\begin{array}{l}\text { Within-layer } \\
\text { centrality }\end{array}$ & -0.03089 & 0.11010 & -0.28 & 0.779 \\
$\begin{array}{l}\text { Among-layer } \\
\text { centr. ratio }\end{array}$ & -0.16615 & 0.12537 & -1.33 & 0.185 \\
$Z I_{0}$ & -2.4673 & 0.3263 & -7.562 & $3.97 \mathrm{e}-14$
\end{tabular}



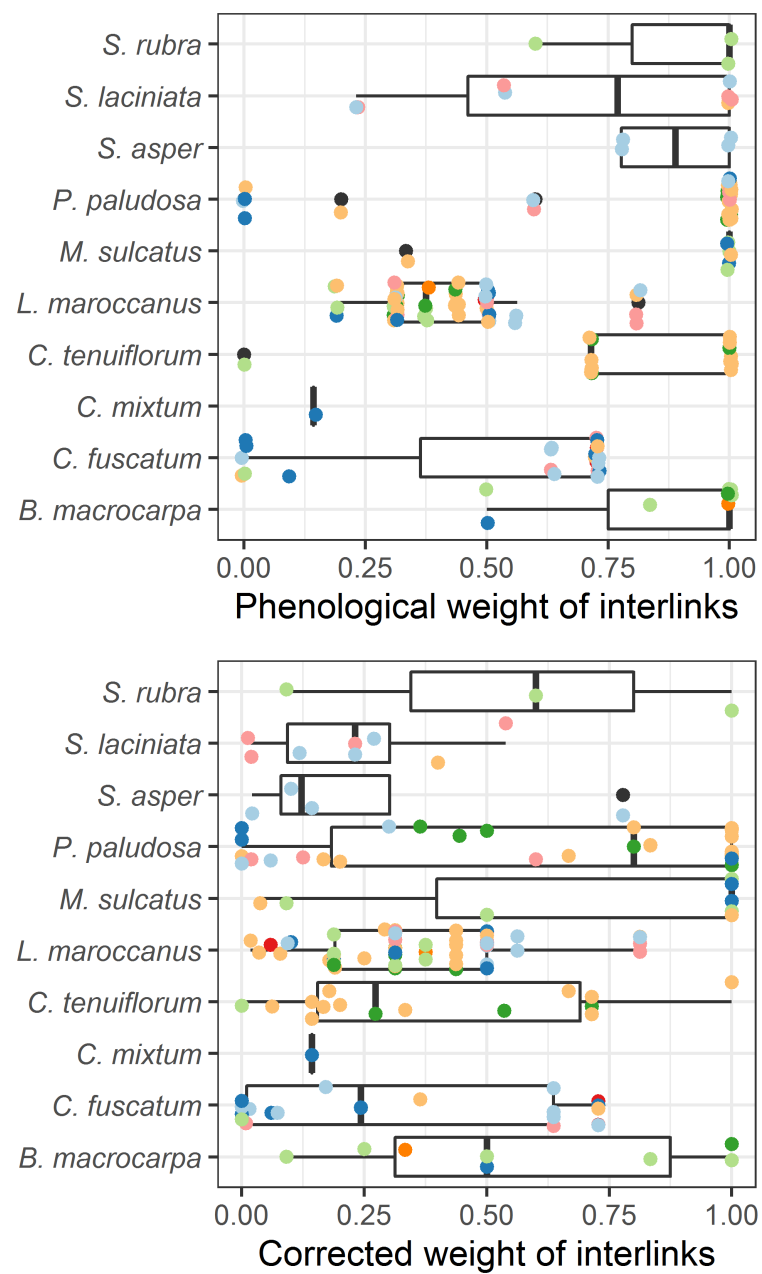

- Flower beetles

- House flies

- Hoverflies

- Humbleflies

- Small beetles

- Small flies

- Solitary bees

- Wasps

Fig. A4.1. Boxplot diagrams of the weight of the interlinks by plant species. Points represent the results for the taxonomic group of insect visitors. (a) Upper panel: Results when the strength of the interaction only takes into account the phenological overlap of plant species (phenological weight of interlinks). (b) Lower panel: Results when the strength of the interaction is also proportional to the number of visits shared (corrected weight of interlinks).

\section{Appendix 5: List of taxonomic groups, families and species of Caracoles (2020)}

Table A5. Number of visits observed in Caracoles Ranch by taxonomic group, family and identifier.

\begin{tabular}{lr}
\hline Taxonomic groups, Family, ID & Visits \\
\hline Big beetles & $\mathbf{5}$ \\
Cerambycidae & $\mathbf{2}$ \\
Cerambycidae & 2 \\
Meloidae & $\mathbf{3}$ \\
Lagorina sericea & 3 \\
\hline Butterflies & $\mathbf{1 3}$ \\
Geometridae & $\mathbf{2}$ \\
Geometridae & 2 \\
Lasiocampidae & $\mathbf{5}$ \\
Lasiocampa trifolii & 5 \\
Nymphalidae & $\mathbf{2}$ \\
Vanessa cardui & 2 \\
Pieridae & $\mathbf{4}$ \\
Euchloe crameri & 1 \\
Pieris brassicae & 3 \\
Flies & $\mathbf{1}$
\end{tabular}


Diptera

Other diptera

Flower beetles

395

Chrysomelidae

Cryptocephalus sp.

Elateridae

Elateridae

Melyridae

Malachius bipustulatus

Melyridae

Psilothrix viridicoerulea

Mordellidae

Mordellidae

Oedemeridae

15

Oedemeridae

House flies

Calliphoridae

Calliphoridae

Muscidae

Musca sp.

Sarcophagidae

Sarcophaga sp.

Tachinidae

Cylindromyia sp.

Hoverflies 62

Syrphidae $\quad 62$

Episyrphus balteatus 14

Eristalis sp. $\quad 3$

Eupeodes corollae 1

Lomatia sp. $\quad 9$

Sphaerophoria scripta $\quad 32$

Syrphidae $\quad 3$

Humbleflies $\quad 57$

Bombyliidae $\quad 57$

Anastoechus sp. $\quad 44$

Bombilus major 13

Small beetles $\quad \mathbf{7 5 6}$

Anthicidae $\quad 10$

Anthicidae 10

Chrysomelidae $\quad 2$

Cassida sp. 1

Phaedon sp. $\quad 1$

Curculionidae $\quad 1$

Curculionidae 1

Nitidulidae $\quad \mathbf{7 4 3}$

Brassicogethes sp. $\quad 743$

Small flies 135

Bibionidae $\quad 4$

Dilophus sp. 4

Empididae $\quad 2$

Empis sp. $\quad 2$

Stratiomyidae $\quad 6$

Nemotelus sp. $\quad 6$

Ulidiidae $\quad \mathbf{1 2 3}$

Ulidiidae 123

Solitary bees 280

Andrenidae 136


Andrena argentata $\quad 4$

Andrena humilis $\quad 76$

Andrena sp. $\quad 56$

Apidae 4

Eucera sp. $\quad 4$

Halictidae $\quad 126$

Lasioglossum immunitum 4

Lasioglossum malachurum 111

Lasioglossum sp. 11

Megachilidae 14

\begin{tabular}{lr} 
Osmia ligurica & 14 \\
\hline Wasp & $\mathbf{8}$
\end{tabular}

Braconidae $\quad 8$

Braconidae 8

Total 1,794

\section{Appendix 6: Graph representation of the multilayers analyzed}

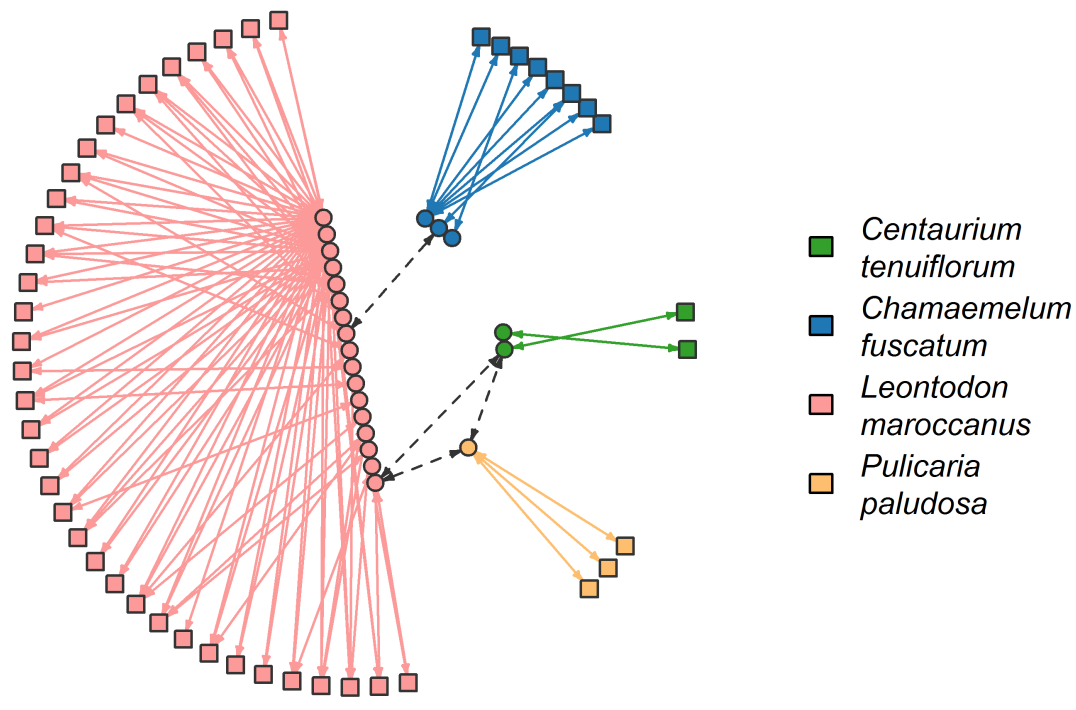

Fig. A6.1. Resulting multilayer for plot 1. Symbols and lines correspond to those in Fig. 2 
bioRxiv preprint doi: https://doi.org/10.1101/2021.04.23.441120; this version posted August 6, 2021. The copyright holder for this preprint (which was not certified by peer review) is the author/funder, who has granted bioRxiv a license to display the preprint in perpetuity. It is made available under aCC-BY-NC-ND 4.0 International license.

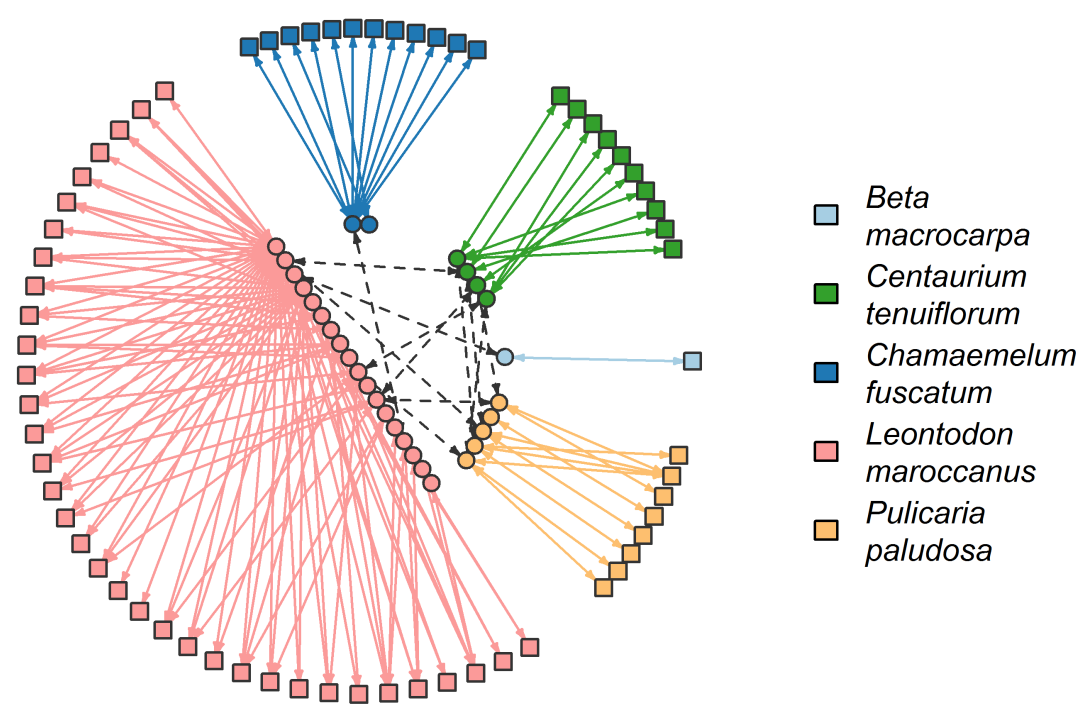

Fig. A6.2. Resulting multilayer for plot 2. Symbols and lines correspond to those in Fig. 2

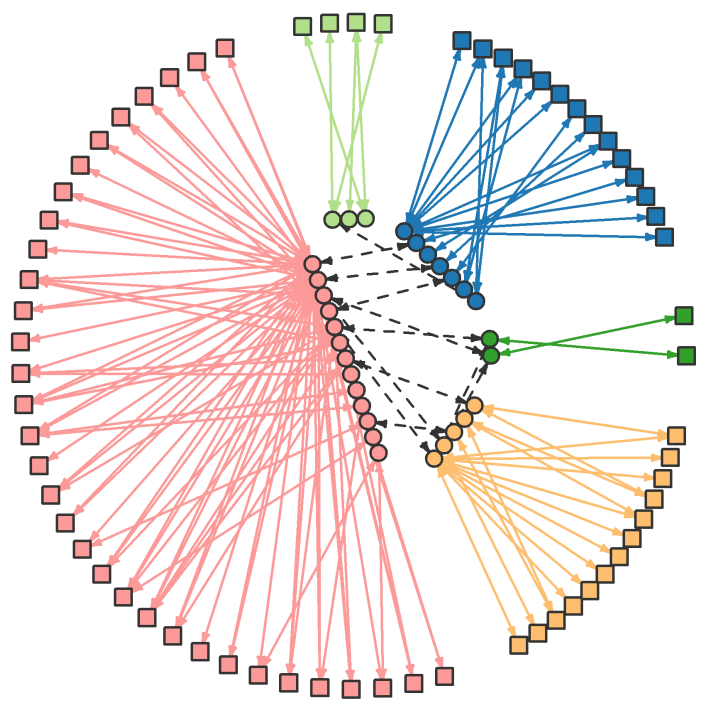

Centaurium tenuiflorum

Chamaemelum fuscatum

Chamaemelum mixtum Leontodon maroccanus

Pulicaria paludosa

Fig. A6.3. Resulting multilayer for plot 3. Symbols and lines correspond to those in Fig. 2 
bioRxiv preprint doi: https://doi.org/10.1101/2021.04.23.441120; this version posted August 6, 2021. The copyright holder for this preprint (which was not certified by peer review) is the author/funder, who has granted bioRxiv a license to display the preprint in perpetuity. It is made available under aCC-BY-NC-ND 4.0 International license.

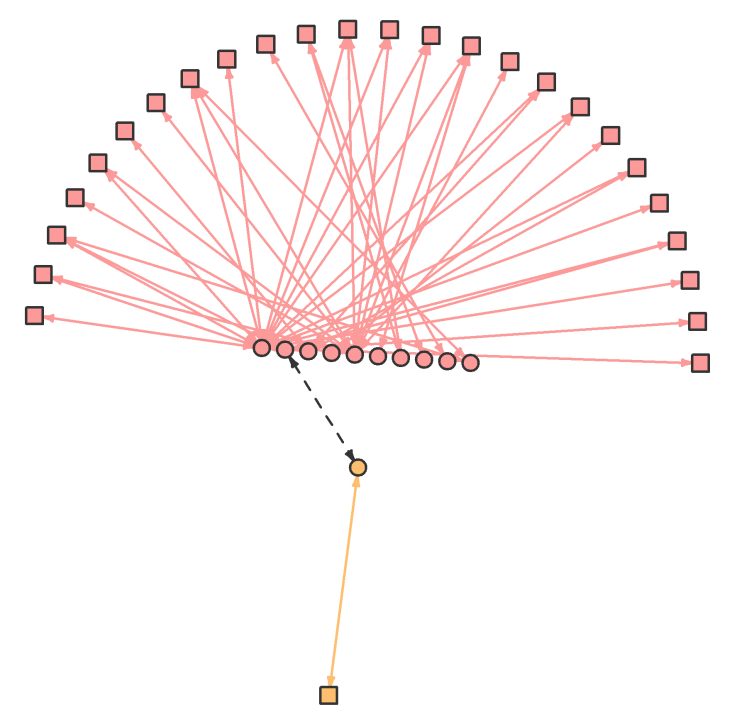
Leontodon maroccanus
Pulicaria
paludosa

Fig. A6.4. Resulting multilayer for plot 4. Symbols and lines correspond to those in Fig. 2
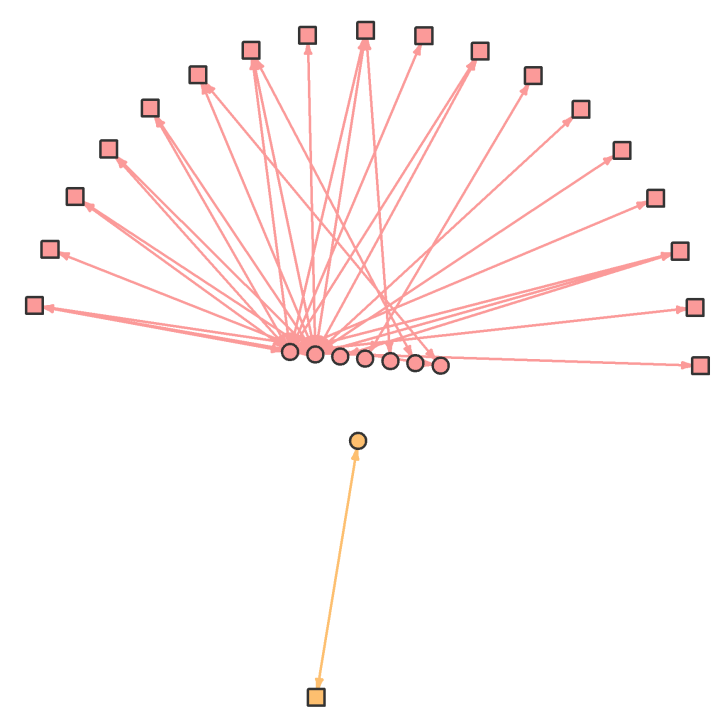

$\square$ Leontodon maroccanus

Pulicaria paludosa

Fig. A6.5. Resulting multilayer for plot 1. Symbols and lines correspond to those in Fig. 2 
bioRxiv preprint doi: https://doi.org/10.1101/2021.04.23.441120; this version posted August 6, 2021. The copyright holder for this preprint (which was not certified by peer review) is the author/funder, who has granted bioRxiv a license to display the preprint in perpetuity. It is made available under aCC-BY-NC-ND 4.0 International license.

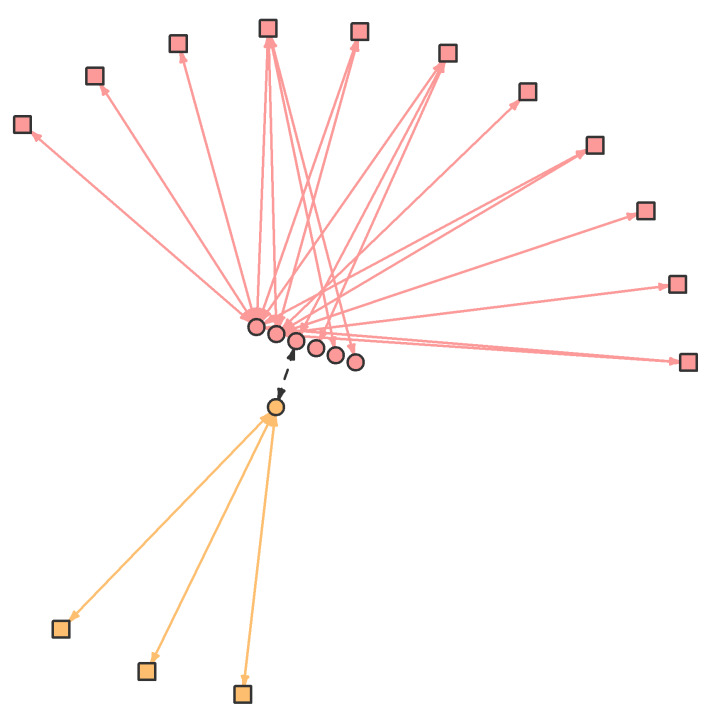

Leontodon

maroccanus

Pulicaria

paludosa

Fig. A6.6. Resulting multilayer for plot 1. Symbols and lines correspond to those in Fig. 2

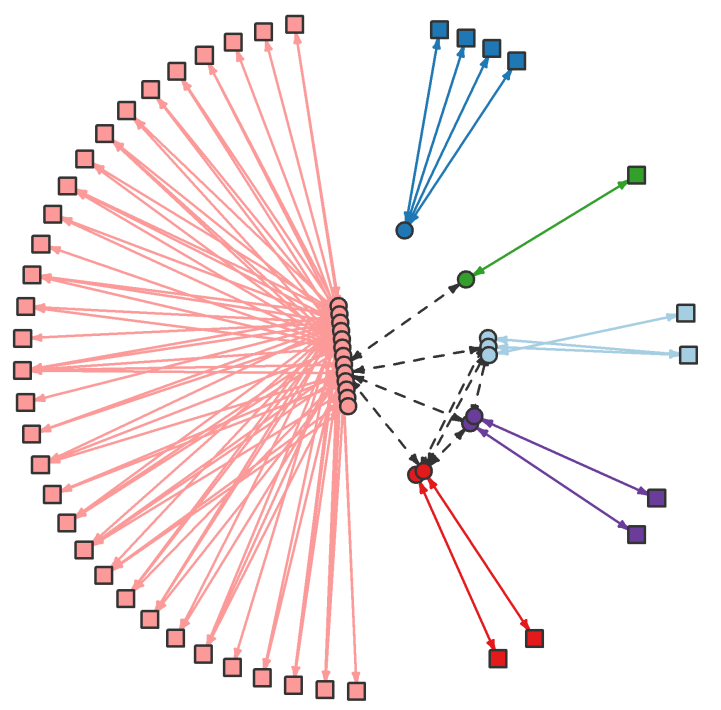

Beta macrocarpa

$\square$ Centaurium

tenuiflorum

Chamaemelum fuscatum

Leontodon maroccanus

Melilotus

sulcatus

Spergularia rubra

Fig. A6.7. Resulting multilayer for plot 1. Symbols and lines correspond to those in Fig. 2 
bioRxiv preprint doi: https://doi.org/10.1101/2021.04.23.441120; this version posted Auqust 6, 2021. The copyright holder for this preprint (which was not certified by peer review) is the author/funder, who has granted bioRxiv a license to display the preprint in perpetuity. It is made available under aCC-BY-NC-ND 4.0 International license.

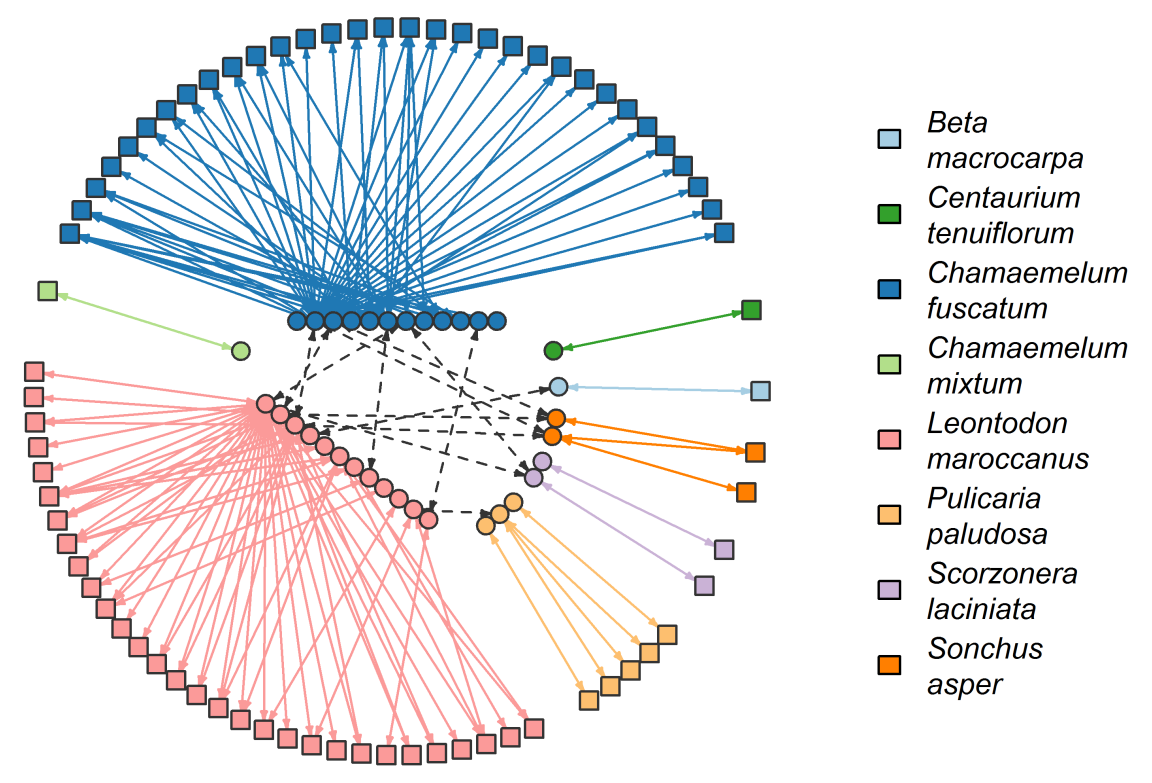

Fig. A6.8. Resulting multilayer for plot 9. Symbols and lines correspond to those in Fig. 2 
bioRxiv preprint doi: https://doi.org/10.1101/2021.04.23.441120; this version posted August 6, 2021. The copyright holder for this preprint (which was not certified by peer review) is the author/funder, who has granted bioRxiv a license to display the preprint in perpetuity. It is made available under aCC-BY-NC-ND 4.0 International license.

\section{Appendix 7: Characterization of community structure}

As can be seen in Fig. A7.1 the main visitors by functional groups were small beetles (756), followed by pollenivorous flower beetles (395), solitary bees (280) and small flies (135). The remaining visits are distributed between house flies (82), hoverflies (62), humbleflies (57), butterflies (13), wasps (8), big beetles (5) and flies(1). Regarding plants, during 2020, only ten focal species received insect visits in Caracoles, namely: L. maroccanus (1,337), C. fuscatum (268), P. paludosa (111), C. tenuiflorum (23), M. sulcatus (15), B. macrocarpa (14), C. mixtum (14), S. laciniata (7), S. asper (3), and S. rubra (2).
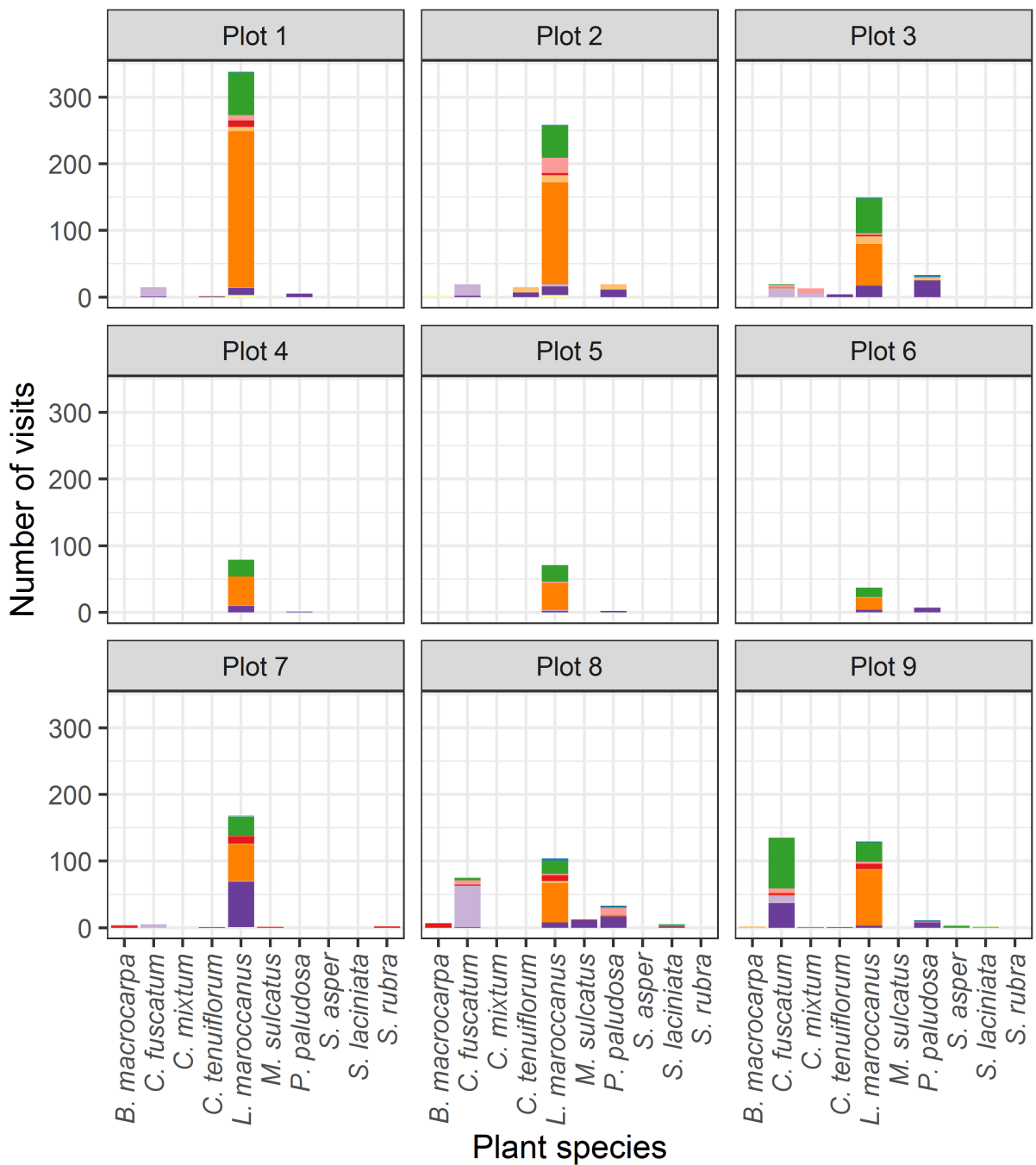

\begin{tabular}{|c|c|c|c|}
\hline Big beetles & Flower beetles & Humbleflies & Solitary bees \\
\hline Butterflies & House flies & Small beetles & Wasps \\
\hline Flies & Hoverflies & Small flies & \\
\hline
\end{tabular}

Fig. A7.1. Number of insect visits per functional group, plant species and plot. 

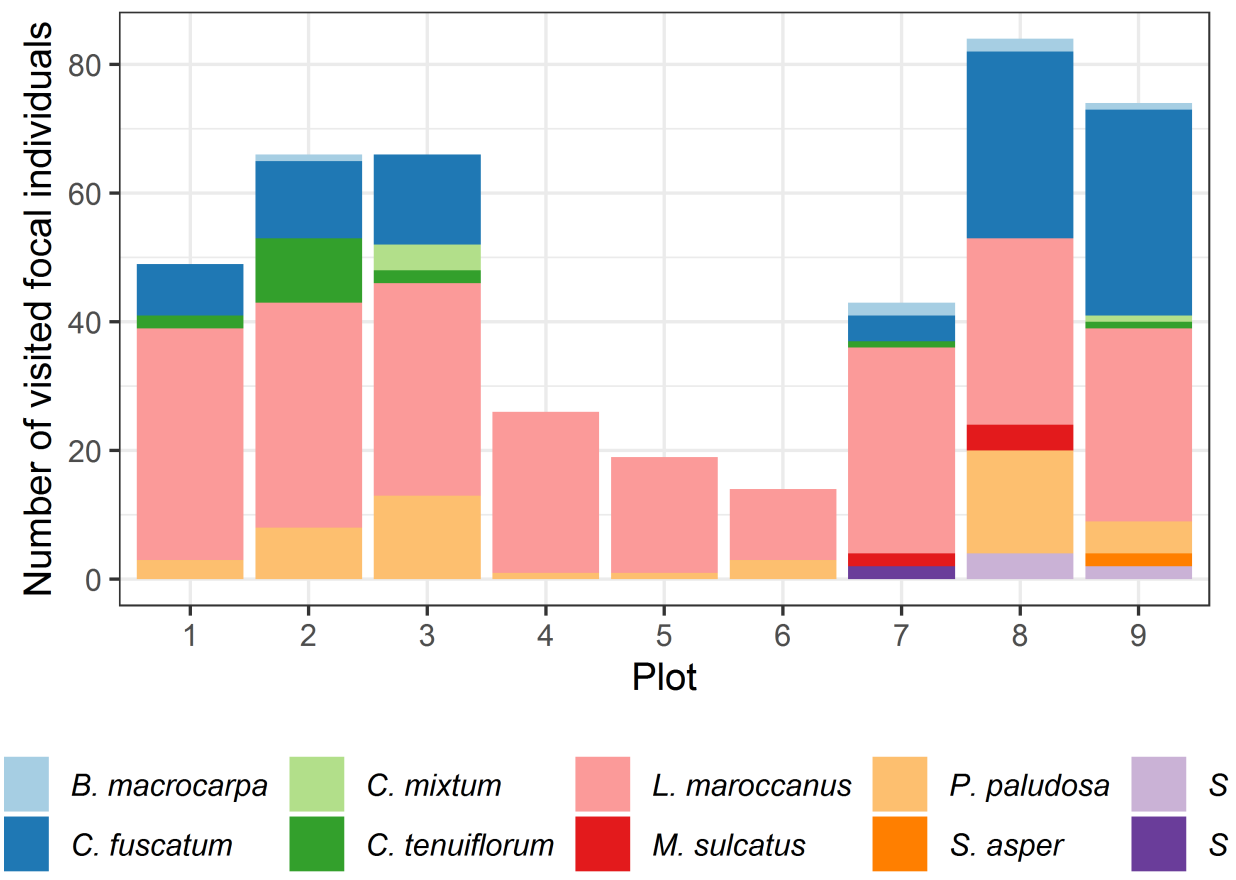

Fig. A7.2. Number of individuals with visits per plant species.

Table A7. Characterization of the modules in each plot. Values in parenthesis show the results with $95 \%$ confidence intervals.

\begin{tabular}{|c|c|c|c|c|c|c|}
\hline Plot & $\begin{array}{l}\text { Plant individuals } \\
\text { with visitors }\end{array}$ & $\begin{array}{c}\text { Plant } \\
\text { visitors }\end{array}$ & $\begin{array}{l}\text { Number of } \\
\text { modules }\end{array}$ & $\begin{array}{l}\text { Plant species } \\
\text { per module }\end{array}$ & $\begin{array}{l}\text { Visitors per } \\
\text { module }\end{array}$ & $\begin{array}{l}\text { Plant individuals } \\
\text { per module }\end{array}$ \\
\hline 1 & 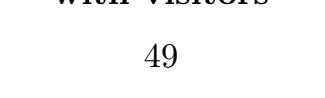 & 23 & स⿴囗十 & $\begin{array}{l}1.20 \\
(1,3)\end{array}$ & $\begin{array}{l}2.00 \\
(1,8)\end{array}$ & $\begin{array}{c}4.90 \\
(1,28)\end{array}$ \\
\hline 2 & 66 & 30 & 11 & $\begin{array}{l}1.55 \\
(1,3)\end{array}$ & $\begin{array}{l}1.91 \\
(1,8)\end{array}$ & $\begin{array}{c}6.00 \\
(1,29)\end{array}$ \\
\hline 3 & 66 & 30 & 14 & $\begin{array}{l}1.64 \\
(1,3)\end{array}$ & $\begin{array}{l}1.50 \\
(1,4)\end{array}$ & $\begin{array}{c}4.71 \\
(1,13)\end{array}$ \\
\hline 4 & 26 & 11 & 7 & $\begin{array}{l}1.14 \\
(1,2)\end{array}$ & $\begin{array}{l}1.43 \\
(1,2)\end{array}$ & $\begin{array}{l}3.71 \\
(1,14)\end{array}$ \\
\hline 5 & 19 & 8 & 6 & $\begin{array}{l}1 \\
1\end{array}$ & $\begin{array}{l}1.33 \\
(1,3)\end{array}$ & $\begin{array}{l}3.17 \\
(1,10)\end{array}$ \\
\hline 6 & 14 & 7 & 3 & $\begin{array}{l}1 \\
1\end{array}$ & $\begin{array}{l}2.33 \\
(1,4)\end{array}$ & $\begin{array}{c}4.67 \\
(1,10)\end{array}$ \\
\hline 7 & 43 & 22 & 14 & $\begin{array}{l}1.29 \\
(1,3)\end{array}$ & $\begin{array}{l}1.21 \\
(1,2)\end{array}$ & $\begin{array}{c}3.07 \\
(1,10)\end{array}$ \\
\hline 8 & 84 & 41 & 16 & $\begin{array}{l}1.81 \\
(1,4)\end{array}$ & $\begin{array}{l}1.56 \\
(1,5)\end{array}$ & $\begin{array}{c}5.25 \\
(1,26)\end{array}$ \\
\hline 9 & 74 & 34 & 16 & $\begin{array}{l}1.50 \\
(1,3)\end{array}$ & $\begin{array}{l}1.50 \\
(1,3)\end{array}$ & $\begin{array}{c}4.62 \\
(1,21)\end{array}$ \\
\hline
\end{tabular}

Regarding insect nodes per module, the average amount of them is 2.12 with CI $(1,6)$, and the amount of different species and morphospecies per module is 1.57 with CI $(1,7.92)$. Overall, there are 64 modules with a single insect species (or morphospecies), 24 with two different species, 4 modules with three, 2 modules with four, 1 with 5 , and 2 modules with 8. Additional details on modules features can be found in table A7 
bioRxiv preprint doi: https://doi.org/10.1101/2021.04.23.441120; this version posted August 6, 2021. The copyright holder for this preprint (which was not certified by peer review) is the author/funder, who has granted bioRxiv a license to display the preprint in perpetuity. It is made available under aCC-BY-NC-ND 4.0 International license.
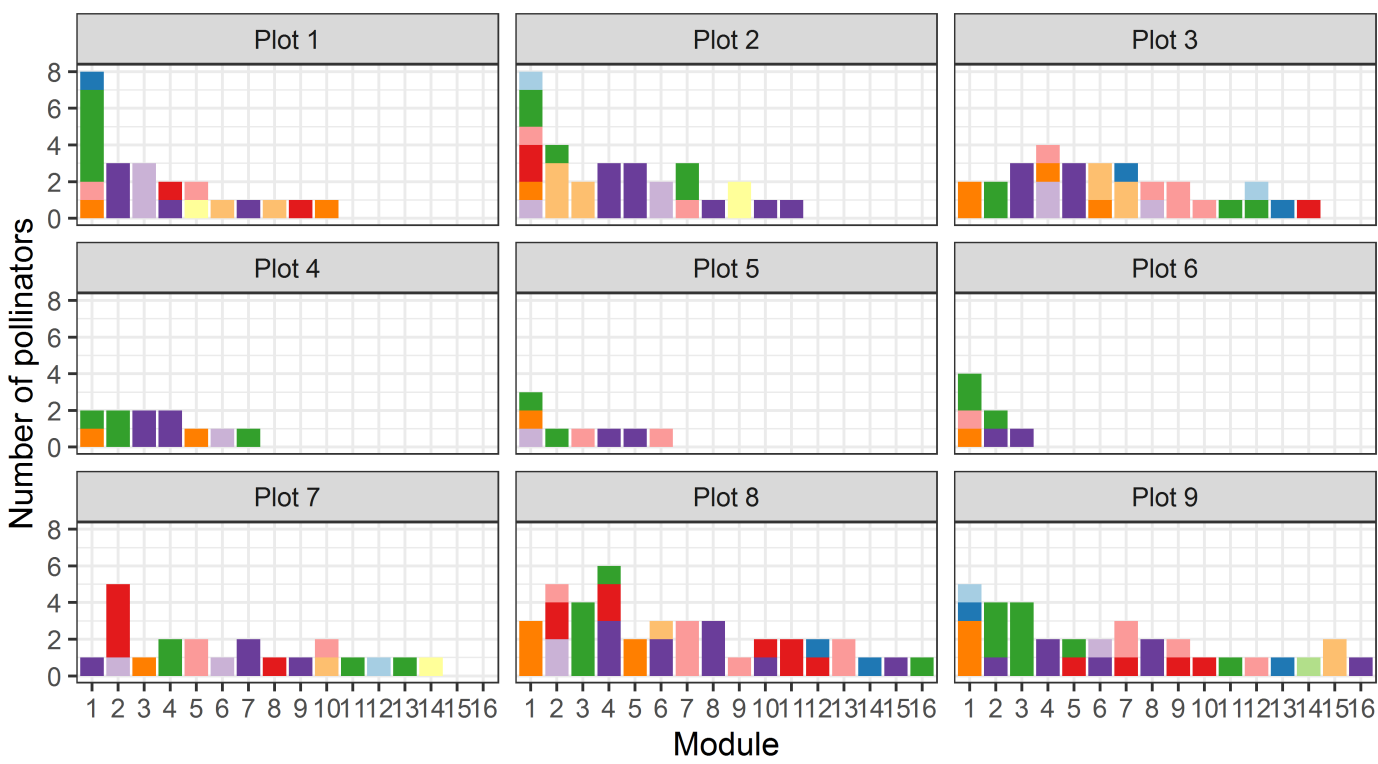

Module

\begin{tabular}{|l|l|l|l|}
\hline Big beetles & Flower beetles & Humbleflies & Solitary bees \\
\hline Butterflies & House flies & Small beetles & Wasps \\
\hline Flies & Hoverflies & Small flies & \\
\hline
\end{tabular}

Fig. A7.3. Number of insect visitors per module, taxonomic group and plot.
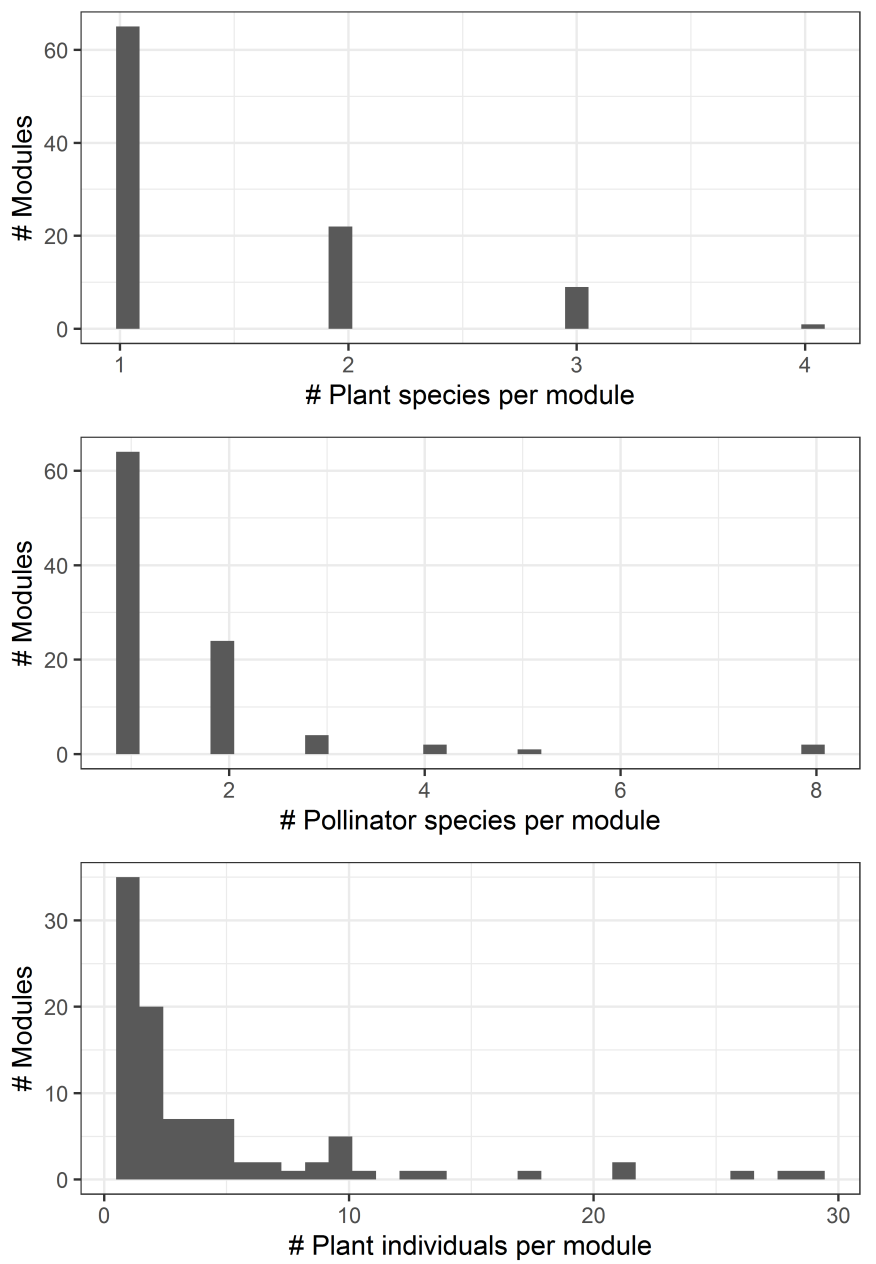

Fig. A7.4. Distribution of number of plant species, insect visitors' species, and plant individuals per module. 

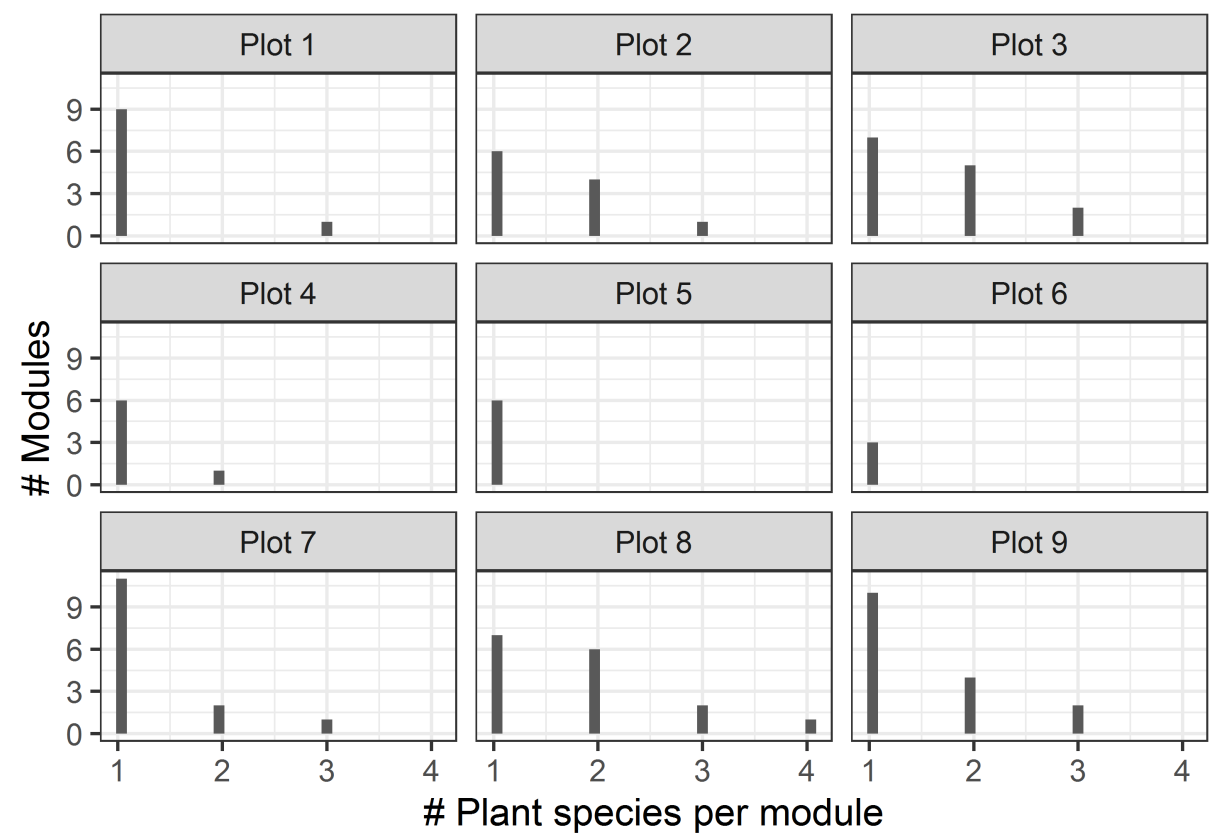

Fig. A7.5. Distribution of number of plant species per module and plot.
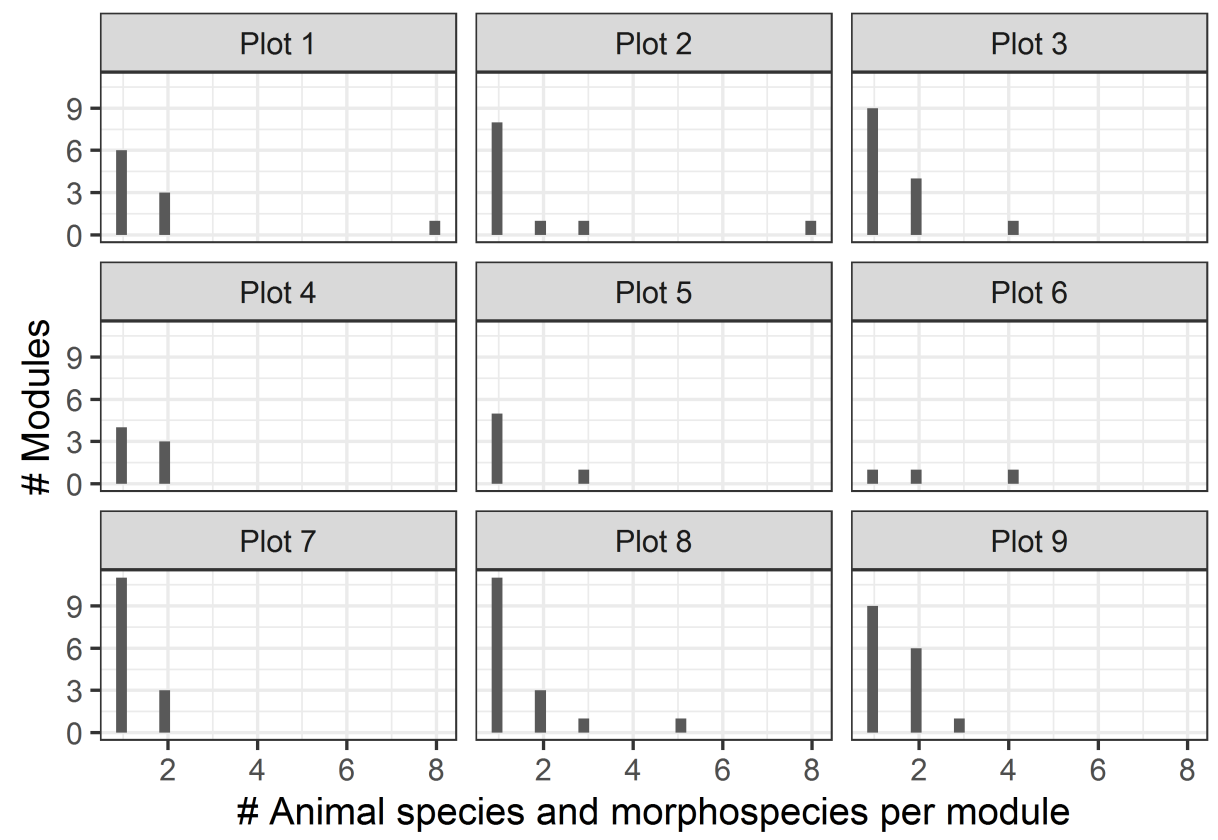

Fig. A7.6. Distribution of insect visitors species per module and plot. 
bioRxiv preprint doi: https://doi.org/10.1101/2021.04.23.441120; this version posted Auqust 6. 2021. The copyright holder for this preprint (which was not certified by peer review) is the author/funder, who has granted bioRxiv a license to display the preprint in perpetuity. It is made available under aCC-BY-NC-ND 4.0 International license.

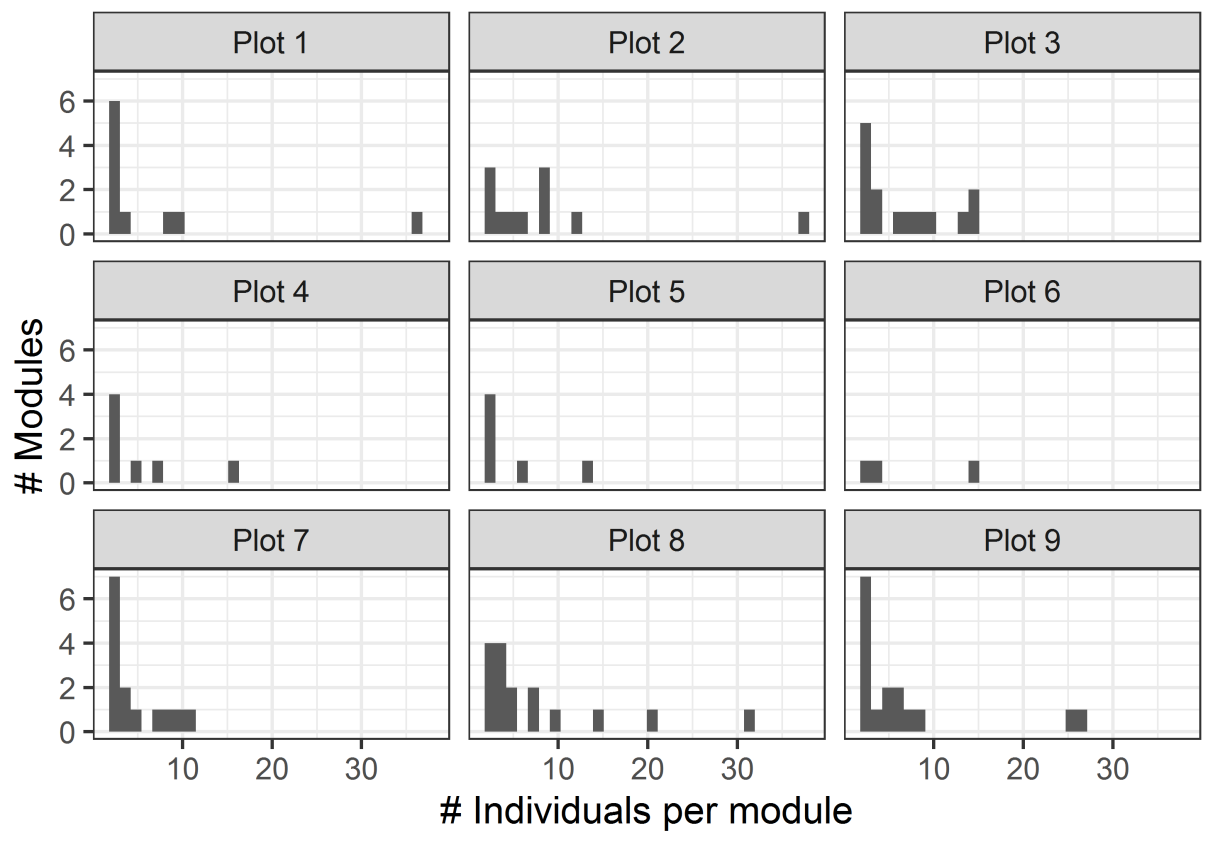

Fig. A7.7. Distribution of number of plant individuals per module and plot. 


\section{Appendix 8: Specialization roles of plant individuals and floral visitors}

Plant individuals and insect species within a module may exert a different impact on the pollen flow that they trap. For instance, depending on their centrality metrics, nodes may hoard the pollen influx and/or outflux. Besides, in the case of insect species, those that connect several plant species and modules can be responsible for distributing high loads of heterospecific pollen. To assess the roles of plant individuals and insect species in each multilayer, we classified them in the following categories: (i) peripherals, i.e., vertices linked to very few nodes that usually are within their module; (ii) module hubs, i.e., highly connected vertices linked to many nodes within their own module; (iii) connectors, i.e., nodes that link several modules; and (iv) network hubs, i.e., nodes acting as both connectors and module hubs (Olesen et al. 2007). To do so, we calculated their weighted standard among module connectivity and within module degree, denoted by c and z, respectively (Dormann \& Strauss, 2013, Olesen et al. 2007). In unweighted and undirected networks, the former represents the level to which a given node is linked to other modules, and the later is its standardized number of links to other species in the same module (Guimerà \& Amaral, 2005). Since our multilayers are weighted and directed, we must distinguish between the links that arrive at a node (or in-links) and those that depart from it (or out-links). For that reason, we adapted the previous definitions and computed two values of c (namely: in- and out-c) and two of z (in- and out-z) by using in- and out-strength of each node, which correspond to the sum of the weights of its in-links and the one for its out-links, respectively. From the in-links (out-links) perspective, we assigned the following roles to nodes: peripherals [low in-(out-)c and low in-(out-)z], module hubs [low in-(out-)c and high in-(out-)z], connectors [high in-(out-)c and low in-(out-)z], and network hubs [high in-(out-)c and high in-(out-)z].

To define the thresholds for in/out-c- and in/out-z-values, we followed Watts et al. (2016) and used the 95\% quantiles of such metrics obtained from a null model for our original multilayer networks. Specifically we generated an ensemble of 100 null multilayers for each plot, respectively, and we calculated in/out-c- and in/out-z-values for each randomized multilayer. Our null model preserves the total number of observed interactions per insect visitor and assumes that the weight of interlinks are those of the observed multilayers. We estimated the thresholds for in/out-c and in/out-z over all the plots (i.e., over the results for 900 null multilayers), and their values are 1.00/1.00 and 1.93/1.62, respectively. By using those thresholds, overall, around $30-40 \%$ of the plant and insect nodes were peripherals (with all their inand out-links outside their own module), 40 - $60 \%$ were connectors among modules, $2.5-10 \%$ of insect species acted as module hubs, and $2.5-10 \%$ of insect species were network hubs. Since insect species channel all the links between conspecific and heterospecific plant individuals (see Fig. 1(e)), the observed absence of plant hubs is expected. In addition, our results also confirmed that most network and module hubs belong to the main insect visitors of the most visited plant species, namely: flower beetles, humbleflies, small beetles, bees. Specific details are as follows. From the in-link (or pollen influx to nodes) perspective, we found that $37.87 \%$ of all plant individuals and $29.61 \%$ of all floral visitors were peripherals (with c greater than 0, i.e., they all have in-links outside their own module), $58.50 \%$ of plant individuals and $50.00 \%$ of insect visitors were connectors among modules, $9.71 \%$ of insect visitors were module hubs, whereas $2.91 \%$ of insects were network hubs (Figs. A8.1 and A8.2. Influx roles for the remaining plant individuals $(3.63 \%)$ and insect visitors $(7.77 \%)$ can not be computed because the standard deviation of their respective within-layer centralities is equal to zero, and consequently their within module in-strength (i.e. in-z), which is defined in multiples of the within-layer centralities' standard deviations Dormann \& Strauss (2013); Olesen et al. (2007) (Olesen et al. 2007, Dormann et al. 2009), can not be properly assessed. Influx network hubs were Lasioglossum malachurum (bee) in P. paludosa (plot 8), Ulidiidae (small flies) in C. fuscatum (plots 1, 2 and 3), Psilothrix viridicoerulea (flower beetles) in L. maroccanus layers (plot 6), and Bombylius sp. (humbleflies) in C. tenuiflorum (plot 2), whereas module hubs were Anastoechus sp. (humbleflies) in L. maroccanus (plot 3), Andrena humilis (solitary bees) in L. maroccanus (plot 7), Andrena sp. (solitary bees) in C. fuscatum (plot 9), Brassicogethes sp. (small beetles) in L. maroccanus (all plots), Lasioglossum malachurum (bee) in P. paludosa (plot 3), Psilothrix viridicoerulea (flower beetles) in C. fuscatum (plot 9) and L. maroccanus (plots 3, 4, 5, 7, and 8), and Ulidiidae (small flies) in C. fuscatum (plot 8). Results for the out-links (or pollen outflux from nodes) show that $37.87 \%$ of all plant individuals and $34.47 \%$ of all floral visitors were peripherals (with c greater than 0), $51.25 \%$ of plant individuals and $37.86 \%$ of insect visitors were connectors among modules, $2.91 \%$ of insect visitors were module hubs, whereas only $0.45 \%$ of plant individuals and $10.68 \%$ of insects were network hubs (see Figs. A8.3 and A8.4. Outflux roles for $10.88 \%$ of plant individuals and $14.08 \%$ of insect visitors are omitted. Outflux network hubs were Anastoechus sp. (humbleflies) in layer C. tenuiflorum (plot 2), Andrena humilis (solitary bees) in S. laciniata (plot 8), Bombilus major (humbleflies) in P. paludosa (plot 3), Brassicogethes sp. (Small beetles) in C. fuscatum (plots 3 and 9), P. paludosa (plot 8) and S. laciniata (in plot 8 and 9, respectively); Empis sp. (small flies) in C. fuscatum (plot 1); Lasioglossum malachurum (bees) in C. tenuiflorum (2 and 3), M. sulcatus (plot 8), and P. paludosa (1, 4, 8, and 9); Mordellidae (flower beetles) in S. asper (plot 9); Musca sp. (house flies) in P. paludosa (plot 8); Psilothrix viridicoerulea (flower beetles) in C. fuscatum (plot 3) and P. paludosa layers (plot 8); Sphaerophoria scripta (hoverflies) in M. sulcatus (plot 7); and Ulidiidae (Small flies) in C. fuscatum (plot 2), whereas module hubs are Anastoechus sp. (humbleflies) in 
bioRxiv preprint doi: https://doi.org/10.1101/2021.04.23.441120; this version posted August 6, 2021. The copyright holder for this preprint (which was not certified by peer review) is the author/funder, who has granted bioRxiv a license to display the preprint in perpetuity. It is made available under aCC-BY-NC-ND 4.0 International license.

P. paludosa (plot 3); Bombylius major (humbleflies) in P. paludosa (plot 2); Brassicogethes sp. (small beetles) in $L$. maroccanus (plot 9); Lasioglossum malachurum (solitary bees) in P. paludosa (plot 3); and Psilothrix viridicoerulea (flower beetles) in C. fuscatum and S. asper (both in plot 9).
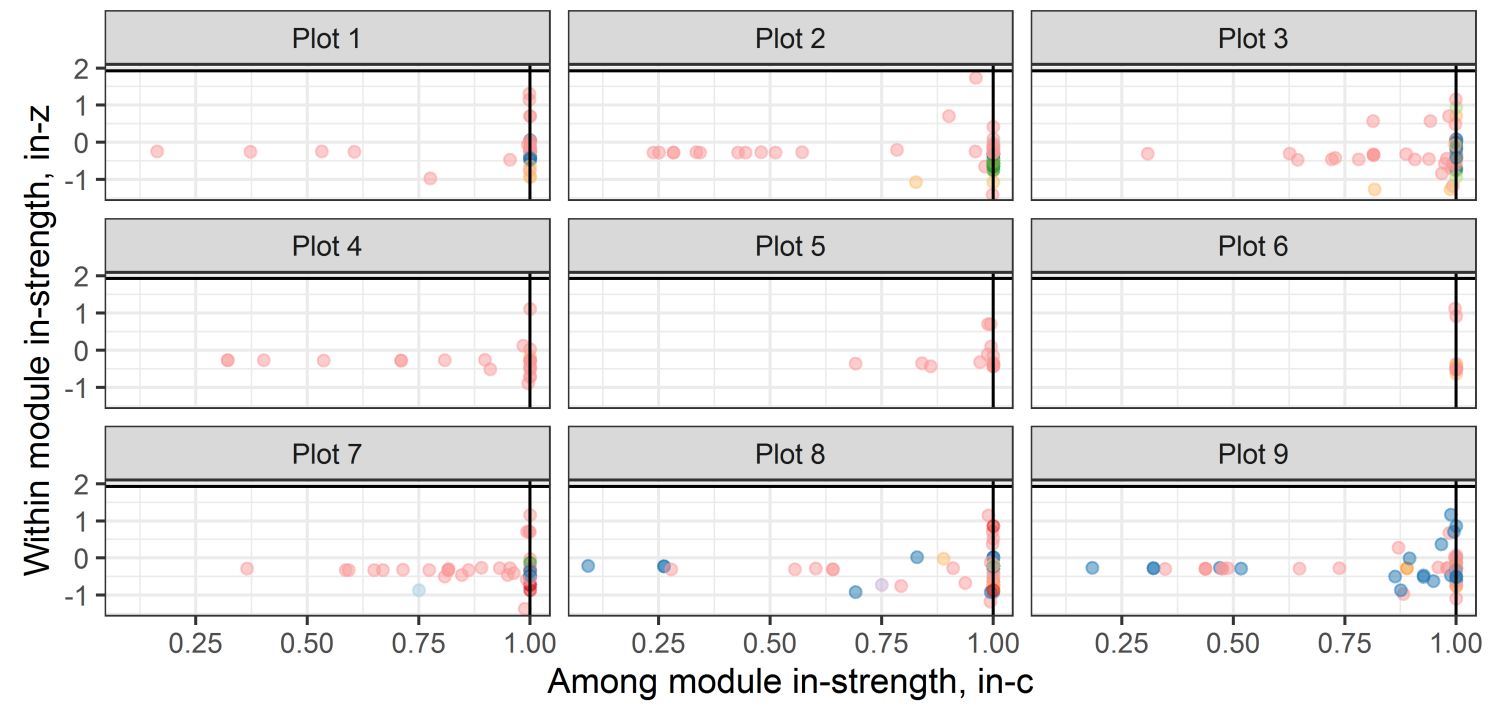

\begin{tabular}{|c|c|c|c|c|c|c|c|c|}
\hline B. macrocarpa & - & C. mixtum & - & L. maroccanus & - & P. paludosa & - & S. laciniata \\
\hline C. fuscatum & $\bullet$ & C. tenuiflorum & $\bullet$ & M. sulcatus & $\bullet$ & S. asper & $\bullet$ & S. rubra \\
\hline
\end{tabular}

Fig. A8.1. Roles performed by plant individuals in the plot multilayers according to within module in-strength (in-z) and among module in-strength (in-c). Lines at in- $z=1.93$ and in-c $=1.00$ define species roles.
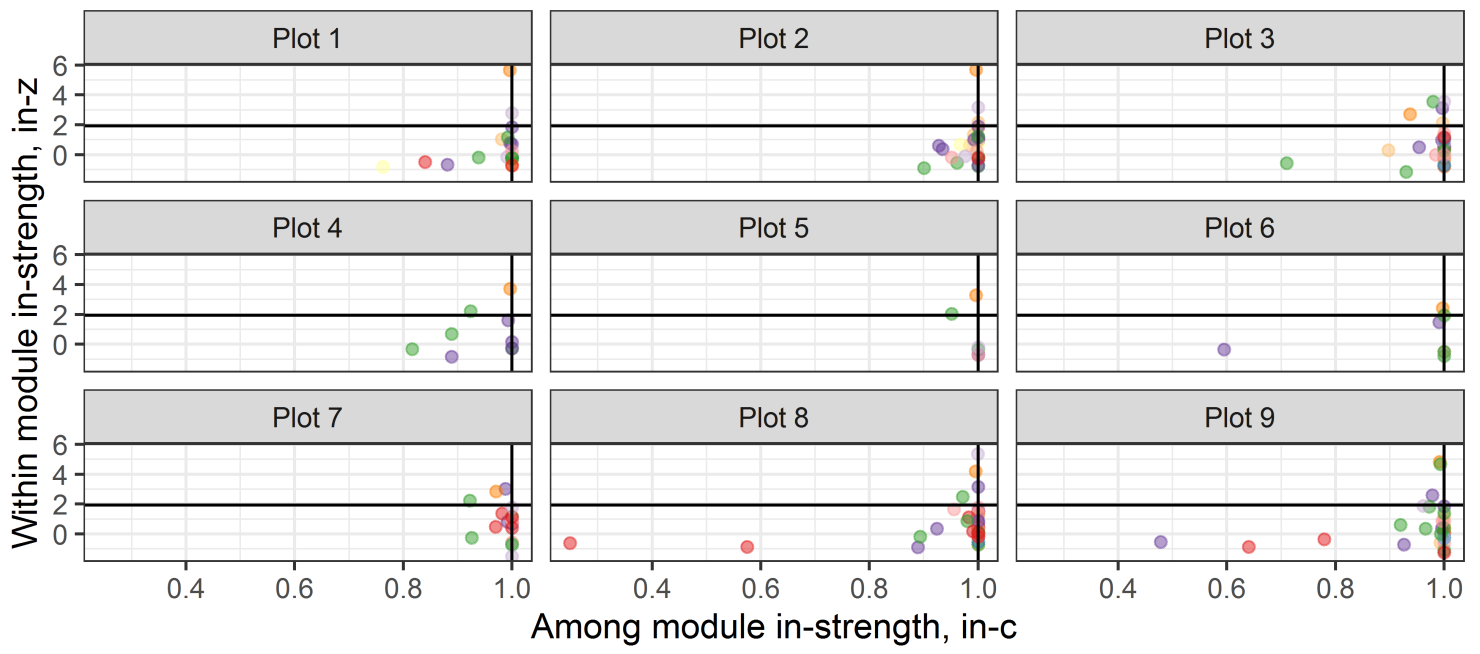

$\begin{array}{llll}\text { Big beetles } & \text { Flower beetles } & \text { Humbleflies } & \text { Solitary bees } \\ \text { Butterflies } & \circ \text { House flies } & \text { Small beetles } & \text { Wasps } \\ \text { Flies } & - \text { Hoverflies } & \text { Small flies } & \end{array}$

Fig. A8.2. Roles performed by floral visitors in the plot multilayers according to within module in-strength (in-z) and among module in-strength (in-c). Lines at in-z $=1.93$ and in-c $=1.00$ define species roles. 
bioRxiv preprint doi: https://doi.org/10.1101/2021.04.23.441120; this version posted August 6, 2021. The copyright holder for this preprint (which was not certified by peer review) is the author/funder, who has granted bioRxiv a license to display the preprint in perpetuity. It is made available under aCC-BY-NC-ND 4.0 International license.
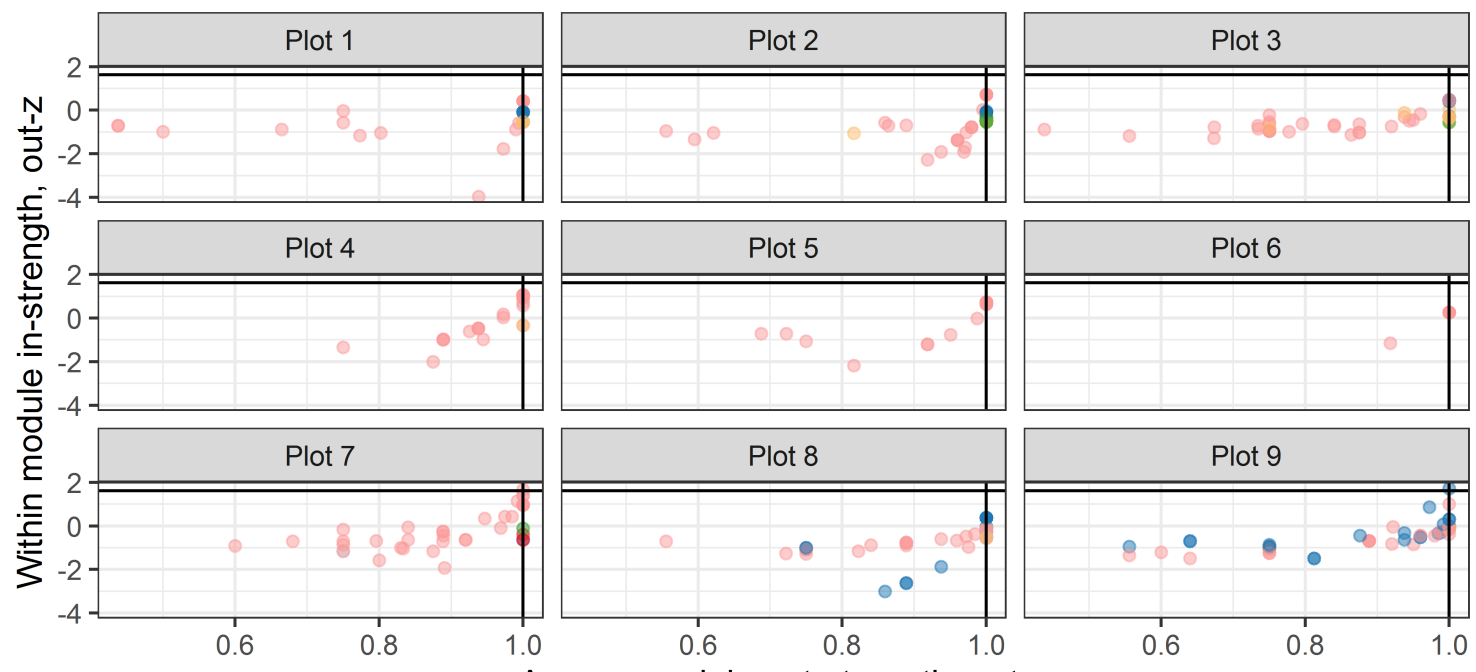

Among module out-strength, out-c

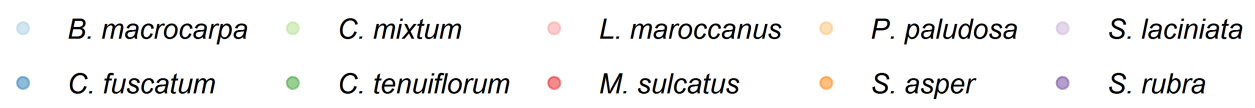

Fig. A8.3. Roles performed by plant individuals in the plot multilayers according to within module out-strength (out-z) and among module out-strength (out-c). Lines at out- $z=1.62$ and out- $c=1.00$ define species roles.
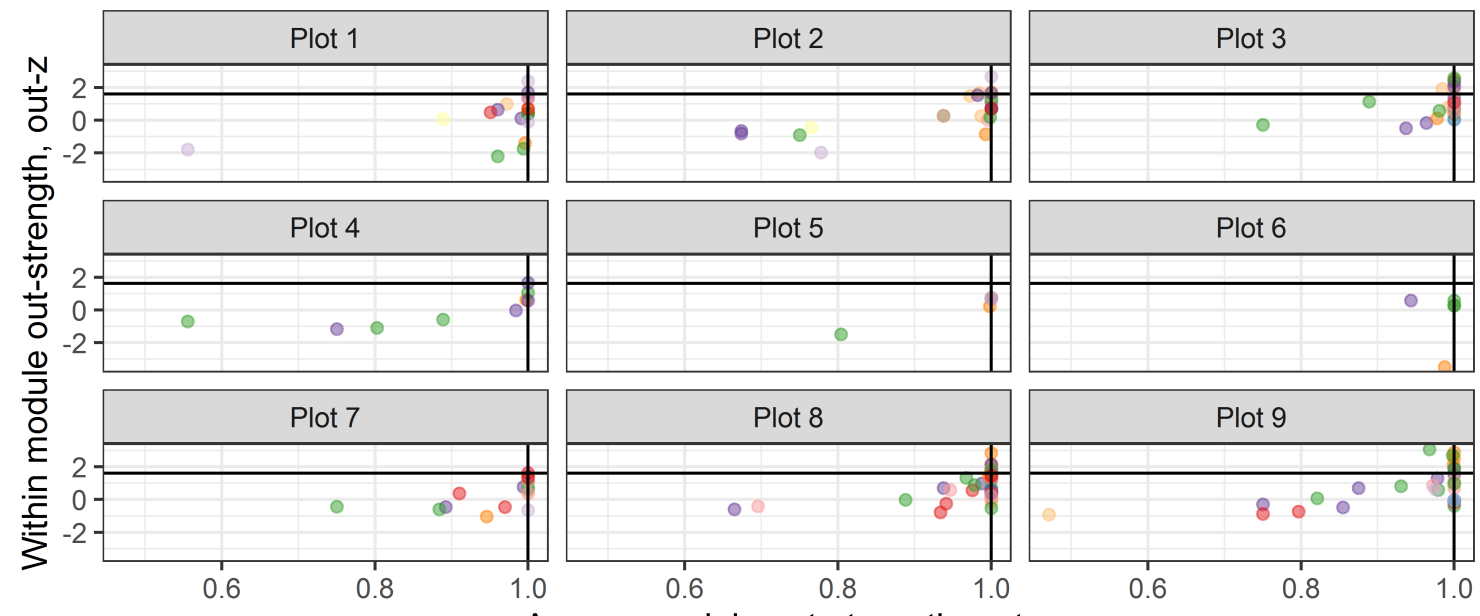

Among module out-strength, out-c

$\begin{array}{lllll}\text { Big beetles } & - \text { Flower beetles } & \text { Humbleflies } & \text { Solitary bees } \\ \text { Butterflies } & \circ \text { House flies } & \text { Small beetles } & \text { Wasps } \\ \text { Flies } & - \text { Hoverflies } & \text { Small flies } & \end{array}$

Fig. A8.4. Roles performed by floral visitors in the plot multilayers according to within module out-strength (out-z) and among module out-strength (out-c). Lines at out-z $=1.62$ and out-c $=1.00$ define species roles.

\section{Appendix 9: Testing significance of modularity}

After estimating the map equation (in bits, $\left.L_{\text {Observed }}\right)$ and the number modules $\left(m_{\text {Observed }}\right)$ for the multilayer of a given plot, we want to know whether these values are significant compared with a random expectation. To contrast the significance of such measures, we proposed two null models. In our first null model (Null model 1), the total number of observed interactions per plant species and per insect visitor are preserved in each layer. That is, only intra-layer connections with plant individuals are randomly reshuffled in this null model. Thus, the experimental phenology of each plot and the inter-links that codify it are equal to those of observed networks. Regarding our second null model (Null model 2), it preserves the total number of observed interactions per insect visitor and assumes 
bioRxiv preprint doi: https://doi.org/10.1101/2021.04.23.441120; this version posted August 6, 2021. The copyright holder for this preprint (which was not certified by peer review) is the author/funder, who has granted bioRxiv a license to display the preprint in perpetuity. It is made available under aCC-BY-NC-ND 4.0 International license.

that the weight of interlinks are those of the observed multilayers.

To derive a null distribution of map equation and number of modules for each null model, we generated an ensemble of 500 null multilayers for each plot, respectively. For each randomized multilayer, we have calculated the map equation $\left(L_{\text {Simulated }}\right)$ and number of modules $\left(m_{\text {Simulated }}\right)$. Then, we estimated the confidence interval for each null distribution and tested whether the observed values of our metrics belong to such intervals (non-significant result) or not (significant result). Our results are summarized in tables A9.1 and A9.2, and Figs. A9.1, A9.2, A9.3 and A9.4 As can be seen, in each plot $L_{\text {Observed }}$ is significantly smaller than the results for randomized multilayer with a confidence level of $95 \%$. Consequently, observed network flows tend to be more constrained within modules than in any of the random multilayers. On the other hand, we found no significant differences between $m_{\text {Observed }}$ and the number of modules of randomized multilayers with a confidence level of $95 \%$.

Table A9.1. Observed map equation ( $\left.L_{\text {Observed }}\right)$ and number of modules $\left(m_{\text {Observed }}\right)$ for each plot, and the corresponding confidence intervals (C.I.) for the simulated map equation ( $\left.L_{\text {Simulated }}\right)$ and simulated number of modules $\left(m_{\text {Simulated }}\right)$, when the null model 1 is considered. Null distributions for $L_{S i m u l a t e d}$ and $m_{\text {Simulated }}$ are shown in Figs A9.1 and A9.2 Bold values denote significant results.

\section{NULL MODEL 1}

\begin{tabular}{ccccc} 
Plot & $L_{\text {Observed }}$ & C. I. for $L_{\text {Simulated }}$ & $m_{\text {Observed }}$ & C. I. for $m_{\text {Simulated }}$ \\
\hline 1 & $\mathbf{3 . 7 0 9}$ & $(\mathbf{3 . 9 0 8 , 4 . 1 2 6})$ & $\mathbf{1 0}$ & $(4,8)$ \\
2 & $\mathbf{3 . 9 7 1}$ & $(\mathbf{4 . 3 6 7 , 4 . 5 5 3 )}$ & 11 & $(8,11)$ \\
3 & $\mathbf{3 . 6 9 6}$ & $(\mathbf{3 . 9 4 3}, \mathbf{4 . 2 9 7})$ & 14 & $(11,16)$ \\
4 & $\mathbf{3 . 2 5 9}$ & $(\mathbf{3 . 6 7 8}, \mathbf{4 . 1 4 1})$ & 7 & $(4,8)$ \\
5 & $\mathbf{3 . 1 2 6}$ & $(\mathbf{3 . 1 7 5}, \mathbf{3 . 5 3 8})$ & 6 & $(2,6)$ \\
6 & $\mathbf{2 . 9 9 7}$ & $\mathbf{( 3 . 0 9 3 , 3 . 6 1 1 )}$ & 3 & $(3,5)$ \\
7 & $\mathbf{3 . 6 8 0}$ & $(\mathbf{3 . 8 5 1}, \mathbf{4 . 1 8 9})$ & $\mathbf{1 4}$ & $(7,11)$ \\
8 & $\mathbf{3 . 5 3 9}$ & $\mathbf{( 4 . 0 1 9 , 4 . 3 1 5 )}$ & 16 & $(14,19)$ \\
9 & $\mathbf{3 . 7 0 1}$ & $\mathbf{( 3 . 9 4 0 , 4 . 2 3 0 )}$ & 16 & $(13,19)$
\end{tabular}

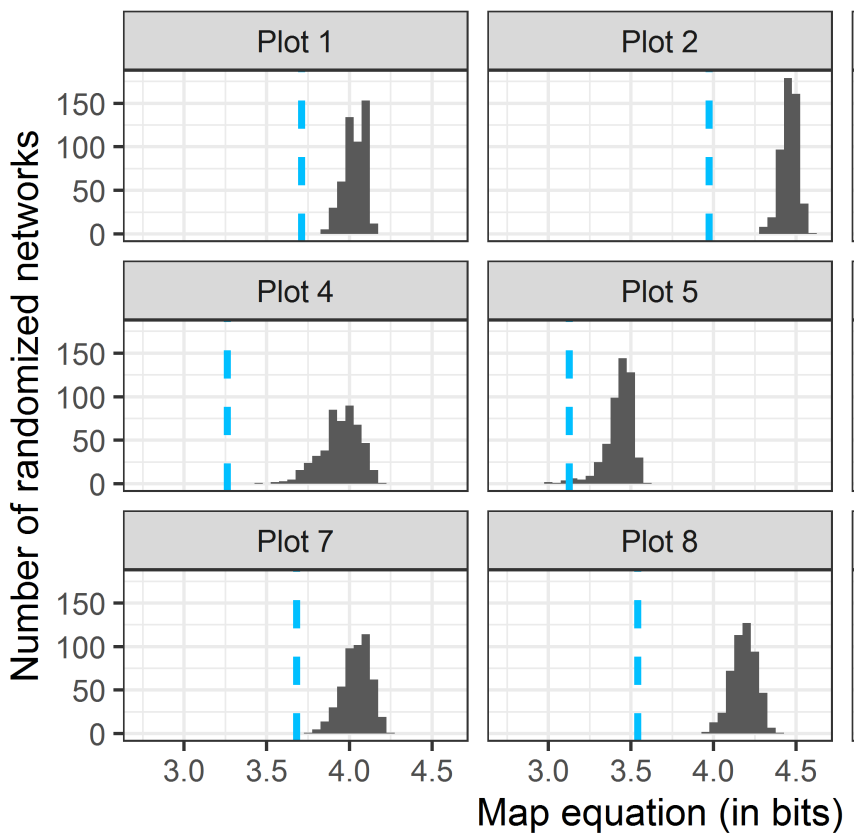

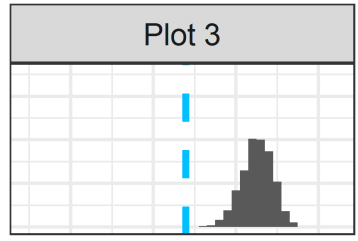
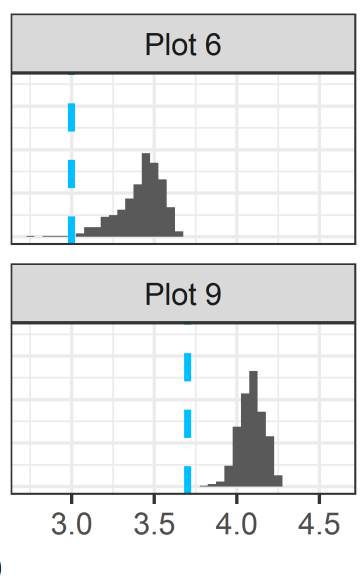

Fig. A9.1. Null distribution of map equation (in bits) obtained from 500 simulations for each plot. Each panel represents the results for a plot. The respective observed values are marked with vertical blue dashed lines. 
bioRxiv preprint doi: https://doi.org/10.1101/2021.04.23.441120; this version posted August 6, 2021. The copyright holder for this preprint (which was not certified by peer review) is the author/funder, who has granted bioRxiv a license to display the preprint in perpetuity. It is made available under aCC-BY-NC-ND 4.0 International license.

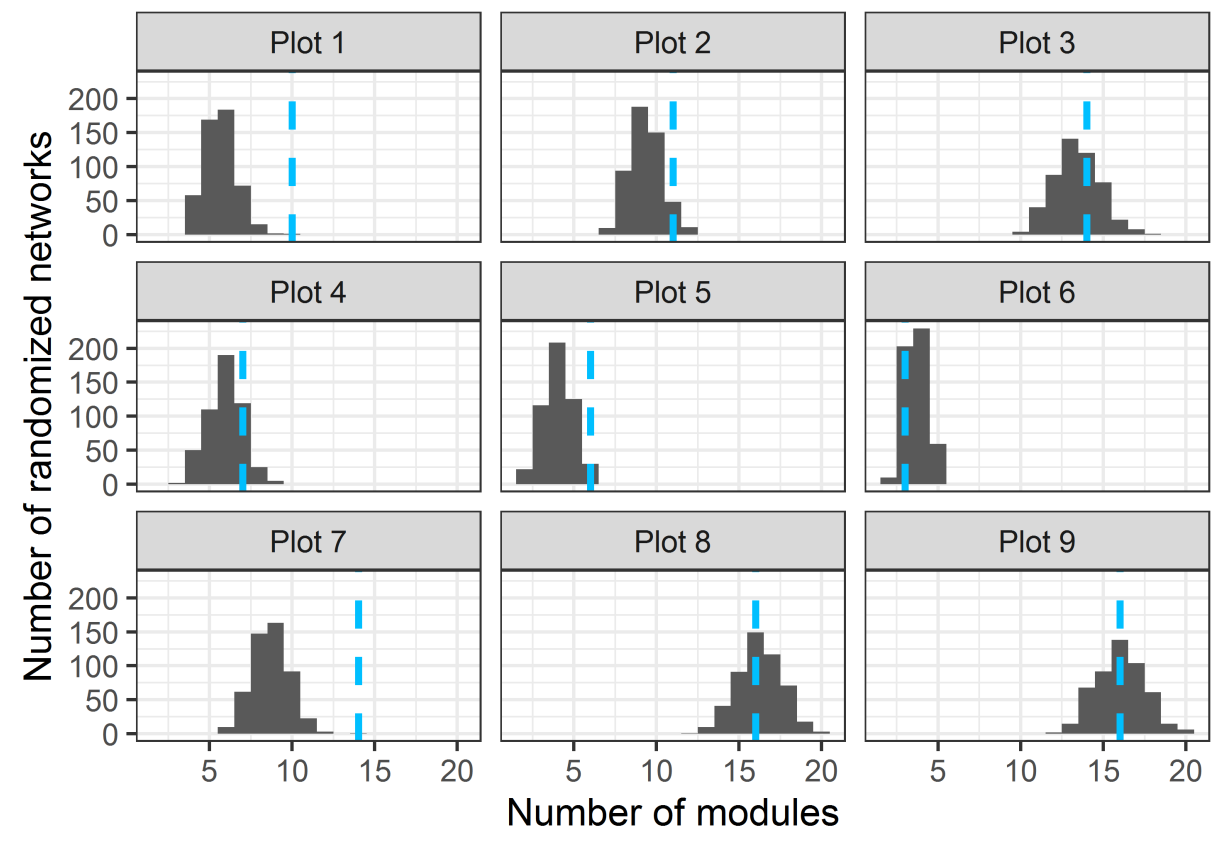

Fig. A9.2. Null distribution of number of modules obtained from 500 simulations for each plot. Each panel represents the results for a plot. The respective observed values are marked with vertical blue dashed lines.

Table A9.2. Observed map equation ( $L_{\text {Observed }}$ ) and number of modules $\left(m_{\text {Observed }}\right)$ for each plot, and the corresponding confidence intervals (C.I.) for the simulated map equation $\left(L_{\text {Simulated }}\right)$ and simulated number of modules $\left(m_{\text {Simulated }}\right)$, when the null model 2 is considered. Null distributions for $L_{S i m u l a t e d}$ and $m_{\text {Simulated }}$ are shown in Figs. A9.3 and A9.4 Bold values denote significant results.

\section{NULL MODEL 2}

\begin{tabular}{ccccc} 
Plot & $L_{\text {Observed }}$ & C. I. for $L_{\text {Simulated }}$ & $m_{\text {Observed }}$ & C. I. for $m_{\text {Simulated }}$ \\
\hline 1 & $\mathbf{3 . 7 0 9}$ & $(4.590,4.755)$ & $\mathbf{1 0}$ & $(11,16)$ \\
2 & $\mathbf{3 . 9 7 1}$ & $(4.940,5.111)$ & $\mathbf{1 1}$ & $(15,19)$ \\
3 & $\mathbf{3 . 6 9 6}$ & $(4.744,4.955)$ & 14 & $(14,19)$ \\
4 & $\mathbf{3 . 2 5 9}$ & $(3.716,4.192)$ & 7 & $(4,8)$ \\
5 & $\mathbf{3 . 1 2 6}$ & $(3.481,3.937)$ & 6 & $(2,7)$ \\
6 & $\mathbf{2 . 9 9 7}$ & $(3.376,3.980)$ & 3 & $(2,6)$ \\
7 & $\mathbf{3 . 6 8 0}$ & $(4.512,4.743)$ & 14 & $(10,16)$ \\
8 & $\mathbf{3 . 5 3 9}$ & $(4.733,4.961)$ & $\mathbf{1 6}$ & $(17,23)$ \\
9 & $\mathbf{3 . 7 0 1}$ & $(4.658,4.856)$ & 16 & $(16,22)$
\end{tabular}


bioRxiv preprint doi: https://doi.org/10.1101/2021.04.23.441120; this version posted August 6, 2021. The copyright holder for this preprint (which was not certified by peer review) is the author/funder, who has granted bioRxiv a license to display the preprint in perpetuity. It is made available under aCC-BY-NC-ND 4.0 International license.

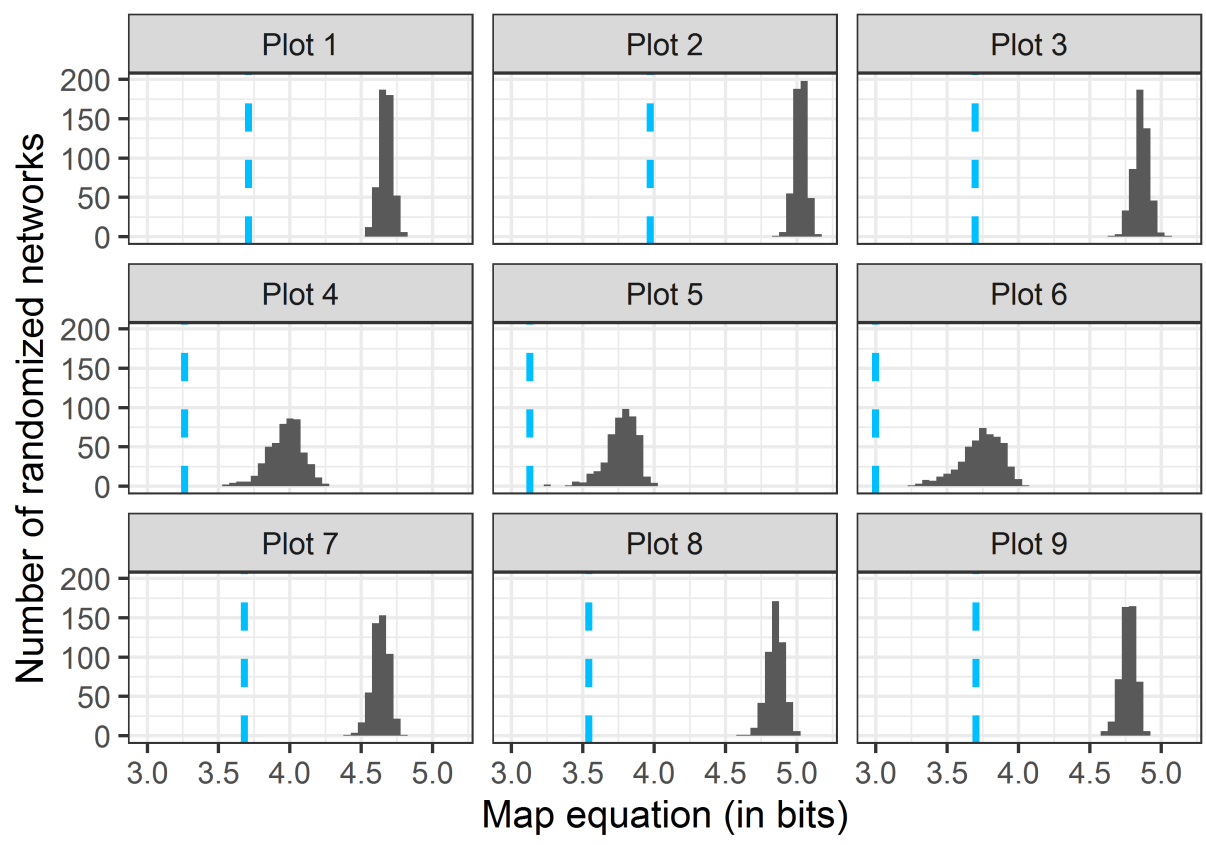

Fig. A9.3. Null distribution of map equation (in bits) obtained from 500 simulations for each plot by using Null model 2. Each panel represents the results for a plot. The respective observed values are marked with vertical blue dashed lines.

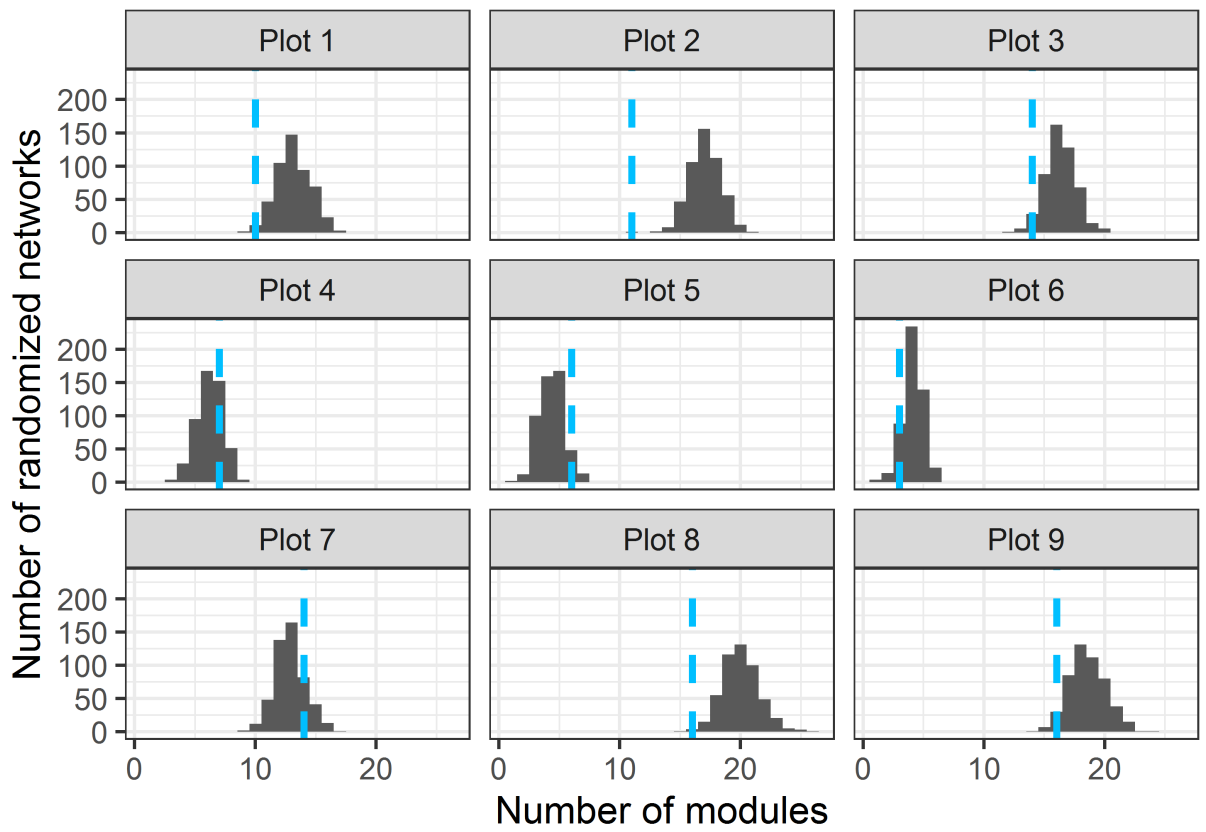

Fig. A9.4. Null distribution of number of modules obtained from 500 simulations for each plot by using Null model 2 . Each panel represents the results for a plot. The respective observed values are marked with vertical blue dashed lines.

\section{Appendix 10: Supplementary figures for centrality measures}


bioRxiv preprint doi: https://doi.org/10.1101/2021.04.23.441120; this version posted August 6, 2021. The copyright holder for this preprint (which was not certified by peer review) is the author/funder, who has granted bioRxiv a license to display the preprint in perpetuity. It is made available under aCC-BY-NC-ND 4.0 International license.
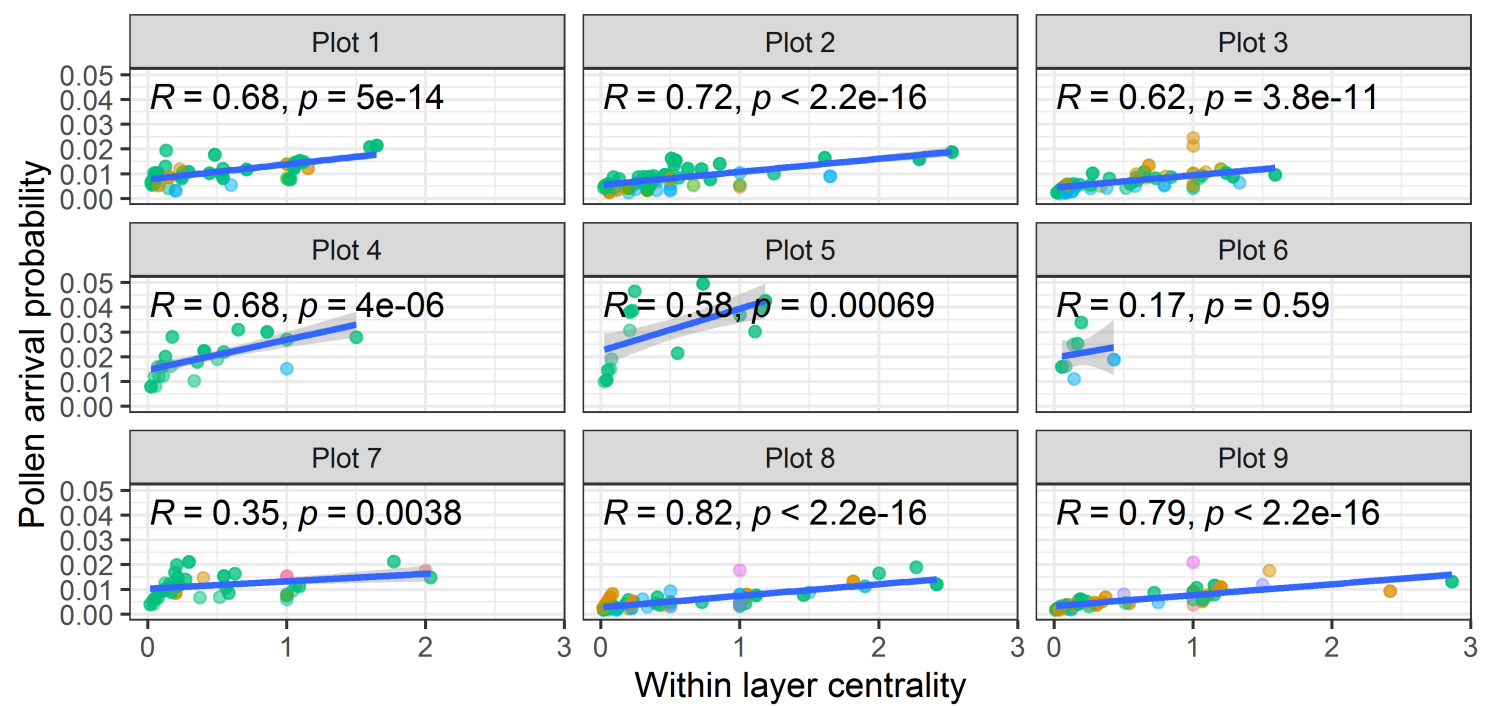

B. macrocarpa
- C. fuscatum

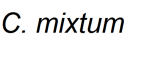
- M. sulcatus

S. laciniata

C. fuscatum

C. tenuiflorum

S. asper

S. rubra

Fig. A10.1. Dependence of (multilayer) pollen arrival probabilities (PageRank) on within-layer centrality (in-strength) and plot. Linear regression lines are displayed in blue, with their corresponding coefficient of determination $\left(R^{2}\right)$ and p-values.
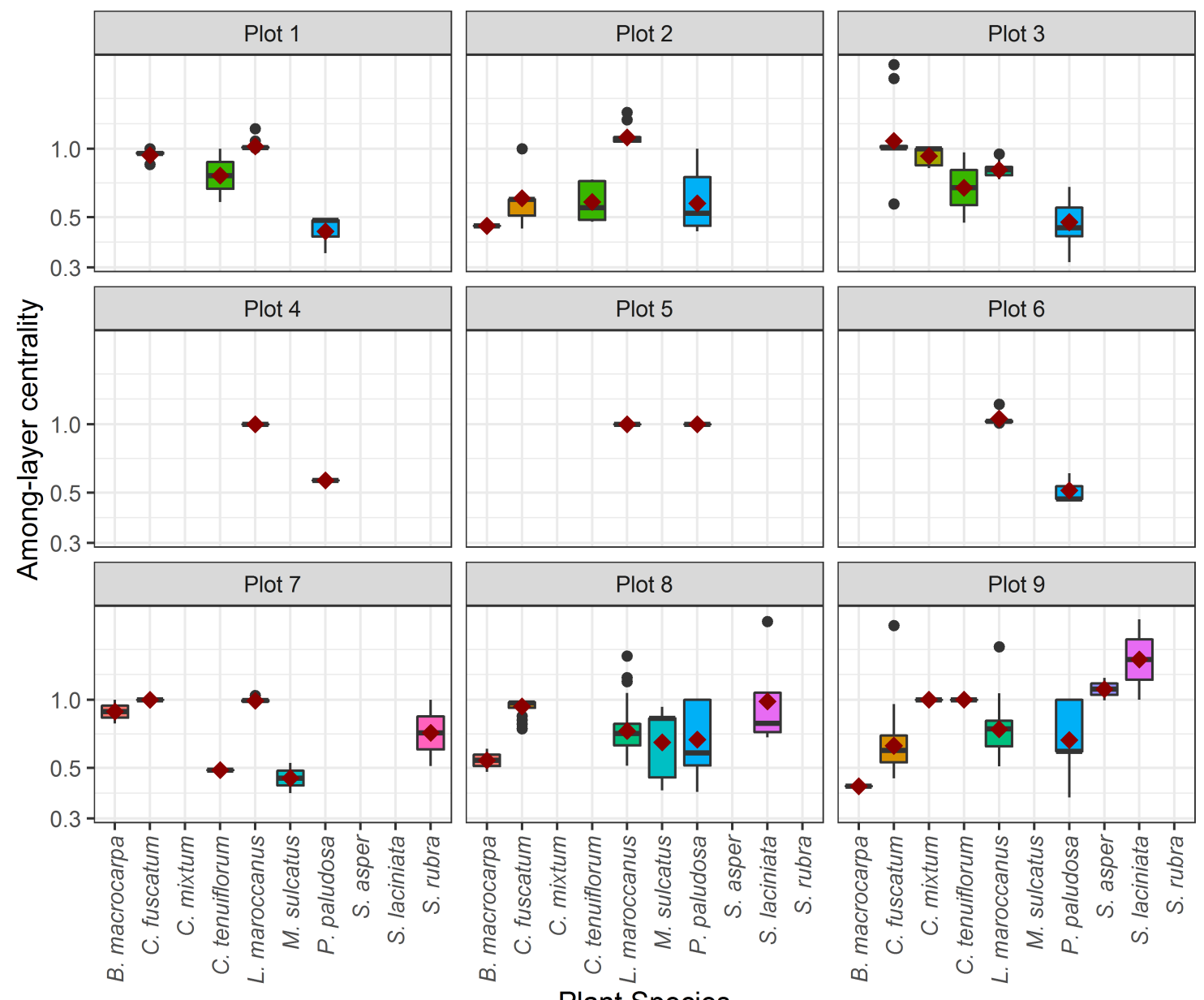

Fig. A10.2. Dependence of the among-layer centrality ratio on plot and plant species. Mean values are shown with red diamonds. 


\section{Appendix 11: Supplementary figures for centrality measures}

After calculating the total number of homospecific and heterospecific motifs for those plant individuals that received insect visits, we contrasted the significance of such values by comparing them with a random expectation. To do so, we proposed a null model in which the total number of observed visits per plant species and per insect visitor are preserved in each plot and week. In that model, we randomly reshuffled the insect visits received by one plant species among those plant individuals that were present in a certain plot, during a given week. Thus, the experimental phenology observed in each plot was preserved.

To derive a null distribution of the total number of homospecific and heterospecific motifs per focal individual, we generated an ensemble of 500 null networks for each plot and week. For each randomized realization, we calculated the number of homospecific and heterospecific motifs per plant individual, insect visitor, and week; and we pooled the results for plant individuals. Then, since null distributions are not usually Gaussian (see Fig. A11.1 for an example), we estimated their confidence intervals for our metrics and tested whether the observed values belong to such intervals (non-significant result) or not (significant result). Our findings are summarized in Figs. A11.2 and A11.3. According to such figures, $46.71 \%(82.09 \%)$ of plant individuals have a total amount of homospecific (heterospecific) motifs that is significantly different from the values obtained for randomized systems, with a confidence level of $95 \%$. In the case of homospecific motifs, it is possible to see that, as expected, plant species with few (many) plant individuals tend to exhibit a higher (lower) proportion of significant results, specifically significantly larger (smaller) number of homospecific motifs. Remarkably, in the case of C. fuscatum, we observe that most of its homospecific triples are non-significant. This is due to the reduced phenological overlap among C. fuscatum and other plant species (see Fig. A2.1. Finally, it is worth mentioning that $97.27 \%$ of individual plants with significant heterospecific motifs exhibit larger values of such motifs than the randomized arrangements.

\section{Plot 1 L. maroccanus}

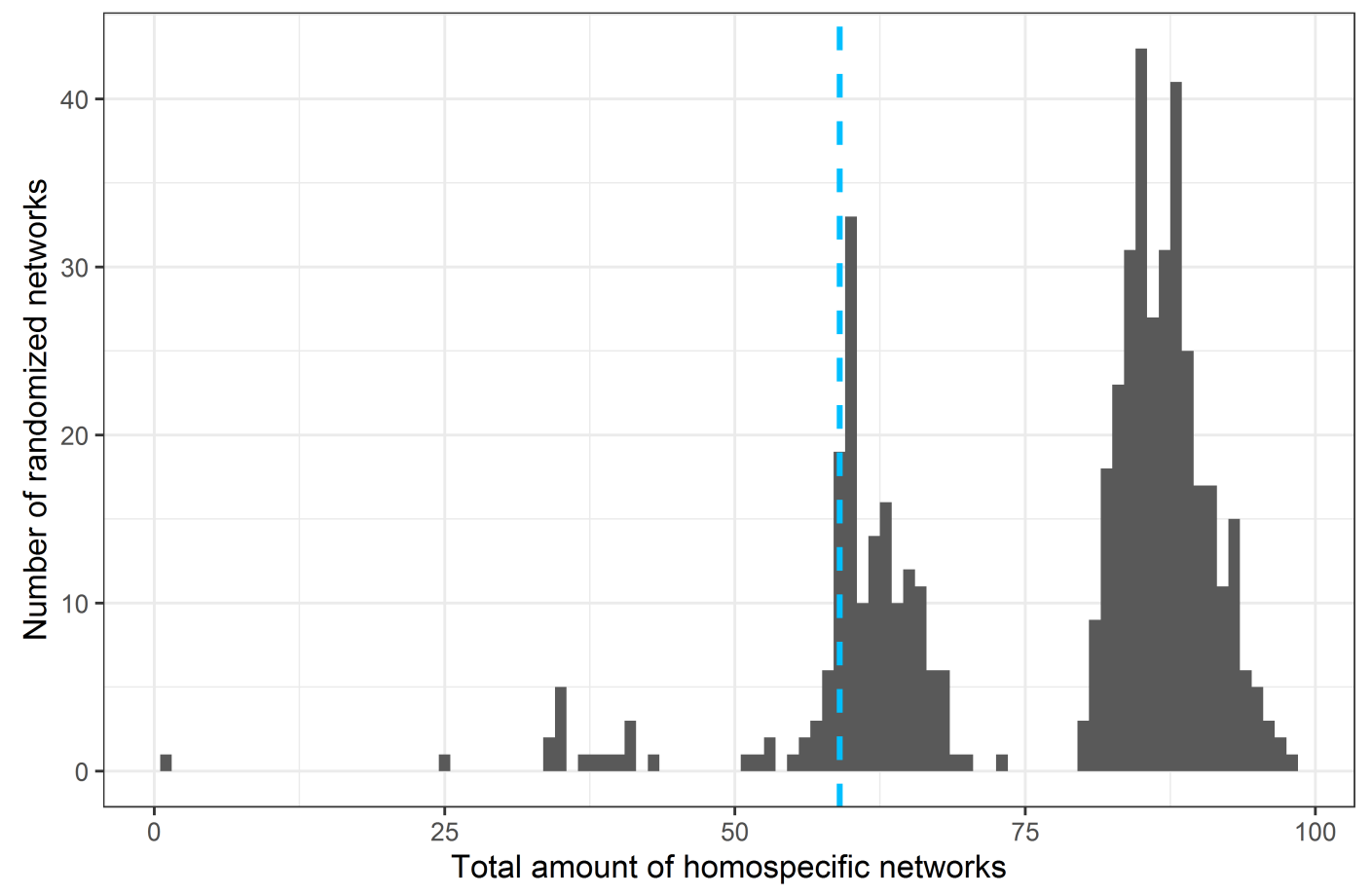

Fig. A11.1. Null distribution of homospecific motifs for the focal individual of $L$. maroccanus located in the plot 1 and subplot A3, obtained from 500 simulations. The observed value is marked with a vertical blue dashed line, and it is significantly smaller. 
bioRxiv preprint doi: https://doi.org/10.1101/2021.04.23.441120; this version posted August 6, 2021. The copyright holder for this preprint (which was not certified by peer review) is the author/funder, who has granted bioRxiv a license to display the preprint in perpetuity. It is made available under aCC-BY-NC-ND 4.0 International license.

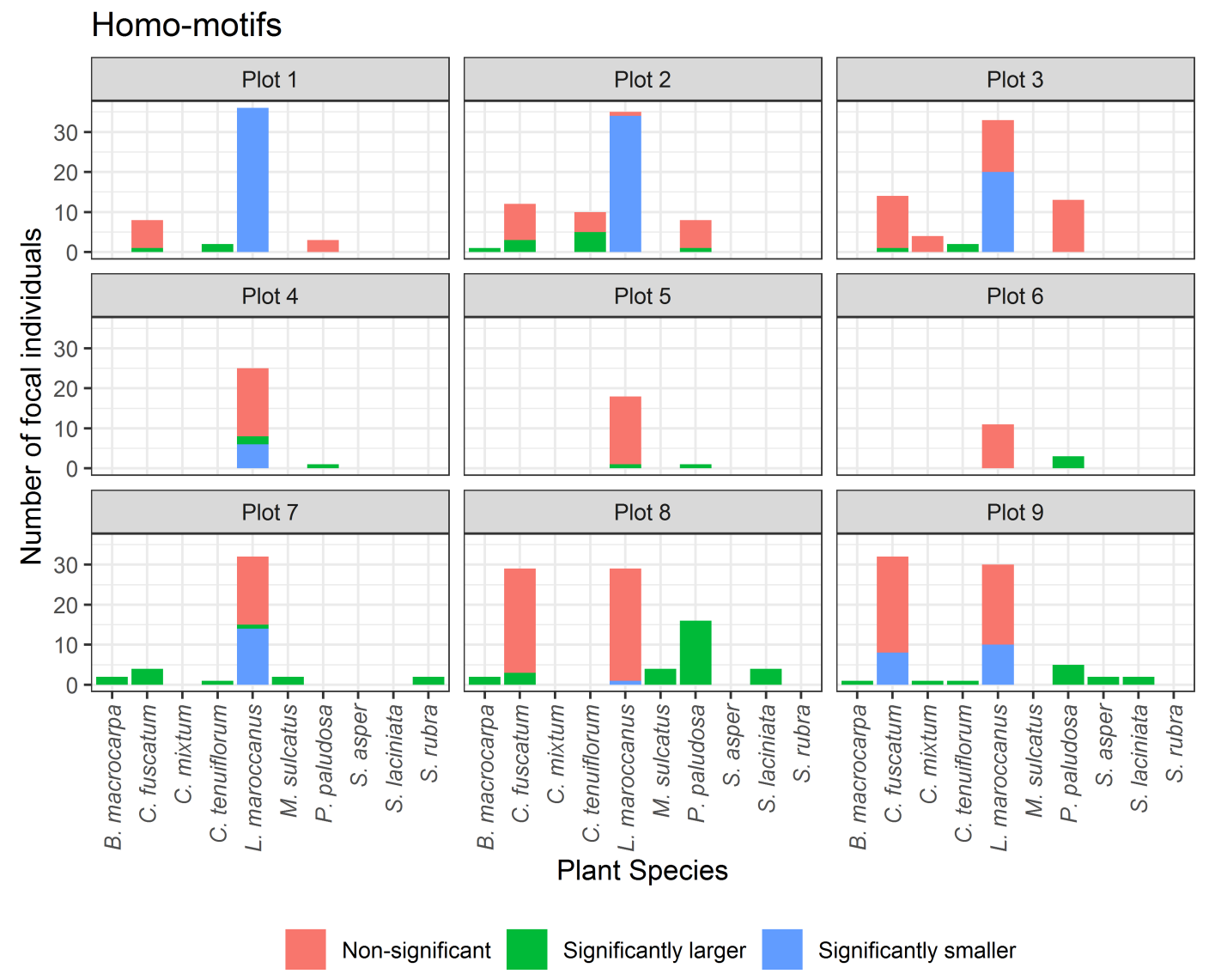

Fig. A11.2. Number of plant individuals with significant and non-significant homospecific motifs per plot and plant species. 
bioRxiv preprint doi: https://doi.org/10.1101/2021.04.23.441120; this version posted Auqust 6. 2021. The copyright holder for this preprint (which was not certified by peer review) is the author/funder, who has granted bioRxiv a license to display the preprint in perpetuity. It is made available under aCC-BY-NC-ND 4.0 International license.

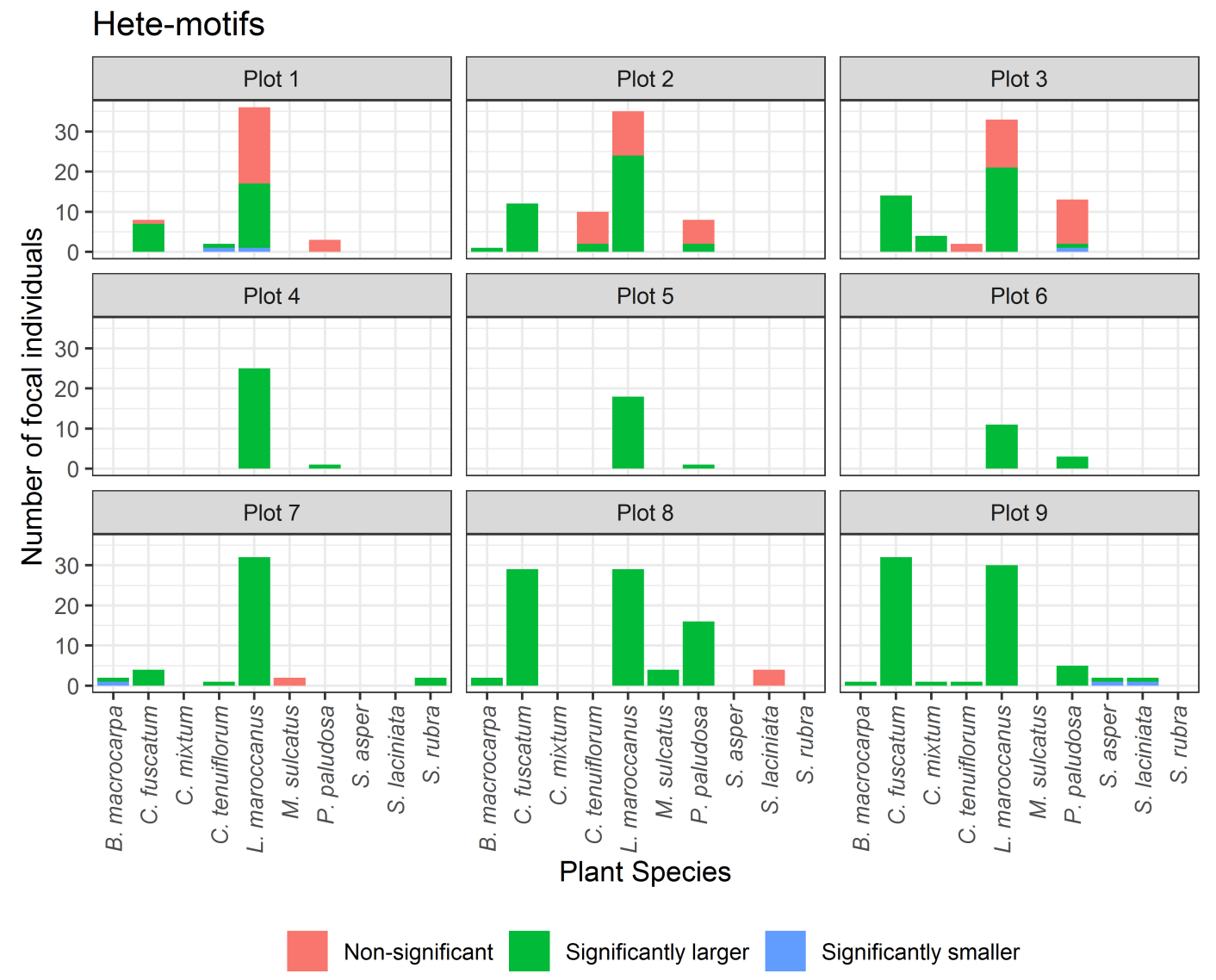

Fig. A11.3. Number of plant individuals with significant and non-significant heterospecific motifs per plot and plant species. 
bioRxiv preprint doi: https://doi.org/10.1101/2021.04.23.441120; this version posted August 6, 2021. The copyright holder for this preprint (which was not certified by peer review) is the author/funder, who has granted bioRxiv a license to display the preprint in perpetuity. It is made available under aCC-BY-NC-ND 4.0 International license.

\section{Appendix 12: PageRank indices within and among plant species}

We found that PageRank values show significant differences among plant species (Kruskal-Wallis rank sum test: pvalue $<2.2 \mathrm{e}-16)$. Specifically, pairwise comparisons using Wilcoxon rank sum test confirm the significant differences between $L$. maroccanus and the following plant species: . fuscatum (p-value $=3.1 \mathrm{e}-16)$, C. tenuiflorum (p-value $=$ $0.0071), P$. paludosa ( $\mathrm{p}$-value $=7.1 \mathrm{e}-10)$. The above significant differences mean that we cannot directly apply an ANOVA analysis, since there is no homogeneity of variance.

If we want to conduct an analysis of variance (ANOVA) to compare the within-plant variance with the among-plant variance, we need to log transform the PageRank indices. By doing so, it is possible to meet the main requirements of an ANOVA analysis, namely: homogeneity of variance (Levene's Test for Homogeneity of Variance: p-value = 0.329) and normality (in Fig.A12.1, as most of the points fall approximately along the 45-degrees reference line, we can assume normality). Then, we fitted the linear regression model $\log (\text { PageRank })_{i j} \sim$ PlantSpecies ${ }_{i}$, where $\log (\text { PageRank })_{i j}$ is the logarithm of the PageRank index of the $j$ th individual that belongs to plant species $i$ for $i=1, \cdots, 10$. In this model, the p-value for plant species is smaller than $2 \mathrm{e}-16$, and within-plant species variance is 0.505, whereas the among-plant species variance is 7.133. This confirms the previous evidence for the existence of differences between the plant species.

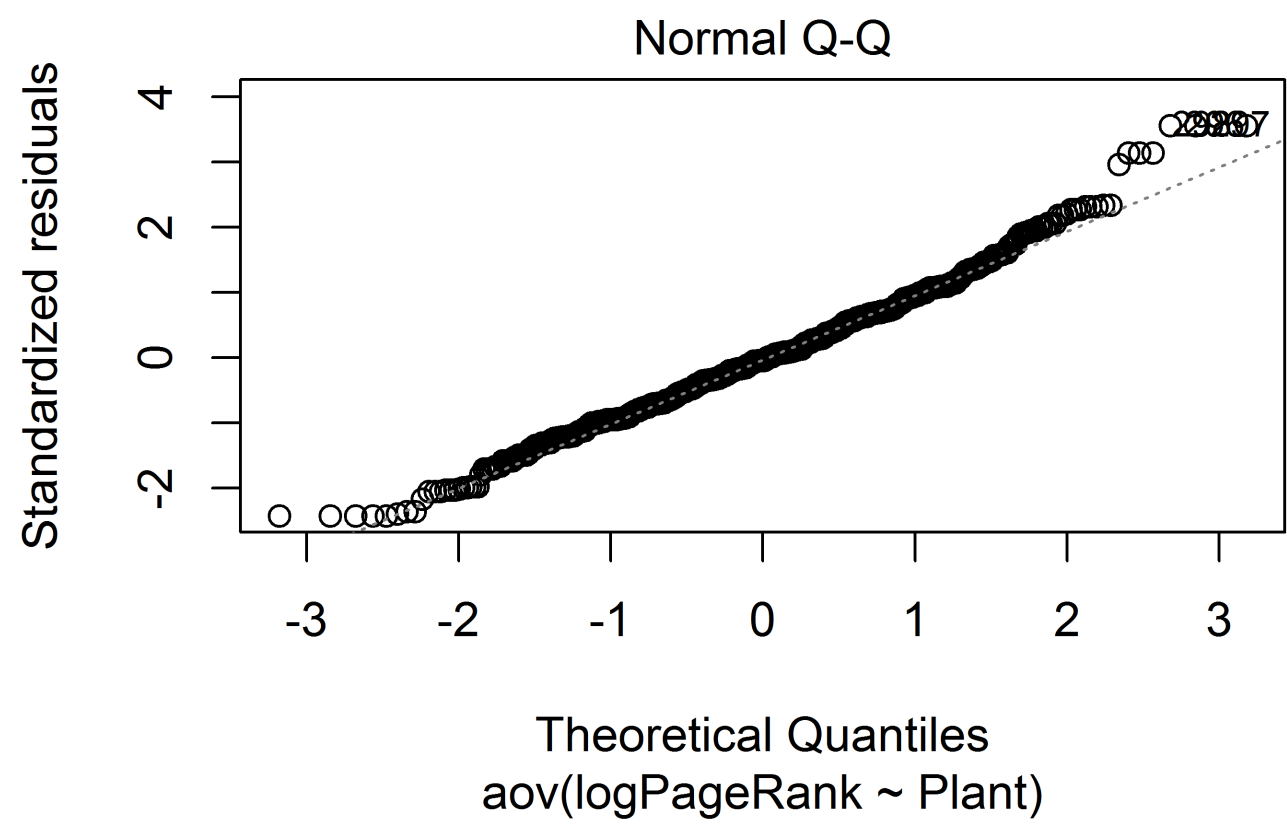

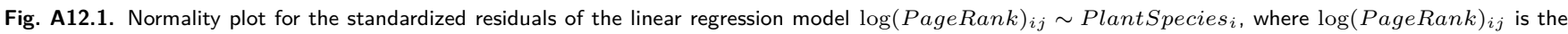
logarithm of the PageRank index of the $j$ th individual that belongs to plant species $i$ for $i=1, \cdots, 10$. Dots show the quantiles of the residuals against the quantiles of the normal distribution, and the dashed line is a guide to the eye that represents a 45-degree reference line. 


\section{Appendix 13: Specification of the zero inflated negative binomial mixed models}

The model for each plant species that is described in subsection "Reproductive success analysis" can be fully specified as follows (Moghimbeigi et al., 2008):

Seed $s_{i j} \sim 0$ with probabilty $\varphi_{i j}($ Process 1$)$

Seed $s_{i j} \sim N B\left(\mu_{i j}, \alpha\right)$ with probabilty $1-\varphi_{i j}($ Process 2$)$,

$E\left(\operatorname{Seed}_{i j}\right)=\mu_{i j}\left(1-\varphi_{i j}\right)$,

$\operatorname{Var}\left(\operatorname{Seeds}_{i j}\right)=\mu_{i j}\left(1-\varphi_{i j}\right)\left(1+\mu_{i j}\left(\varphi_{i j}+1 / \theta\right)\right)$,

$\log \left(\mu_{i j}\right)=$ homospecific motif $s_{i j}$

+ heterospecific motif $s_{i j}$

+ within-layer centrality ${ }_{i j}$

+ among-layer centrality ratio ${ }_{i j}$

+ Plot $_{i}$

Plot $_{i} \sim N\left(0, \sigma_{u}\right)$,

$\operatorname{logit}\left(\varphi_{i j}\right)=Z I_{0}$,

where $S e e d s_{i j}$ is the seed production of the $j$ th individual in Plot $i$ for $i=1, \cdots, 9 ;$ Plot $_{i}$ is the random intercept, which is assumed to be normally distributed with mean 0 and variance $\sigma_{u}^{2}$; and represents the overdispersion parameter of the negative binomial. In addition, notice that, for each observation, there are two possible data generation processes and the result of a Bernoulli trial determines which process is used. For observation $i j$, Process 1 is selected with probability $\varphi_{i j}$ and Process 2 with probability $1-\varphi_{i j}$, where $\varphi_{i j}$ is constant and depends on the constant term $Z I_{0}$. Process 1 generates only zero counts, whereas Process 2 generates counts from a negative binomial model. 


\section{Appendix 14: Alternative GLMMs with the covariate "visits"}

An alternative mixed model to that in Eq. A13.1 that also includes the number of visits as an explanatory variable:

Seed $s_{i j} \sim 0$ with probabilty $\varphi_{i j}($ Process 1$)$

(A14.1)

Seed $s_{i j} \sim N B\left(\mu_{i j}, \alpha\right)$ with probabilty $1-\varphi_{i j}($ Process 2$)$,

$E\left(\right.$ Seed $\left._{i j}\right)=\mu_{i j}\left(1-\varphi_{i j}\right)$,

$\operatorname{Var}\left(\operatorname{Seeds}_{i j}\right)=\mu_{i j}\left(1-\varphi_{i j}\right)\left(1+\mu_{i j}\left(\varphi_{i j}+1 / \theta\right)\right)$,

$\log \left(\mu_{i j}\right)=$ homospecific motif $s_{i j}$

+ heterospecific motif $s_{i j}$

+ within-layer centrality ${ }_{i j}$

+ among-layer centrality ratio ${ }_{i j}$

+ visits $_{i j}$

+ Plot $_{i}$

Plot $_{i} \sim N\left(0, \sigma_{u}\right)$,

$\operatorname{logit}\left(\varphi_{i j}\right)=Z I_{0}$,

where visits $_{i j}$ is the total number of insect visits received by the $j$ th individual in Plot $i$ for $i=1, \cdots, 9$. The remaining variables and processes are described in Supplementary material Appendix 13

Table A.14. Results for the GLMMs of $C$. fuscatum (a), L. maroccanus (b), $P$. paludosa (c) showing the effect on plant reproductive success (seeds per individual plant). The term $Z I_{0}$ describes the zero inflation probability $\varphi_{i j}$, given by $\operatorname{logit}\left(\varphi_{i j}\right)=Z I_{0}$ (see Eq. A13.1. in Supplementary material Appendix 13. We highlighted in bold the most important estimates based on effect sizes and its variability. P-values have been obtained from the Wald test reported in the summary on the models fitted with R-library glmmTMB (Brooks et al. 2017).

(a) C. fuscatum: the model contains 163 plant individuals. Conditional $R^{2}=0.310$, marginal $R^{2}=0.096$, with $\sigma_{u}^{2}=0.3243$ and $\theta=1.2$.

\begin{tabular}{lclcl}
$\begin{array}{l}\text { Seeds per } \\
\text { indiv. plant }\end{array}$ & Est. & $\begin{array}{l}\text { Std. } \\
\text { Error }\end{array}$ & $\begin{array}{l}\mathrm{z} \\
\text { value }\end{array}$ & $\begin{array}{l}\mathrm{p} \\
\text { value }\end{array}$ \\
\hline $\begin{array}{l}\text { (Intercept) } \\
\text { Homospec. }\end{array}$ & $\mathbf{5 . 1 0 8 6 0}$ & $\mathbf{0 . 2 2 2 2 7}$ & $\mathbf{2 2 . 9 8 4}$ & $<\mathbf{2 e - 1 6}$ \\
$\begin{array}{l}\text { motifs } \\
\text { Heterospec. }\end{array}$ & 0.09991 & 0.15186 & 0.658 & 0.4073 \\
$\begin{array}{l}\text { motifs } \\
\text { Within-layer }\end{array}$ & $\mathbf{- 0 . 1 6 1 9 3}$ & $\mathbf{0 . 0 7 9 1 4}$ & $\mathbf{- 2 . 0 4 6}$ & $\mathbf{0 . 0 4 0 8}$ \\
$\begin{array}{l}\text { centrality } \\
\text { Among-layer }\end{array}$ & 0.04851 & 0.09838 & 0.493 & 0.6967 \\
$\begin{array}{l}\text { centr. ratio } \\
\text { Visits }\end{array}$ & 0.07677 & 0.10652 & 0.721 & 0.4207 \\
$\mathbf{Z I}_{\mathbf{0}}$ & $\mathbf{5 . 1 0 8 6 0}$ & $\mathbf{0 . 2 2 2 2 7}$ & $\mathbf{2 2 . 9 8 4}$ & $<\mathbf{2 e - 1 6}$ \\
& $\mathbf{- 3 . 7 8 4}$ & $\mathbf{0 . 6 3 9}$ & $\mathbf{- 5 . 9 2}$ & $\mathbf{3 . 1 5 e - 0 9}$
\end{tabular}

(b) L. maroccanus: the model contains 293 plant individuals. Conditional $R^{2}=0.297$, marginal $R^{2}=0.079$, with $\sigma_{u}^{2}=0.2255$ and $\theta=2.35$.

\begin{tabular}{lclll}
$\begin{array}{l}\text { Seeds per } \\
\text { indiv. plant }\end{array}$ & Est. & $\begin{array}{l}\text { Std. } \\
\text { Error }\end{array}$ & $\begin{array}{l}\mathrm{z} \\
\text { value }\end{array}$ & $\begin{array}{l}\mathrm{p} \\
\text { value }\end{array}$ \\
\hline $\begin{array}{l}\text { (Intercept) } \\
\text { Homospec. } \\
\text { motifs }\end{array}$ & $\mathbf{5 . 7 2 0 8 8 9 4}$ & $\mathbf{0 . 1 6 3 5 4 8 7}$ & $\mathbf{3 4 . 9 8}$ & $<\mathbf{2 e - 1 6}$ \\
$\begin{array}{l}\text { Heterospec. } \\
\text { motifs }\end{array}$ & -0.0465956 & 0.0438775 & -1.06 & 0.2920 \\
$\begin{array}{l}\text { Within-layer } \\
\text { centrality }\end{array}$ & -0.0189605 & 0.0531020 & -0.36 & 0.7824 \\
$\begin{array}{l}\text { Among-layer } \\
\text { centr. ratio }\end{array}$ & $\mathbf{0 . 1 0 6 3 9 0 4}$ & $\mathbf{0 . 0 5 6 4 9 0 3}$ & $\mathbf{1 . 8 8}$ & $\mathbf{0 . 0 9 8 4}$ \\
$\begin{array}{l}\text { Visits } \\
Z I_{0}\end{array}$ & 0.0005333 & 0.0806229 & 0.01 & 0.9215 \\
& -20.97 & 2087.67 & -0.01 & 0.993
\end{tabular}


bioRxiv preprint doi: https://doi.org/10.1101/2021.04.23.441120; this version posted August 6, 2021. The copyright holder for this preprint (which was not certified by peer review) is the author/funder, who has granted bioRxiv a license to display the preprint in perpetuity. It is made available under aCC-BY-NC-ND 4.0 International license.

(c) P. paludosa: the model contains 150 plant individuals. Conditional $R^{2}=0.204$, marginal $R^{2}=0.134$, with $\sigma_{u}^{2}=0.05534$ and $\theta=1.9$.

\begin{tabular}{lclll}
$\begin{array}{l}\text { Seeds per } \\
\text { indiv. plant }\end{array}$ & Est. & $\begin{array}{l}\text { Std. } \\
\text { Error }\end{array}$ & $\begin{array}{l}\mathrm{z} \\
\text { value }\end{array}$ & $\begin{array}{l}\mathrm{p} \\
\text { value }\end{array}$ \\
\hline $\begin{array}{l}\text { Intercept) } \\
\text { Homospec. }\end{array}$ & $\mathbf{5 . 5 3 3 7 3 0}$ & $\mathbf{0 . 1 0 6 2 5 9}$ & $\mathbf{5 2 . 0 8}$ & $<\mathbf{2 e - 1 6}$ \\
$\begin{array}{l}\text { motifs } \\
\text { Heterospec. } \\
\text { motifs }\end{array}$ & -0.214337 & 0.127462 & -1.68 & 0.1859 \\
$\begin{array}{l}\text { Within-layer } \\
\text { centrality }\end{array}$ & -0.109872 & 0.080153 & -1.37 & 0.2349 \\
$\begin{array}{l}\text { Among-layer } \\
\text { centr. ratio }\end{array}$ & 0.004201 & 0.101274 & 0.04 & 0.8850 \\
$\begin{array}{l}\text { Visits } \\
\text { ZI }\end{array}$ & $\mathbf{0 . 3 3 9 8 9 5}$ & $\mathbf{0 . 1 0 3 7 6 1}$ & $\mathbf{0 . 2 8}$ & $\mathbf{0 . 0 2 9 4}$ \\
& $\mathbf{- 3 . 6 0 0 2}$ & $\mathbf{0 . 5 0 8 3}$ & $\mathbf{- 7 . 0 8 3}$ & $\mathbf{1 . 8 9 e - 1 4}$
\end{tabular}


bioRxiv preprint doi: https://doi.org/10.1101/2021.04.23.441120; this version posted August 6, 2021. The copyright holder for this preprint (which was not certified by peer review) is the author/funder, who has granted bioRxiv a license to display the preprint in perpetuity. It is made available under aCC-BY-NC-ND 4.0 International license.
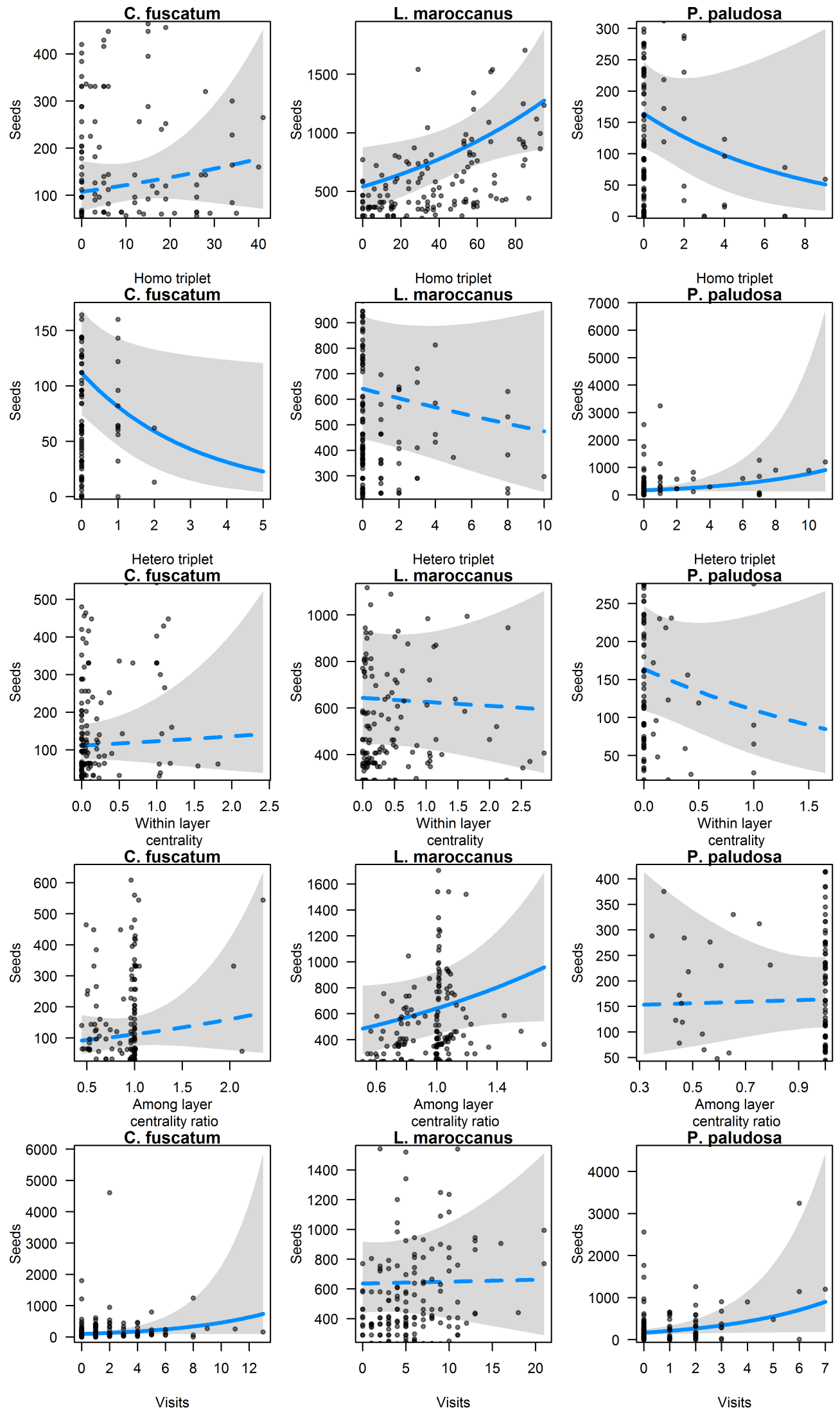

Fig. A14.1. Conditional plots for plant explanatory variables (R-package "visreg" (Breheny \& Burchett 2017)): Homo-triplets (first row), hetero-triplets (second row), within-layer centrality (third row), among-layer centrality ratio (fourth row) and visits (fifth row). Notice that, for the conditioning, the other numeric variables are set to their median, whereas the factor covariate "Plot" is set to its most frequent value. In each panel, we represent (i) the expected values of explanatory variables (continuous lines for variables p-value $<0.1$ and dashed lines otherwise), (ii) the confidence interval for the expected values (gray band), and (iii) dependence of seed production on the explanatory variable (dark gray dots). 